\title{
Volunteer melanoma screening : pros and cons
}

Citation for published version (APA):

de Rooij, M. J. M. (1997). Volunteer melanoma screening : pros and cons. [Doctoral Thesis, Maastricht University]. Universiteit Maastricht. https://doi.org/10.26481/dis.19970924mr

Document status and date:

Published: 01/01/1997

DOI:

10.26481/dis.19970924mr

Document Version:

Publisher's PDF, also known as Version of record

\section{Please check the document version of this publication:}

- A submitted manuscript is the version of the article upon submission and before peer-review. There can be important differences between the submitted version and the official published version of record.

People interested in the research are advised to contact the author for the final version of the publication, or visit the DOI to the publisher's website.

- The final author version and the galley proof are versions of the publication after peer review.

- The final published version features the final layout of the paper including the volume, issue and page numbers.

Link to publication

\footnotetext{
General rights rights.

- You may freely distribute the URL identifying the publication in the public portal. please follow below link for the End User Agreement:

www.umlib.nl/taverne-license

Take down policy

If you believe that this document breaches copyright please contact us at:

repository@maastrichtuniversity.nl

providing details and we will investigate your claim.
}

Copyright and moral rights for the publications made accessible in the public portal are retained by the authors and/or other copyright owners and it is a condition of accessing publications that users recognise and abide by the legal requirements associated with these

- Users may download and print one copy of any publication from the public portal for the purpose of private study or research.

- You may not further distribute the material or use it for any profit-making activity or commercial gain

If the publication is distributed under the terms of Article $25 \mathrm{fa}$ of the Dutch Copyright Act, indicated by the "Taverne" license above, 
Volunteer Melanoma Screening pros and cons 


\section{Volunteer Melanoma Screening pros and cons}

PROEFSCHRIFT

ter verkrijging van de graad van doctor aan

de Universiteit Maastricht, op gezag van de Rector Magnificus, prof.mr. M.J. Cohen volgens het besluit van het College van Decanen, in het openbaar te verdedigen op woensdag 24 september 1997 om 16.00 uur

door 


\section{Promotores:}

Prof.dr. H.A.M. Neumann

Prof.drdr. P.C.M. van de Kerkhof (Katholieke Universiteit Nijmegen)

\section{Co-promotor:}

Dr. F.H.J. Rampen

\section{Beoordelingscommissie:}

Prof.dr. A.J. Knottnerus (voorzitter)

ProE.dr. G.J. Kok

Prof.dr. M.F von Meyenfeldt

Prof.dr. A.L.M. Verbeek (Katholieke Universiteit Nijmegen)

Prof.dr. W.A. van Vloten (Universiteit Utrecht)

This study was supported in part by a grant from the Comprehensive Cancer Centres IKL (Maastricht) and IKO (Nijmegen) 
With big enough hopes and serious enough convictions, no human being need die of malignant melanoma

A Bermard Ackerman 
ISBN : 90-9010934-X

Druk : Drukkerij Em. de Jong b.v., Baarle-Nassau

Cover : Bep Scheeren 


\section{CONTENTS}

Preface

Chapter 1 : Cutaneous melanoma; general introduction

Chapter 2 : Screening for melanoma; methods, advantages, and limits

Chapter 3 : Factors influencing participation among melanoma screening attenders

Chapter 4 : Skin cancer screening focusing on melanoma yields more selective attendance

Chapter 5 : Total skin examination during screening for malignant melanoma does not increase the detection rate

Chapter 6 : Volunteer melanoma screenings: follow-up, compliance, and outcome

Chapter 7 : Screening for melanoma: watch the early bird!

Chapter 8 : General discussion and conclusions.

Appendix

Summary

Samenvatting

Dankwoond

List of publications

Curriculum vitae

List of abbreviations 
PREFACE 
The rise in the incidence rates of cutaneous melanoma in white populations during the last decades has caused considerable concern worldwide. Basal cell carcinomas and squamous cell carcinomas are more prevalent, however the mortality of malignant melanoma is highest of all malignancies of the skin. There were 383 deaths. from cutaneous melanoma in 1992 in our country."

Prognosis of malignant melanoma depends strongly on the tumour thickness. Primary surgery is the cornerstone in the treatment of melanoma. Decrease of mortality can at the moment only be reached by early recognition. Several secondary prevention programmes have been developed to manage this issue and to detect melanomas as early as possible. Screening theoretically reduces death and morbidity from cancer in general. With regard to melanoma visual examination of the skin is an acceptable, safe, reliable, and inexpensive screening tool.

Since 1985 annual, free skin cancer/melanoma screenings sponsored by the American Academy of Dermatology (AAD) have been organized in the United States. ${ }^{2,3}$ Also in the Netherlands such early detection campaigns have been held and developed Eurther since $1989 .{ }^{4}$ During all these campaigns attention was paid to all skin cancers. Because of the good prognosis and very low mortality rate of basal cell carcinomas, these tumours should not be screened for. The same, although to a lesser extent, applies to squamous cell carcinomas.

We organized a screening campaign in June 1993 in Southern Limburg, the Netherlands. In the announcements of this project special emphasis was placed on the symptoms and risk factors of melanoma and its precursor lesions. The screenings were attended by 4146 persons. Because of suspicious cancerous or precancerous lesions, 486 persons $(11.7 \%)$ received a letter of referral for their general practitioner with the proposed line of management. The motivation and reasons to participate, the yield of these selective screenings, the effect of additional skin examination of persons presenting with a specific skin mark, the compliance and follow-up of positive screenees, and the awareness of the screenees of their own risk profile were subject of this thesis. 


\section{REFERENCES}

1. Incidence of cancer in the Netherlands, 1992. Fourth report of the Netherlands Cancer Registry. Eds: Visser OP Coebergh JWW, Schouten LI. Utrecht, 1995.

2. Koh HK, Lew RA and Prout MN. Screening for melanoma/skin cancer: Theoretic and practical considerations. J Am Acad Dermatol 1989;20:159-72.

3. Koh HK, Caruso $A$, Gage $I$ et al. Evaluation of melanoma/skin cancer screening in Massachusetts: Preliminary results. Cancer 1990,65:375-9.

4. Rampen FHI), wath Hustee BEWL and Kemeney LALM. Melanoma/skin cancer screening climies: Experiences in the Netherlands. J Am Acad Dermatol 1991;25:776-7. 
Qmenger

Chapter 1

CUTANEOUS MELANOMA; GENERAL INTRODUCTION 


\section{EPIDEMIOLOGY}

Cutaneous melanoma is a malignant tumour originating from the epidermal pigment cell system. These pigment cells arise from neural-crest tissue during early fetal development. They migrate to the skin and several other peripheral sites.

Melanocytes harbour in the basal layer of the epidermis and form functional units with the surrounding keratinocytes. Clusters of cutaneous pigment cells may form common naevocellular naevi, which are important precursor lesions for melanoma of the skin. Whether "melanocytes" and "naevocytes" represent different cell systems, is a matter of debate. ${ }^{1,3}$ Their distinctive clinical behaviour and their different role in melanoma aetiology suggest a dual ontology and nosology.

Until recently, the incidence of melanoma has been rising in most western countries with a predominantly fair-skinned population. This increase can not be explained by major changes in diagnostic criteria ${ }^{3}$. Also in the Netherlands, with a population of 15 million, the incidence has been rising during the last few decades. ${ }^{4}$ At the moment the incidence is approximately $13-14 / 100,000$ inhabitants. ${ }^{5}$ There are about 2000 new melanoma patients each year, including invasive (1700) and non-invasive (300) melanomas.

Basal cell carcinoma and squamous cell carcinoma of the skin are more prevalent than melanoma. However, the mortality from melanoma is highest of all malignancies of the skin. There were 383 deaths from cutaneous melanoma in 1992 in this country. The mortality rate has been rising during the past decades, although less dramatically than the incidence rate. The rate of increase of new cases has been cited to be more rapid than for any other malignancy with exception of lung cancer in women. Recent data from the United States indicate that the proportionate mortality over time changes dramatically with age. The largest mortality increases are seen in the middle-aged and elderly persons. In the younger age groups mortality rates are actually decreasing. These observations underline the promise that melanoma rates may stabilize and in fact decline in the coming decades. Interestingly, in the Netherlands melanoma incidence rates have not been increasing during the period 1989-1992."

Melanoma affects all age groups from adolescence. Its peak occurrence is between 40 and 50 years, with exception of acral-lentiginous melanoma and lentigo maligna melanoma. These latter types are more often seen in the elderly. Cutaneous melanoma is rarely diagnosed in childhood. When it presents in early life it often develops from a giant congenital naevus. Melanoma of childhood must not be confused with 'juvenile melanoma' (naevus of Spit $z^{8}$, spindle cell naevus). This is a benign naevocytic lesion, differing both clinically and histologically from the common 
naevocellular naevus. The cellular and architectural characteristics may be bizarre to give resemblance to melanoma.

In Europe the sex distribution of cutaneous melanoma is unequal. Females outnumber males to a ratio of approximately $3: 2$. In the United States and in Australia there is a more equal sex distribution. There is no good explanation for these differences.

In males melanoma is most often found on the back. In females the tumour is more often seen on the lower leg.

The exact cause of melanoma is unknown. Host factors as well as environmental factors seem to play a role. Especially people with a fair skin complexion, freckling traits, and tendency to burn rather than tan have an increased risk of cutaneous melanoma. ${ }^{10,11}$ Most melanomas develop from naevocellular naevi. People with a more than average mole count have an increased risk of melanoma. ${ }^{10,11}$ In fact, elevated numbers of naevi have been associated with the highest individual relative risks observed for melanoma. ${ }^{12,13}$ Furthermore, a personal and/or family history of melanoma is a major risk factor.

The influence of UV radiation is still a matter of debate. Case-control and cohort studies suggest that sunlight plays an important role in the aetiology of malignant melanoma. ${ }^{14}$ Melanoma incidence and mortality rates in North America and Australia are higher closer to the equator. The same trend does not apply to Europe with higher rates in the Scandinavian than in the Mediterranean countries. The European pattern most probably is the result of skin complexion differences. Contrarily to expectation, melanoma is mainly represented in indoor workers in the higher socioeconomic groups. This is clearly different from the occupation pattern of the nonmelanoma skin cancers, which are more common in persons with outdoor jobs. These latter tumours occur almost exclusively on sun-exposed skin. Melanomas are not concentrated on skin areas that are most exposed to the sun. These clinical and epidemiologic data led to the "intermittent exposure" hypothesis. ${ }^{15,16}$ Especially intermittent exposure to the sun (with sunburn) of skin that is not heavily tanned or thickened, rather than regular outdoor occupational exposure seems to be of crucial importance.

However, too many inconsistencies in the evidence remain. A meta-analysis of casecontrol studies highlighting the links between melanoma and the sun, disclosed a weak relationship. ${ }^{17}$ UV exposure cannot explain all epidemiologic trends. Other environmental factors must be involved. It has been suggested that water chlorination and water pollution could play an important rolle through recreational activities involving contact with water. ${ }^{18,19}$ This hypothesis may also explain the increase in the relative risk for melanoma with higher socioeconomic status. In this context, UV exposure might be a confounding factor. 
Human models have not really advanced our knowledge concerning the sunlight hypothesis. ${ }^{20}$ Certain patient groups are particularly prone to develop nonmelanoma skin cancers due to exposure to harmful UV rays: patients receiving photochemotherapy (PUVA), organ transplant recipients, patients with xeroderma pigmentosum, and albino patients. Although melanomas have been reported among these categories, the incidence is very low and disproportionate to the numbers of squamous cell carcinomas that are encountered.

Artificial sources of UV radiation may play a role." However, sunbed users aiso exhibit greater solar exposure than nonusers. Both effects are closely intertwined precluding meaningful assessment of studies on the subject.

The role of stratospheric ozone depletion is, as yet, negligible. In the years to come, even the most reasonable estimates of ozone depletion will only result in small increases in melanoma incidence, compared with the nearly doubling rate per 10 years observed in many countries over recent decades.

Finally, the immunosuppressive action of UV radiation may contribute to the induction and pathogenesis of melanoma. ${ }^{22}$

\section{CLASSIFICATION}

Epidemiologic, clinical and histologic data suggest that different melanoma subtypes exist. Mishima distinguished between melanomas developing from melanocytes in the basal layer of the epidermis (melanocytic melanomas) and melanomas developing from naevocellular naevi (naevocytic melanomas). ${ }^{1}$ In this dual pathway theory the melanocyte and naevocyte are two different cell types with their own biologic features, growth characteristics and potential of malignant degeneration.

Clark et al ${ }^{23}$ described in 1969 three clinical and histologic melanoma subtypes: superficial spreading melanoma (SSM), nodular melanoma (NM), and lentigo maligna melanoma (LMM). Later, a fourth subtype, acral-lentiginous melanoma (ALM) was added. ${ }^{24}$

SSM has an initial phase of predominantly horizontal, radial growth in the epidermis and papillary dermis. After a period that may last for years a vertical, invasive growth phase will follow. Especially this phase has the capacity for metastasis.

$N M$ has a more aggressive, vertical growth phase from the beginning and it will metastasize earlier. It clinically presents often as a blue-black, dome-shaped nodule, a.though amelanotic forms exist. SSM and NM account for $90 \%$ of all melanomas in white populations. 
Nowadays it is accepted that NM is a later stage of SSM "Superficial" merely reflects an early microstage of melanoma and not a distinct histogenetic growth pattern. All melanomas probably pass through a stage of radial extension, but some enter the vertical growth phase more precipitously than others. It is emphasized that the histogenetic tumour type; SSM or NM, largely depends on the time the diagnosis is made.

According to Clark and co-workers ${ }^{23}$, melanomas with radial growth phase of three rete ridges or more, should de designated as $S S M_{;}$if less than three rete ridges, the tumour must be classified as NM. The cut-off point of three rete ridges seems rather artificial. The emergence of vertical growth phase bears serious reprisals upon survival. The nodular component of melanoma; whether arising in SSM or recognized "de novo" in NM, is the prognostic determinant. Yet, in Clark's terminology, the radial growth phase defines the histologic type, SSM vs NM. Thus, there is a clear discrepancy between clinicopathologic definition and biologic behaviour of these tumour types.

LMM occurs especially on sun-exposed skin in the elderly. There is no pre-existent naevus. LMM develops after a prolonged non-invasive in situ phase called lentigo maligna (Hutchinson's melanotic freckle, Dubreuihl's melanosis). Especially outdoor workers are at risk. It initially presents as a slowly growing dark brown macule with irregular borders in the face. Later, nodular invasive components arise. LMM is an entirely different entity from the other variants of melanoma because of the distinct growth characteristics. ${ }^{23,25}$ LMM accounts for about $5 \%$ of all melanomas. Also ALM accounts for about $5 \%$ of melanomas: It affects the palms, soles, and nail beds (subungual melanomas). This subtype is the predominant type in coloured populations. ALM appears to be more aggressive than IMM. Invasive growth will start earlier. However, it has to be taken into account that the preinvasive phase is symptomless and that patients tend to visit their doctor later for pigmented lesions on the acra than when they occur in the face.

Cellular and architectural atypia of more or less circumscribed foci of pigment cells in contiguity with the epidermis form the histopathologic hallmark of cutaneous melanoma. Early melanoma is characterized by tumour cells, isolated or in clusters, adjacent to the dermoepidermal junction. The lentiginous preinvasive component of LMM and ALM consists of isolated melanoma cells in the basal layer of the epidermis, almost in a linear pattern. In SMM and NM the tumour cells may ascend to the higher parts of the epidermis. The dominant cell type in LMM and ALM are spindle cells, in SMM and NM mostly epitheloid tumour cells are seen. 


\section{CLINICAL SIGNS AND DIFFERENTIAL DIAGNOSIS}

Most melanomas arise from naevocellular naevi. Changes and symptoms in an acquired naevus are important warning signs. Some 20 years ago the $\mathrm{ABCD}(\mathrm{E})$ rule has been developed to recognize early melanoma in pigmented lesion. ${ }^{36-28}$ This is a mnemonic for Asymmetry, Border irregularity, Colour variegation, Diameter $>6 \mathrm{~mm}$, and Elevation. Recently, a seven-point checklist of features of value in identifying early melanomas has been suggested. ${ }^{29}$ These include major features: 1. changes in size, 2. changes in shape, and 3. changes in colour, and minor features: 4 . diameter $>6 \mathrm{~mm}, 5$. inflammation, 6 . oozing or bleeding, and 7. changes in sensation. Although subjective symptoms like itching, burning, or pain in a pigmented lesion might be suspicious of malignant change, most patients, especially those with early melanomas, have few changes and may have no symptoms at all. In general ulceration, bleeding and pain are late symptoms.

Dermatologists and non-dermatologist physicians see very often solitary pigmented and nompigmented skin lesions that mimic melanoma. The most important of these will be briefly described:

Naevocellular naevus. It can be difficult to differentiate an acquired common mole from melanoma. Moles may grow and darken, especially during certain periods in life like puberty or pregnancy. More problems arise in differentiating specific precursor lesions, dysplastic or atypical naevi, from melanoma. Cutaneous melanoma and dysplastic naevi are both characterized by an irregular border, different colours and a red hue. The diameter of these lesions is usually $>5 \mathrm{~mm}$. Most common moles are $1-3 \mathrm{~mm}$ in diameter. Larger moles may give problems in differentiating them from melanoma and dysplastic naevi.

Spitz's naevus or spindle cell naevus is a benign naevocytic lesion usually occurring in children and adolescents. The clinical and histological features may give resemblance to melanoma.

Blue naevus (naevus caeruleus) is a dome-shaped, smooth, gun-metal or blue-black nodule generally less than $1 \mathrm{~cm}$ in diameter. It occurs on all body sites and at all ages. Malignant degeneration has been described but is uncommon.

Congenital naevi most often present as velvety, pigmented plaques. They are often covered with large terminal hairs.

Solar lentigines (lentigo senilis) are sharply defined, uniformly pigmented light brown maculas on sun-exposed sites in the elderly. Lentigo maligna is darker and shows more colour variegation. The lentigo simplex resembles lentigo senilis, but occurs on all body sites and usually at a younger age. Probably, the lentigo simplex is an early stage of seborrhoeic keratosis. 
Seborrhocic keratoses belong to the nonmelanocytic lesions. They are benign, brown or black, well-defined plaques with a "stuck on" appearance. Irritated or traumatized seborrhoeic warts can mimic nelanoma

Dermatofibromas (histiocytomas) are skin-coloured or pigmented cutaneaus nodules. After pushing the surrounding skin "dimpling" can be achieved.

Pigmented basal cell carciwoma. Basal cell carcinomas principally present as pearly, translucent papules or nodules with telangiectasias. When they are pigmented it can be hard to differentiate them from melanoma.

Capillary angioma most often presents as a red vascular lesion. When it has been thrombosed it can turn dark brown or black in colour and can be easily confused with melanoma.

Pyogenic granuloma is characterized as a rapidly growing pink or red vascular nodule with a strong tendency to bleed. It can be clinically identical to amelanotic melanoma. Kaposi's sarcoma may mimic melanoma. It presents as multiple pink, red, blue or violaceous maculas, papules, nodules, or plaques.

There are several other skin lesions which may resemble primary melanoma: subungual haematoma, black heel, Bowen"s disease, strangulated skin tag, traumatized (plantar) wart, squamous cell carcinoma, and cutaneous metastases from other malignancies. The epiluminescence microscope is an easy to handle device that can be helpful in solving differential diagnostic problems. ${ }^{30,31}$

\section{STAGING AND PROGNOSTIC FACTORS}

The prognosis of cutaneous melanoma strongly depends on the stage of the tumour at the time of diagnosis. Staging is important to determine appropriate treatment. There are different staging systems for melanoma. Earlier methods defined three stages of melanoma: Stage I: local disease, Stage II: regional metastases, and Stage III: distant metastases. More than $90 \%$ of all melanoma patients are diagnosed with the primary tumour alone. Consequently, the three-stage system fails to differentiate risk for mortality for the great majority of cases. Current staging systems, therefore, emphasize the role of histologic parameters by subdividing the primary tumour by level of invasion according to Clark et a $\mathrm{l}^{23}$ and lesion thickness according to Breslow. ${ }^{32}$ Clark and co-authors correlated prognosis with increasing levels of invasion into the dermis or subcutaneous tissues. Breslow measured the vertical tumour thickness, assessed by an ocular micrometer from the top of the granular cell layer of the epidermis to the deepest point of tumour penetration. Nowadays it is accepted that the microstaging according to Breslow gives the rele- 
vant prognostic information, and that Clark's level of invasion does not add substantially to this. ${ }^{3}$ The TNM classification of the Union Internationale contre le Cancer (UTCC), ${ }^{34,35}$ and the classification of the American Joint Committee on Cancer $(A J C C)^{36}$ recommend more uniform staging systems based on the Clark and Breslow microstages.

The initial UICC staging encouraged subdivision of thickness microstages into 1 mm classes. ${ }^{34}$ The AJCC staging proposes cutoff points at $0.75 \mathrm{~mm}, 1.50 \mathrm{~mm}$, and $4 \mathrm{~mm}^{3}$ "The current UICC system also adheres to these endpoints. ${ }^{30}$ Conversely, the New York and Massachusetts Cooperative Group postulated natural breakpoints For tumour thickness at $0.85 \mathrm{~mm}, 1.70 \mathrm{~mm}$, and $3.60 \mathrm{~mm}{ }^{37}$ It is questionable whether "natural" breakpoints for melanoma thickness exist. For practical purposes it is recommended that stratification is made according to the cutoff points at $1 \mathrm{~mm}, 2$ $\mathrm{mm}$, and $4 \mathrm{~mm}{ }^{33}$ Staging with thickness alone is very powerful and should be recommended, not at least because of its simplicity. ${ }^{33}$

Melanoma may form lymphogenic cutaneous metastases just around the tumour: satellites, or in the area between the primary tumour and the regional lymph nodes: in-transit metastases. Where satellites stop and in-transit secondaries begin, is a matter of convention. Currently, a $2 \mathrm{~cm}$ distance from the border of the primary tumour is agreed. Satellitosis heralds a poor prognosis.

Various other factors influence the course of cutaneous melanoma. Often a subdivision is made in clinical and histologic prognostic factors. A more logic and comprehensive enumeration of prognostic factors is presented in Table $1^{38}$ These factors involve stage and microstage of the disease, host factors, tumour characteristics, and iatrogenic factors. The stage of the disease at the time of diagnosis is probably the most important prognostic indicator. For stage I melanomas, tumour thickness according to Breslow $w^{32}$ is the most important denominator. The Clark's 5 -level grading system ${ }^{23}$ is less accurate.

Cutaneous melanoma is notorious for its tendency to develop satellites and in-transit metastases. These are lymphatic deposits in the skin and subcutaneous fat surrounding the primary tumour, or within the draining area of the regional lymph nodes. Satellites and in-transit lesions carry a grave burden upon survival. Also, the presence of microscopic satellites, i.e discrete intraspecimen tumour nests in the vicinity of the main tumour body, has a major influence on survival The anatomic site of the tumour is of relevance with respect to prognosis . Most of the proposed concepts for anatomic stratification into high and low risk sites have 
Table 1. Prognostic factors of cutancous melanoma*

\begin{tabular}{|c|c|c|c|}
\hline Stage of disease & Host characteristics & $\begin{array}{l}\text { Tumour } \\
\text { characteristics }\end{array}$ & $\begin{array}{l}\text { latrogenic } \\
\text { factors }\end{array}$ \\
\hline Clinical scage & Patient's clelay & Histologic type & Doctor's delay \\
\hline $\begin{array}{l}\text { Microstages according } \\
\text { to Breslow and Clark }\end{array}$ & Sex & Mitotic rate & $\begin{array}{l}\text { Inadequate } \\
\text { treatarent }\end{array}$ \\
\hline $\begin{array}{l}\text { Presence of satellites } \\
\text { and/or in-transit } \\
\text { metastases }\end{array}$ & $\begin{array}{l}\text { Age } \\
\text { Localization of tumour }\end{array}$ & $\begin{array}{l}\text { Vasoinvasive } \\
\text { properties }\end{array}$ & \\
\hline Lymph node involvement & Immunologic factors & $\begin{array}{l}\text { Uiceration } \\
\text { Amelanosis }\end{array}$ & \\
\hline $\begin{array}{l}\text { Presence of distant } \\
\text { metastases }\end{array}$ & Hormonal factors & $\begin{array}{l}\text { Microscopic } \\
\text { satellites }\end{array}$ & \\
\hline
\end{tabular}

"Modified from Rampen

been based on the classification into four major body sites: bead and neck, trunk, arms, and legs. Axial locations (head and trunk) are associated with a poor prognosis compared to extremity locations. These concepts have the disadvantage of lack of controlling for other risk factors such as tumour thickness and histologic subtype. Day et al introduced the BANS concept, which identified the upper Back, posterior Arms, posterior Neck, and posterior Scalp, as independent risk areas. ${ }^{40}$ The validity of the BANS concept has been questioned. Recently, Garbe et al were able to confirm and modify the BANS stratification by using multivariate analysis. ${ }^{41}$ They established high risk TANS lesions: Thorax (back and breast), upper Arms, Neck, and $\mathbf{S}$ calp.

Females have a better prognosis than males. ${ }^{42}$ Probably there is a difference in outcome because of the location of preference of the primary melanoma. Melanomas in women are more often located on the lower leg, a site easy to see. Melanomas in men however, are more often located on the back, an anatomic region that is hard to see by the patient himself. Women present with thinner lesions and at an earlier clinical stage. Furthermore, lymph drainage is easier to predict in melanomas located on the leg than on the trunk. The exact role of sex hormones has not been elucidated yet. The possibility that oral contraceptives have an association with melanoma has never been substantiated. Pregnancy may have a deleterious effect on melanoma activity, although this suggestion was not confirmed in a recent study ${ }^{43}$ Prognosis in the pregnancy group in this communication was not worse after allowance for Breslow thickness. Interestingly, however, microstage was found to be unfavourable in the 
pregnancy group. This may indicate exacerbation of melanoma during pregnancy, possibly because of elevated androgen levels. ${ }^{\text {th }}$

With regard to tumour type, it has been suggested that superficial spreading melanoma and lentigo maligna melanoma have a better outcome than nodular melanoma and acral-lentiginous melanoma. However, after correction for tumour thickness there are no differences with respect to prognosis. Other prognostic features are mitotic activity, vasoinvasive properties, and ulceration. Of these, ulceration is probably the most important risk factor.

Prompt and proper treatment is essential. Physician's delay may bear severely upon survival. The same applies to inadequate management and follow-up.

\section{TREATMENT}

Every skin lesion suspicious of melanoma should be excised. Sampling error by incisional biopsies may be a source of misinformation. Often, the type of tumour and the Breslow thickness cannot be assessed properly on a partial specimen. Furthermore, there is evidence that malignant cells could detach and reach lymphatics or blood vessels during incisional procedures, which may occasion metastatic spread. ts $^{\text {s. }}$ Other authors have failed to detect a detrimental effect of incisional biopsy on prognosis. ${ }^{46}$ The diagnostic excision has to be performed under field block anaesthesia with a $2-5 \mathrm{~mm}$ margin.

After the diagnosis melanoma has been established by histology, a therapeutic excision has to be performed as soon as possible. Because of the propensity of melanoma to develop satellites, the margin of the therapeutic excision differs from that of nonmelanoma skin cancer. The chance of development of satellites is dependant on tumour thickness. ${ }^{30}$ Therefore, thick lesions necessitate more extensive surgery. ${ }^{47}$ For thin melanomas with thickness $\leq 1 \mathrm{~mm}$ an excision margin of $1 \mathrm{~cm}$ is sufficient, for melanomas with thickness between 1 and $2 \mathrm{~mm}$ an excision margin of $2 \mathrm{~cm}$ is appropriate, and for melanomas with thickness $>2 \mathrm{~mm}$ an excision margin of $3 \mathrm{~cm}$ is advocated.

For patients with clinical stage I disease elective or prophylactic lymph node dissection is still a matter of debate. Theoretically, there is a subgroup of patients with clinical stage I disease with microscopic metastases in nonpalpable regional lymph nodes. Prognosis could possibly be improved by early node dissection.

In general, patients with melanomas $\leq 1.5 \mathrm{~mm}$ thick (low risk of lymphogenic metastases) or $>4 \mathrm{~mm}$ thick (high risk of haematogenic metastases) have little benefit from elective lymph node dissection. It has been suggested that only patients with 
intermediate thickness experience better prognosis after elective lymph node dissection. However, the role of elective node dissection remains a matter of many controversies since the WHO study of $1977,49.52$

At present, studies are ongoing to show the value of sentinel node biopsy in patients with clinical stage 1 disease. ${ }^{53,54}$ The aim of this procedure is to determine a subgroup of patients with microscopic metastatic disease in nonpalpable lymph nodes. Therapeutic lymph node dissection can then be performed. Theoretically, these patients would have a better prognosis. Further research is necessary to elucidate this issue.

When there are palpable lymph nodes (stage II disease), therapeutic lymph node dissection has to be performed.

In selected cases like loco-regional recurrent disease (satellites and in-transit metastases) or poor-prognosis primary lesions on the extremities, therapeutic isolation perfusion can be decided upon. Cytostatics, usually melphalan, are administered to the regional circulation in high dosages. Good results have been reported. ${ }^{55}$ No controlled clinical trial has been performed yet comparing isolation perfusion as an adjuvant procedure with surgery alone. Studies are going on. The results of refinements of the procedure such as hyperthermic perfusion, multiple perfusions, use of cytostatic drugs other than melphalan, and combination with T'NF and IFN-gamma, remain to be awaited. In the Netherlands perfusion therapy is carried out in the University Hospital Groningen, the Antoni van Leeuwenhoek Hospital Amsterdam and the Dr Daniel den Hoed Hospital Rotterdam.

There is no standardized therapy for advanced melanoma (Stage III). In general, response rates to all forms of chemotherapy are poor. DIIC (dacarbazine) is the most effective agent. Response rates vary between $10 \%$ and $40 \%$, and remission periods are short. The subject of other modalities like radiotherapy, hormonal therapy, and immunotherapy, is beyond the scope of this review.

\section{FOLLOW-UP}

When a patient has been treated for cutaneous melanoma, close follow-up is recommended (Table 2). ${ }^{\text {i7 }}$

During each exam inspection and palpation of the area of the primary tumour has to be performed. Furthermore, palpation of the regional lymph nodes is necessary. Also, the skin between the primary lesion and the regional lymph nodes has to be examined for satellites and in-transit metastases. Inspection of the entire skin is 
recommended once a year in cases with the dysplastic naevus syndrome phenotype. Routine X-rays and blood tests are not advocated. The presence of symptomless distant metastases has no inference as long as there is no appropriate systemic therapy.

Table 2. Recommended follow-up after treatment for cutaneous melanoma.

$\begin{array}{ll}1^{\text {st }} \text { year } & \text { once every } 2 \text { months } \\ 2^{\text {tad }} \text { year } & \text { once every } 3 \text { months } \\ 3^{\text {rd }} \text { year } & \text { once every } 4 \text { months } \\ 4^{\text {th }}-5^{\text {th }} \text { year } & \text { once every } 6 \text { months } \\ 6^{\text {th }}-10^{\text {th }} \text { year } & \text { once each year }\end{array}$

\section{PRECURSOR LESIONS}

Congenital naevi and dysplastic naevi are recognized precursor lesions to cutaneous mellanoma. Congenital naevocytic naevi usually present at birth or appear soon afterwards.

About $4 \%$ of newborns have pigmented skin lesions ${ }^{56}$. In a minority of these cases there is a congenital naevus. Other pigmented skin lesions found at birth are mongolian spots, café-au-lait maculas, naevus of Ito, and naevus of Ota. Not all congenital naevi are present at birth; some will develop after several weeks or months after delivery.

There are different classification systems according to the size of congenital naevi. For the purpose of convenience, congenital naevi have arbitrarily been divided according to size into small congenital naevi $(\leq 1.5 \mathrm{~cm}$ greatest diameter), mediumsized congenital naevi ( $1.5-20 \mathrm{~cm}$ diametter), and giant congenital naevi ( $>20 \mathrm{~cm}$ diameter). ${ }^{57}$ These sizes are based on diameter at the time of presentation. It has to be taken into account that a diameter of $6 \mathrm{~cm}$ is something different in a newborn infant than in an adult. Other authors prefer classification according to easy versus difficult to treat surgically.

Of all newborns $1 \%$ has a genuine congenital naevus ${ }^{58}$. Most of these are small congenital naevi. Giant congenital naevi are rare. They often present with multiple satellites. Congenital naevi are pigmented, sharply demarcated, and slightly elevated lesions. They often have a verrucous or pebbled surface and some terminal hair growth. 
Giant congenital naevi localised in the head and neck region may be associated with leptomeningeal melanocytosis. Epilepsy, mental retardation, and leptomeningeal melanoma may occur ${ }^{59}$

The risk of malignancy in congenital naevi seems to be correlated with the size of the naevus. 60 The reported incidence of melanoma in small congenital naevi is greater than what one may expect (3-20\%). Rhodes and Melski ${ }^{61}$ describe a 21 -fold increased relative risk to develop a melanoma in solitary small congenital naevi. They calculated a $5 \%$ cumulative risk till the age of 60 years to develop a melanoma.

Development of a melanoma in a giant congenital naevus can occur in the first years of life. ${ }^{62,63}$ Therefore, many authors advocate prophylactic removal of these lesions as soon as possible. Another reason to remove a giant congenital naevus are the cosmetic aspects and possible emotional effects it has on the child and parents. Theoretically, excision is the first and best choice of therapy to remove all naevus cells. This is not always possible because of the presence of naevus cells in subcutaneous tissues. Furthermore, total excision, often in multiple sessions, is not always practicable or conceivable. Split skin grafting, the use of tissue expanders, and keratinocyte cultures have their limitations. Several investigators have reported good cosmetic results from deep dermabrasion or curettage in the first few weeks of life. ${ }^{6-66}$ This approach is based on the drop off theory. During the first few weeks the naevus cell are mainly present in the papillary dermis. Thereafter they will migrate (drop off) to deeper structures. Dermabrasion may cause a considerable reduction of the number of naevus cells. One may expect that the chance of malignant degeneration will be reduced. The cosmetic outcome of this techrique is promising.

When an expectative approach is considered periodic examination of giant congenital naevi is advocated. Furthermore, patient and parents must know the early signs and symptoms of melanoma.

Because the risk of melanoma among patients with small and medium sized congenital naevi remains throughout life, prophylactic excision would be suitable. Excision performed before the age of 12 is recommended.

Familial occurrence of melanoma has been known for many decades. ${ }^{6}$ Only in 1978 Clarket al and Lynch et a ${ }^{70}$ described the familial occurrence of multiple naevi and increased risk of developing melanoma. Members of these families have the remarkable skin phenotype of multiple, atypical acquired naevi ("funny moles"). This familial syndrome was described as the B-K mole syndrome by Clark et al ${ }^{69}$ Lynch et al described this phenomenon as the FAMMM (familial atypical multiple mole melanoma) syndrome. ${ }^{20}$ This phenotype is now known as the dysplastic naevus syndrome (DNS) ${ }^{7}$ 
Later in 1980 dysplastic naevi were recognized not only to occur in families but also in the general population." Individualls with the so-called "sporadic' DNS have the same phenotype of multiple dysplastic naevi but without a family history of dysplastic naevi or melanomas. It is not always possible to differentiate between familial and sporadic DNS. Kraemer et al ${ }^{\text {ra }}$ proposed a DNS classification with increasing melanoma risk, according to the presence or absence of dysplastic naevi and melanomas in the patient and in first grade relatives. In the highest risk category the authors calculated a $100 \%$ lifetime risk of melanoma.

Autosomal dominant inheritance in the familial DNS has been suggested. ${ }^{74}$ However, because of the variability of clinical expression a polygenic inheritance seems more plausible. ${ }^{75}$

The clinical characteristics of dysplastic naevi are:

size : $>5 \mathrm{~mm}$,

colour : variegate shades of brown, often with a pink-red hue, shape : irregular, unsharp outlines,

border : fades slowly into surrounding skin,

surface : usually macular or just palpable.

Newton et al describe a scoring system of the DNS in which not only the above clinical characteristics but also the number, localisation, and distribution (especially buttocks, scalp, and iris) are of importance. ${ }^{76}$ Dysplastic naevi differ histologically from common naevocytic naevi in their atypical architectural, cellular, and stromal features. ${ }^{47}$

Annual evaluation of individuals with the DNS is recommended. Detection of early melanomas developing from dysplastic naevi is the aim. Photodocumentation can be helpful. When DNS is diagnosed, examination of the first grade family members (parents, brothers, sisters, and children as from puberty onwards) is advocated.

Cutaneous melanoma has the unique character that it is a visible tumour. It has a dismal prognosis when not detected early and treated promptly and adequately. In its initial stage it has recognizable features. Thin melanomas are easy to treat by simple outpatient procedures and there is general consensus how to do.

In different countries all over the world early detection programmes have been organized for years. Prevention strategies are worth considering. The practicability and feasibility of secondary prevention by means of screening is the topic of the present thesis. 


\section{REFERENCES}

1. Mishima Y. Melarocytic and nevocytic malignant melanomas: cellular and subcellular differences. Cancer 1967;20:632-49.

2. Rampen $\mathbb{H} H$ J. Naevocytic naevi as an atavism. Their relationship to melanoma risk. Med Hypotheses 1988;27:71-8.

3. Van der Esch EP, Muir CS, Nectoux J, et al. Temporal change in diagnostic criteria as a cause of the increase of malignant melanoma over time is unlikely. Int I Cancer $1991 ; 47: 483-9$.

4. Nelemans PJ, Rampen FHJ. De epidemiologie van het melanoom wan de huid in Nederland: een beschrijvend onderzoek. Ned Tijdschr Ceneeskd 1990;134:2038-42.

5. Incidence of cancer in the Netherlands, 1992 . Fourth report of the Netherlands Cancer Registry. Eds: Visser O, Coebergh JWW, Schouten L... Utrecht, 1995.

6. National Cancer Institute Cancer Statistics Review, 1973-1983. NIH Publications No. (FHS) 90-2789, Bethesda (MD) US Department of Health and Human Services, Public Heaith Services, 1990.

7. Scotto J, Pitcher H, Lee IAH. Indications of future decreasing trends in skim-melanoma mortality among whites in the United States. Int J Cancer 1991;49:490-7.

8. Spitz S. Melanomas of childhood. Am J Pathol 1948;24:591-609.

9. Peters MS, Goellner JR. Spitz naevi and malignant melanomas of childhood and adolescence. Histopathology 1986;10:1289-302.

10. Rhodes $A R$, Weinstock MA, Fitzpatrick TB, Mihm MC, Sober AJ. Risk Factors for culaneous melanoma. IAMA 1987,258:3146-54.

11. Evans RD, KopE AW, Lew RA, et al. Risk factors for the development of malignant melanoma. I. Review of case-control studies. I Dermatol Surg Oncol 1988;14:393-408.

12. Holman CDI, Armstrong BK. Pigmentary traits, ethnic origin, benign nevi, and family history as risk factors for cutaneous malignant melanoma. I Natl Cancer inst $1984 ; 72: 257-66$.

13. Holly EA, Kelly" JW, Shpall SN, Chiu SH. Number of melanocytic nevi as a major risk Factor for malignant melanoma. J Am Acad Dermatol 1987;17:459-68.

14. Elwood JM. Melanoma and ultraviolet radiation. Clin Dermatol 1992;10:41-50.

15. Holman CDI. Armstrong BK, Heenan PI. A theory of the etiology and pathogenesis of human cutaneous maliguant melanoma. J Natl Cancer Inst 1983:71:651-6.

16. Holman CDJ, Armstrong BK, Heenan PJ. Relationship of cutaneous malignant melanoma to individual sunlight-exposure habits. I Natl Cancer Inst 1986;76:403-14.

17. Nelemans PJ, Rampen FHJ, Ruiter DJ, Verbeek ALM. An addition to the controversy on sunlight exposure and melanoma risk: A meta-analytic approach. J Clin Epidemiol $1995,48: 1331.42$

18. Rampen FHI Nelemans PJ Verbeek ALM. Is water pollution a cause of cutaneous melanona? Epidemology $1992 ; 32263-5$.

19. Nelemans PI, Groenendal $\mathrm{H}_{j}$ Kiemeney LALM, et al. Swimming and the risk of cutaneous melanoma. Melanoma Res 1994;4:281-6.

20. Weinstock MA. Human models of melanoma. Clin Dermatol 1992;10:83-9.

21. Walter SD, Marett LD, From L et al. The association of cutaneous malignant melanoma with the use of sunbeds and sunlamps. Am I Epidemiol 1990;131:232 43.

22. Donawho C, Kripke ML. Evidence that the local effect of UV radiation on the growth of murine melanomas is immunologically mediated. Cancer Res $1991 ; 51: 4176-81$.

23. Clark WH, From L, Bernardino EA, Mhm MC. The histogenesis and biologic behavior of primary human malignant melanomas of the skin. Cancer Res 1969;29:705-27.

24. Clark WH, Ainsworth AM, Bernardino EA, Yang C-H, Mihn MC, Reed RI. The developmental biology of primary human malignant melanomas. Sem Oncol 1975;2:83103. 
25. McGovern VI, Shaw HM, Molton $\mathrm{CW}$, et al. Is malignant melanoma arising in Hutchinson's melanotic Ereckle a separate entity Histopat hology 1980;4285 42.

26. Mihm MC, Fitzpatrick TB, Lane Brown MM, et al. Early detection of primary cutaneous malignant melanoma. A colour atlas. N Engl I Med 1973;19:989-96.

27. Solzer AJ, Fitzpatrick TB, Mihm MC, et al. Early recognition of cutaneous melanoma. JAMA 1979;242:2795-9.

28. Friedman RI, Rigel DS, Kopf AW. Early detection of malignant melanoma: the role of physician examination and self-examination of the skin. Cancer J Clin 1985;35:13051.

29. Mackie RM. Malignant melanoma. A guide to early diagnosis. University of GLasgow, 1989.

30. Bahmer EA, Fritsch P, Kreusch J, et al. Terminology in surface microscopy. I Am Acad Dermatol 1990;23:1159-62.


criteria for detecting malignant melanoma. Dermatology $1995,190: 2530$.

32. Breslow $A$. Thickness, cross-sectional areas and depth of invasion in the prognosis of cutaneous melanoma. Ann Surg 1970;172:902-6.

33. Büttner P, Garbe C, Bertz J, et al. Primary cutaneous melanoma: Optimized cut toff points of tumor thickness and importance of Clark's level for prognostic classification. Cancer $1995 ; 75: 2499-506$.

34. TNM classification of malignant melanoma, 2nd Ed. Geneva: International Union Against Cancer 1978.

35. Hermanek $P$, Sobin LH (Eds). UICC: TNM classification of malignant tumours, 4th Ed. Berlin: Springer, 1987.


Kennedy BJ, Eds. Manual for staging of cancer 4 th Ed. Philadelphia: JB Lippincott, 1992:143-8.

37. Day CL, Lew RA, Mihm MC, er al. The natural break points for primary-tumor thickness in clinical Stage I melanoma. M Engl J Med 1981;305-1155.

38. Rampen FHJ. Melanoom van de huid. Nieuwegein: Claxo BV, 1989;43-51.

39. Day CL, Harrist TI, Gorstein $F_{3}$ et al. Malignant melanoma; Prognostic significance of "microscopic satellites" in the reticular dermis and subcutaneous fat. Ann Surg $1981 ; 194: 108 \cdots 12$.

40. Day CL, Mihm MC, Sober $\mathrm{AJ}$, et al. Prognostic factors for melanoma patients with lesions $0.76-1.69 \mathrm{~mm}$ in thickness; An appraisal. of "thin" level IV lesions. Ann Surg $1982 ; 195: 30-4$.

41. Carbe C, Büttner P, Bertz J, et al. Primary cutaneous melanoma; Prognostic Classification of anatomic location. Cancer 1995;75:2492-8.

42. Shaw HM, MoGovern VI. Milton GW, Farago GA, McCarthy WH. Histologic features of tumors and female superiority in survival from malignant melanoma. Cancer $1980 ; 45: 1604-8$

43. Mackie RM, Bufalino R, Morabita A, Sutherland C, Cascinelli N. Lack of effect of pregnancy on outcome of melanoma. Lancet $1991,337: 653-5$.

44. Rampen FHJ, Mulder JH. Malignant melanoma; An androgen dependant tumourc Lancet 1980 ; i: $562-5$.

45. Rampen FHI, van der Esch EP. Biopsy and survival oE malignant melanoma. I Am Acad Dermatol 1985;12:385-8

46. Lederman IS, Sober AJ Does biopsy type influence survival in clinical Stage l cutaneous melanoma? Am Acad Dermatol 1985;13:983-7.

47. Rampen FHI, Ruiter DJ, Kroon BBR, Rümke P. Herziene consensus melanoom van de huid. Ned Tijdschr Geneeskd 1990;134:2031-3. 
48. Balch CM. The role of elective lymph node dissection in melanoma: rationale, results, and controversies. J Clin Oncol 1988;6:163-72.

49. Veronesi $U_{1}$ Adams $J$, Bandiera DC, et al Inefficacy of mmediate node dissection in stage I melanoma of the limbs. N Engl J Med 1997,297:627.30.

50. Cady B. Prophylactic' lymph node dissection in melanoma: does it helpe J Clin Oncol $1980 ; 6: 2-4$

51. Crowly NJ. The case against elective lymphadenectomy. Surg Oncol Clin North Am $1992,1: 223-46$.

52. Petres I, Rompel R. Elektive Lymphknotendissektion bei primären Melanom. Hautarzt $1996: 47: 29-34$.

53. Morton DL, Wen DR, Cochran Al, Management of early-stage melanoma by intraoperative lymphatic mapping and selective lymphadenectomy. Surg Oncol Clin North Am 1992;1:257-9.

54. Veen $H$ wan der, Hoekstra OS, Paul MA, Cuesta MA, Meijer S. Gamma-probe guided sentinel node biopsy to select patients with melanoma for lymphadenectorny. Br J Surg $1994 ; 81: 1769-70$.

55. Schrafford Koops $H$, Kroon BBR, Lejeune EJ. Isolated perfusion in the treatment of local recurrence, satellites and in-transit metastases of extremity melanomas. In: Rümlee $P^{\prime}($ Ed); Therapy of adwanced melanoma. Pigment Cell, Vol 10. Basel: Karger, 1990; p.67. 78.

56. Walton RG, Jacobs AH, Cox AJ. Pigmented lesions in newborn infants. Br J Dermatol $1976,95389-96$

57. Consensus development conference, 1983. National Institute of Health, Bethesda MD. Precursors to malignant melanoma. JAMA 1984,251:1864-6.

58. Castilla EE, Da Graça Dutra M, Orioli-Parreiros IM. Epidemiology of congenital pigmented naevi. I. Incidence rates and relative frequencies. Br I Dermatol 1981;104:307 115.

59. Kadosaga JN, Frieden IJ, Neurocutaneous melanosis: definition and review of the literature I Am Acad Dermatol 1991:24:747-55.

60. Swerdlow AI, English JSC, Z Qiao. The risk of melanoma in patients with congenital nevi: A cohort study. I Am Acad Dermatol 1995;32:595-9.

61. Rhodes AR, Melski JW. Small congenital nevocullular nevi and risk of cutaneous melanoma. J Pediatr 1982;100:219-24.

62. Kopt AW, Bart RS, Heressy P. Congenital newocytic nevi and malignant melanoma. J Am Acad Dermatol 1979;1:123-30.

63. Rhodes AR. Congenital nevomelanocytic nevi: histologic patterns in the first year of life and evolution during childhood. Arch Dermatol 1986;122:1257-62.

64. Johnson HA. Permanent removal of pigmentation from giant hairy nevi by dermabrasion in early life. Br I Plast Surg 1977,30:321-8.

65. Moss ACH. Congenital 'giant' naevus; a preliminary report of new surgical approach. Br. Plast Surg 1987;40:410-9.

66. De Raeve LE, De Coninck AL, Dierickx PR, Rosseeuw DI. Neonatal curettage of giant congenilal melanocytic nevi. Arch Dermatol 1996;132:20-2.

67. Rhodes AR, Sober AJ, Day CL, et al. The malignant potential of small congenital revocellular nevi. An estimate of association based on histologic study of 234 primary cutaneous metanomas J Am Acad Dermatol 1982:6:230-41.

68. Cawley EP. Genetic aspects of malignant melanoma. Arch Dermatol Syphil 1952;65:44050.

69. Clark WH, Reiner RR, Green MH, Ainsworth AM, Mastrangelo MJ. Origin of familial malignant melanomas from heritable melanocytic lesions: the B-K mole syndrome. Arch Dermatol 1978; 14:732-8. 
70. Lynch HT, Frichot BC, Lynch IK. Familial atypical multiple mole melanoma syndrome. JMed Genet 1978;51:352-6.

71. Greene MH, Clark WH, Tucker MA, et al. Precursor naevi in cutaneous malignant melanoma; a proposed nomenclature Lancet 1980; ii: 1024.

72. Elder DE, Goldman LI, Goldman DC, Greene MH, Clark WH. Dysplastic newus syndrome; a phenotypic association of sporadic cutaneous melanoma. Cancer $1980 ; 46: 1787-94$.

73. Kraemer $\mathrm{KH}_{\text {s }}$ Greene $\mathrm{MH}$, Tarone R, Elder DE, Clark WH, Guerry DN. Dysplastic naew and cutaneous melanoma risk. Lancet 1983,ii:1076-7.

74. Bergman W, Palan $A$, Went LN. Clinical and genetic studies in six Dutch kindreds with the dysplastic naevus syndrome. Ann Hum Genet 1986,50:249-58.

75. Happle $\mathrm{R}$, Traupe $\mathrm{H}_{\text {, Vakilzadeh }}$, Macher E. Arguments in favor of a polygenic inheritance of precursor nevi. J Am Acad Dermatol 1982,6:540-3.

76. Newton JA. The dermatologist"s approach to moles, what to look for and when to act. J Eur Acad Dermatol Venereol 1993;2:87-93. 
32 
$s$ rojquad

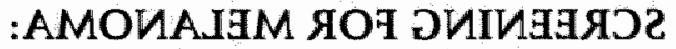

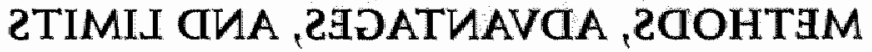

nequas . I.H. sioof gb.M. L.M

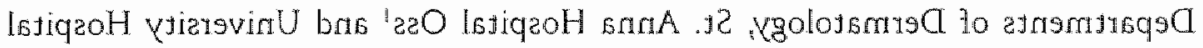

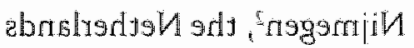

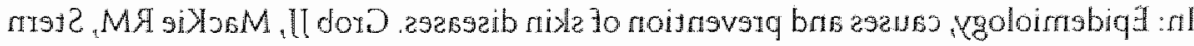

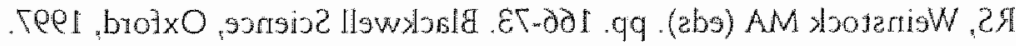


Incidence and mortality rates of cutaneous melanoma have been rising rapidly during the last few decades. Until recently prediction of increased rates of melanoma in the near future were based on the belief that the incidence will continue to rise at a rate of $4 \%$ or more annually. Therefore, in recent years public health bodies and the medical profession have been contemplating and initiating educational programmes directed at primary prevention and early detection.

Currently, screening programmes for skin cancer/melanoma are increasing in number. Screening is thought to be an easy means of secondary prevention. There is the compelling intuitive appeal on the assumption that detection of early stage melanoma will be rewarding. However, screening for cancer is not always simple. This also applies to melanoma and skin cancer. Some critical features relevant to screening for skin cancer in general and melanoma in particular are reviewed here.

\section{FUNDAMENTALS}

The basic principles of screening for disease have been outlined by Wilson and Jungner. "These authors distinguished ten prerequisites for a worthwhile screening programme. They presented their criteria for strictly defined large-scale population screenings. However, the same criteria can also be used for sellective screening exercises such as skin cancer/melanoma screening based on self-selection. The value of the Wilson and Jungner principles has been critically analyzed previously with reference to the skin cancer/melanoma setting. ${ }^{2}$ Here we will briefly review this issue.

\section{The condition sought should be an important health problem.}

Skin cancer is very common, especially in countries with a predominantly white population. In the United States more than 500,000 new nonmelanoma skin cancers and approximately 32,000 new melanomas are diagnosed annually. Melanoma is more common than cervical cancer and leukaemia.

Case fatality rates for nonmelanoma skin cancers are low. However, mortality rates are increasing. ${ }^{.}$

About $20 \%$ of melanoma patients will eventually die from their disease. Annual mortality from melanoma in the United States is now $6900 .^{3}$

The rising incidence of melanoma is worrying. It is one of the principal reasons for the recent emergence of screening exercises. It is worthy of note, however that levelling off of mortality rates with the more recent birth cohorts has been reported. ${ }^{3}$ In the Netherlands, no increase of melanoma incidence has been observed in the period 1989-1992.6. 


\section{There should be an accepted treatment for patients with recognized disease.}

Treatment for all types of skin cancer, including melanoma, is safe; inexpensive, and effective. Management of precursor lesions such as actinic keratoses, and congenital and dysplastic naevi is more controversial. ${ }^{7.9}$

\section{Facilities for diagnosis and treatment should be available.}

Most types of skin cancer/melanoma can be managed by simple office procedures that are readily available. In rare instances, hospital admission or referral to a specialized centre is required. It needs emphasizing here that screening for other cancers are continuous processes; the workload generated by such campaigns is spread over the year. Screening for skin cancer/melanoma so far has involved single-occasion or once-a-year affairs with steep increases in referrals immediately after the campaigns. This may have a marked effect on workload and biopsy rate, especially in countries with a low dermatologist-to-patient ratio. ${ }^{10}$ We found that the extra workload for the general practitioner generated by a skin cancer/melanoma screening clinic was negligible. ${ }^{11}$

\section{There should be a recognizable latent or early symptontatic stage.}

Melanomas and nonmelanoma skin cancers have recognizable early stages. Precursor lesions are also easily detectable.

\section{There should be a suitable test or examination.}

Screening for skin cancer means visual inspection of the skin by, preferably, a dermatologist. Visual examination of skin lesions by the dermatologist constitutes a most reliable screening tool. Koh et al ${ }^{12}$ estimated the validity of a visual examination by dermatologists in a screening setting from $89 \%$ sensitivity for squamous cell carcinoma, to $94 \%$ for basal cell carcinoma, and $97 \%$ for melanoma. In an earlier report we found that the positive predictive value for skin cancer' melanoma in two screening campaigns was $50-60 \%,{ }^{13}$

Few data are available on the accuracy of visual examination by dermatologists as a screening tool because of the lack of false-negative findings. Sensitivity and specificity of the screening test can only be derived from true-negative and false-negative findings. We obtained follow-up information on 1551 persons with a negative screening result; 15 persons had new skin cancers, three of which had probably been present at the original screening and had been missed. ${ }^{14}$ The calculated sensitivity of this screening was $93.3 \%$, its specificity was $97.8 \%$.

The accuracy of clinical examination of the skin differs with the observer. In this respect dermatologists score distinctly better than nondermatologists. ${ }^{15,16}$ 
acceptance to screenees is high. Full-skin inspection may be embarrassing. However, sufficient data are available confirming the high acceptance of total skin examination (Table 1). This applies to patients seen in dermatologic practice as well as to persons seen during screening activities. Inconvenience and concern about privacy and modesty seem to be of trivial importance for most patients and screenees, and should not be a barrier to total skin checks.

Table 1. Patient acceptance of total skin examination

\begin{tabular}{|c|c|c|c|}
\hline Reference & Study population & No. of persons & Acceptance \\
\hline Boyce and Bermhard ${ }^{36}$ & Office patients & 182 & $94 \%$ \\
\hline Rigel et a ${ }^{30}$ & Screening & 2239 & $62 \%$ \\
\hline Lookingbill ${ }^{37}$ & New office patients & 1157 & $96 \%$ \\
\hline Chiarello 38 & Office patients & 1028 & $85 \%$ \\
\hline Bolognia et a ${ }^{32}$ & Screening & 251 & $98 \%$ \\
\hline Lee et a $\mathrm{a}^{40}$ & New office patients & 874 & $81 \%$ \\
\hline de Rooij et al f $^{\mathrm{a}}$ & Screening & 1385 & $98 \%$ \\
\hline
\end{tabular}

\section{The natural history of the condition, including development from latent to declared disease, should be adequately understood.}

Early melanomas, i.e. melanomas with a predominantly radial growth phase, and favourable microstages according to Clark et al" and Breslow", have a good prógnosis. These early stages may last months or even years. Melanoma can be detected far before manifestation of metastatic spread. Accurate prognostication of outcome is possible.

Precursor lesions progress to frank skin cancer very slowly. The lifetime risk of developing melanoma from atypical (dysplastic) naevi ranges from 5 to $100 \%$, according to the personal and family histories of dysplastic naevi or mellanoma. ${ }^{19}$ The potential of malignant transformation of congenital naevi is relatively small.20,21 Actinic keratoses evolve into invasive squamous cell carcinoma only rarely. The exact value of screening for premalignant skin lesions is subject to controversy. It should be considered that screening tests and programmes indicate that although some degree of control of skin cancer and melanoma may be achieved at reasonable costs, the casts of higher degrees of control (precursor states) will be disproportionately more. 


\section{There should be an agreed policy on whow to treat.}

In our view, screening must focus on melanoma only ${ }^{2}$ Screening concentrating on melanoma increases the rates of lesions suggestive of melanoma and dysplastic naevi, whereas the proportions of nonmelanoma skin cancers and actinic keratoses decrease. Without doubt, any type of invasive skin cancer detected through screening must be treated appropriately. Whether all precursor lesions discovered at screening should be treated or not, remains debatable. "Borderline" cases (minor actinic keratoses, vague evidence of dysplastic naevi, small congenital naevi) are preferably left untreated. Depending on definitions and criteria used, the "borderline" group may be larger than the "diseased" group, which may disproportionately burden upon the cost-effectiveness of screening.

\section{The cost of screening including diagnosis and treatment of positive screenees,} showld be econowically balanced in relation to possible expenditures on medical care as a whole.

Screening for skin cancer/melanoma is inexpensive. However, the expenditures generated by the screening itself are not final costs. There are many hidden costs such as the follow-up and treatment of positive screenees, and the management of persons who do not wish to attend the screening itself but visit their own family physician or dermatologist. On the whole, however, total costs of screening for skin cancer/melanoma are regarded as relatively cheap in comparison with the costs of similar procedures for other types of cancer.

\section{Screening should be a continuing process and wot a single-occasion project.}

Periodic skin checks have been advocated since 1985 by the American Academy of Dermatology on a nationwide and voluntary basis. ${ }^{24}$ Periodic screening has the advantage of covering more and more of the population at risk. There are no useful data on the ideal frequency of skin cancer/melanoma screening.

Melanoma fulfils, for the most part, all the criteria for screening for disease enunciated by Wilson and Jungner in 1968. For nonmelanoma skin cancer the fulfilment of these basic requirements is less clear.

Obvious as the integrity of the screening process for melanoma may sound, a comprehensive and scientifically respectable assessment of its value is not available. Screening has many potential benefits, but also disadvantages. ${ }^{25}$ The benefits are clear. Some cases detected during screening will have an improved prognosis because of early intervention. Less radical treatment is necessary. This may save health-care resources. Many individuals with negative test results can be reassured and will refrain from seeking medical care. Also this may save costs. Precampaign publicity 
may elicit changes in knowledge and attitude about skin cancer/melanoma in the target population, with definite primary and secondary prevention effects.

The disadvantages of screening are numerous. There is the longer morbidity of patients whose prognosis is unaltered. The resource costs may be substantial, in terms of the screening itself, the organization and manpower, and the subsequent management and evaluation of positive screenees, including those with precursor lesions and "borderline" cases. There is the dangerous fallacy of the assumption that if one is screened, all is well; absence of evidence is not evidence of absence of disease. Some persons with false-negative screen results will be given unfounded reassurance, which may occasion undue patient delays. On the other hand, those with false-positive results will be offered unnecessary surgery and, inevitably, many persons with minor or questionable disease will also be unnecessarily treated. Finally, there is the question of needless anxiety in the community in general, and in the screened population in particular.

\section{FEASIBILITY}

There are several screening procedures for skin cancer/melanoma. In the 1970s, a number of limited screenings for skin cancer were conducted in the United States at trade fairs, among farmers and rangers, or using mobile house trailers. ${ }^{24}$ Screening programmes of a defined population have also been performed in Australia. ${ }^{25}$ Screening at the workplace is another means of examining defined populations for skin cancer or melanoma. For example, an active diagnosis programme at the Lawrence Livermore National Laboratory was set up in response to recorded increased melanoma rates and survival after diagnosis of melanoma has been more favourable."27 Screening of sunworshippers on beach locations has been performed in Australia ${ }^{23}$ and the Netherlands. ${ }^{29}$

Annual melanoma and skin cancer screening on self-selected persons by dermatologists has been conducted in the United States since 1985. ${ }^{24}$ This national screening programme was initiated by the American Academy of Dermatology (AAD). The effort has been received enthusiastically. Similar clinics have been held in the Netherlands. ${ }^{13,23}$

So far, the type of screening according to the AAD model seems to be the most feasible and ready to organize. However, screening by dermatologists is often hampered by lack of provider time. Especially in countries with a scarcity of dermatologists, like the United Kingdom, screening by dermatologists is not practicable. But also in less adverse situations, a proper and rigic type of organization 
is mandatory. High numbers of attendants necessitate tight schedules in order to examine as many screenees as possible. To that end, we have tried to improve and refine our screenings.

Targeting high-risk persons should enhance the efficiency of skin-cancer screening. Melanoma has a high mortality rate as compared to nonmelanoma skin cancer. In terms of health strategy priorities, nonmelanoma skin cancers are insignificant. In our view, these cancers should not be screened for. In 1993 we organized a screening concentrating on melanoma and dysplastic naevi only. The rates of lesions suggestive of melanoma and its precursors increased substantially, whereas the proportions of nonmelanoma skin cancers, actinic keratoses, and benign skin lesions decreased.

We also investigated the effect of additional complete skin examination of persons attending the screening for single lesions. Complete cutaneous examination may result in better melanoma yields than partial examination. ${ }^{30}$ We assessed the yield of examination of the entire skin, additional to examination of intentionally shown skin lesions. We found no melanomas among 1221 evaluable cases. ${ }^{3 !}$ Thus, total skin exams are probably not worthwhile. Disrobing, gowning, and chaperoning are time consuming. Many more screenees can be seen with limited provider time if only partial skin exams are performed on persons who attend for single lesions. In this way, we have been able to examine 150-200 screenees per dermatologist per day.

There should be sufficient auxiliary personnel and abundant examination rooms. ${ }^{32}$ The dermatologist should only operate as the "screening test", rather than in a physician-to-patient role. The time allotted to each screenee must be restricted. Any set of activities, apart from the visual skin examination, should be performed by auxiliary stafe.

In our view, screening clinics should not be held in private offices, in public premises, or on the beach. Screening in a hospital setting has distinct advantages. Dermatology out-patient departments are well equipped and properly lighted. Follow-up and patient compliance in the case of suspected melanoma is probably facilitated when the screening session is held at the nearby hospital.

Mass screening on the basis of population registries is impracticable. Access to screening would be inappropriate because of poor availability of the "screening test". Only dermatologists should screen. Assessment of skin images by nondermatologists is by-and-large unreliable. ${ }^{15,16}$ This will produce relatively high rates of false-positive and false-negative screens, which will decrease the sensitivity, specificity, and predictive values of the screening exercise. Therefore, melanoma screening based on 
population listings is not recommended. The medical community is not yet sufficiently prepared for embarking upon large-scale systematic and formalized screening. Melanoma screening should be regarded as an experimental procedure with attendant pros and cons. Preferably, randomized studies should be set up to evaluate its benefits. ${ }^{33}$ However, the costs of such trial designs may be considerable. ${ }^{32}$

\section{FURTHER CONSIDERATIONS}

The current situation is that selective and focused screening for skin cancer/ melanoma is recommended in many societies without proper evaluation of its benefits and hazards. In the absence of data on population-based screenings, we have to rely upon the results of non-randomized studies offering screening to subjects at high risk only. Interest in campaigns of selective screening is growing. Screening for melanoma only, based on self-assessment of volunteers who come forward to open-access screening opportunities, recruited by appropriate precampaign media publicity, appears rewarding. Such screenings fulfil the critical elements for an ideal secondary prevention appraach as recommended by Wilson and Jungneri, and meet the necessary practical and organizational requirements if properly planned. ${ }^{2,32}$ A systematic approach to the development and provision of nationwide melanoma screening programmes is a remote goal. There is the issue of disease prevalence. Screening will be more yielding in areas with a high melanoma prevalence such as Australia and the southern parts of the United States. Whether screening for melanoma is justified in areas with lower prevalence is questionable.

There is also the problem of the availability of the screening test, i.e. the dermatologist"s eye. Screening is more feasible in countries with a favourable dermatologist-to-patient ratio, such as Germany. Systematic screening is virtually impossible in countries with few dermatologists, such as the United Kingdom. Screening by nondermatologists is unwarranted for the reasons already mentioned. Volunteer screening campaigns may reach only a small section of the population. If so, the impact on morbidity and mortality is low. From 1985 through 1993, over 650,000 persons were screened during the AAD skin cancer/melanoma detection programmes. ${ }^{54}$ About 7000 presumed melanoma diagnoses were made. Assuming a predictive vallue of the screening test of $30-40 \%$, the number of confirmed melanomas is only approximately 2500 . In the same period, the estimated number of new melanoma cases in the United States was $248,700{ }^{34}$ Thus, only $1 \%$ of all melanomas were diagnosed at the $\mathrm{AAD}$ screenings, which appears to be a negligible proportion. Precampaign publicity may, however, alert many people who consequently seek 
medical advice beyond the open-access screenings. This secondary effect through education and health promotion can be substantial but is difficult to quantify. Public and professionall educational exercises are an inherent ingredient of screening. Ethical issues merit special attention. Skin cancer/melanoma screening should not be initiated for the benefit of the screener, but for the patient-attender only. In this context it is pertinent to mention the "borderline" problem. In our view, persons with minimal disease should not be followed. Only attendants with unequivocal malignancies or precursor lesions should be referred. The referral rate in one American study was extremely high at $31 \%{ }^{12}$ Costs incurred to the health-care system may be considerable. The referral rate in our early studies was about $10 \%$. This discrepancy is likely to be related to the extent to which it is thought that follow-up has to be arranged for trivial or "borderline" lesions.

Programme evaluation is an essential function after implementation. Follow-up data give critical information for feedback, reinforcement, and assessment of effectiveness. Noncompliance of positive screenees is a major problem of free-of charge screenings. In Massachusetts, only $63 \%$ of positive screenees responded to repeated inquiries about recommended care. ${ }^{12}$ Compliance with referral in our $1989-1990$ campaigns was $90 \%{ }^{13}$

A final point relates to the cost-effectiveness of skin cancer/melanoma screening There is the possible strain put on health services. Screening will burden the medical system with a high number of benign lesions. Many of these, however, would be removed anyhow for various reasons (irritation, bleeding, cosmetic reasons). We found an insignificant increase in the general practitioners" workload after screening exercises in Arnhem and Eindhoven." On the other hand, the 1987 publicity campaign (which was not a screening campaign) in the United Kingdom was not continued in 1988 because of the disproportionate demand on health services. ${ }^{35}$ Total. costs of skin cancer/melanoma screening, including follow-up visits, hospital referrals, histopathology, etcetera, are unknown. Special surveys of economic costs to the participants and the health-care system should be mounted. We need more detailed information on hidden costs.

With regard to the efficacy of skin cancer/melanoma screening, no studies have addressed this issue satisfactorily. Crude numbers of positive screenees are incondusive. Ideally, one would discover a high proportion of thin, good-prognosis melanomas. During our recent campaign in Southern Limburg, the Netherlands, most melanomas diagnosed were early lesions. ${ }^{23}$ Such intermediate outcome measures, however, should be interpreted cautiously.

42 Everything possible most be done to enhance the present-day skin cancer/melanoma 
screening exercises in the United States and elsewhere. Options for maximizing benefits, minimizing adverse effects, and lowering costs are presented here. The key components for success are the following: (1) An organizational forum for programme development, including close cooperation of epidemiologists with experience in this field, (2) An intensive precampaign public education programme, (3) dedicated personnel and suitable locations, (4) narrowing the scope of skin cancer screening by focusing on melanoma only, (5) An understanding that complete skin exams are time consuming and unproductive, (6) rigorous follow-up of positive screenees, (7) Use of overall outcome measures, such as changes in the Breslow thickness, and (B) assessment of actual and hidden costs. 


\section{REFERENCES}

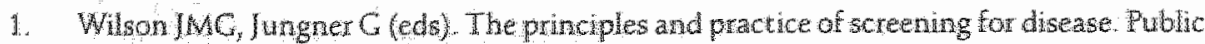
Healh Papers, No.34. WHO, Geneva 1968.

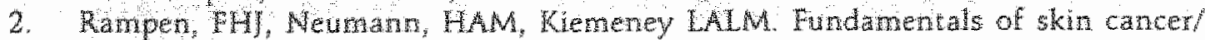
melanoma screentring campaigns. Clin Exp Dematol 1992;17:307-12.

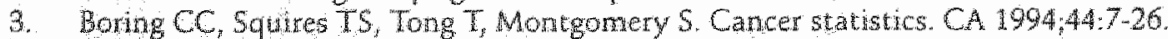

4. Class $\mathrm{AC}$, Hoover RM. The emerging epidemic of melanoma and squamous cell skin cancet. JAMA 1989:262:2097-100.

5. Scoto I, Pitcher $H$, Lee $A$ H. Whdications of future decreasing trends in skin-melanoma mortality among whites in the United States. Int I Cancer 1991; $49.490-7$.

6. Visser O, Cobbergh JWW Schouten LI (eds). Incidence of cancer in the Wetherlands 1992. Netherlands Cancer Ragistry, Utreche 1995

7. Precursors to malignart melanona: Consensus conference. IAMA 1984,251:1864-6.

8. Marks $R$, Rennie $C$, Selwood TS. Malignant transformation of solar keratoses to squamous cell carcinoma. Lancet 1988;:795.7

9. Rhodes AN Congenital nevi: Should these be excised JAMA 1989;262:1696.

10. Melia ], Cooper E), Frost $T$ et al. Cancer Research Campaign health education programme to promote the early detection of cutaneous malignant melanoma. 1 . Workload and teferral patterns. BrI Dermato 1995:132:405-13.

11. Rampen FHh, Bertety PIM, van Huystee BEWL, Kemeney LAM, Nije CHHM General practitioner's' workload after skin cancer/melanoma screening clinics in the Netherlands. Dermatology 1993; $186: 258-60$

12. Koh HK, Caruso A, Gage I et al. Evaluation of melanoma/skin cancer screening in Massachusetts: Preliminary results. Cancer 1990;65:375-9.

13. Rampen FHI, van Huystee BEWL, Kieneney LALM. Melanoma/skin cancer screening clinics: Experiences in the Netherlands. I Am Acad Dermatol 1991,25:776-7.

14. Rampen FHI, Casparie-van Velsen IJAMG, van Huystee BEWL, Kemeney LALM, Schouten LU. False-negative findings in skin cancer and melanoma screening. I Am Acad Dermatol 1995;33:59-63.

15. Cassileth BR, Clark WH, Lusk El, Frederick BE, Thompson CJ, Walsh WP. How well do physicians recognize melanoma and other problem lesions? I Am Acad Dermatol $1986: 14: 555600$.

16. Rampen FHI, Rumke P. Referral pattern and accuracy of climical diagnosis of cutaneous melanoma. Acta Derm Venereol (Stockholm) 1988;68:61-4.

17. Clark WH, From L, Bernardino EA, Mihm MC. The histogenesis and biological behaviour of primary human malignant melanomas of the skin. Cancer Res $1969,29: 705-26$.

18. Bresiow A. Thickness, cross-sectional area, and depth of invasion in the prognosis of cutaneous melanoma. Ann Surg 1970,172:902-8.

19. Creene MH, Clark WH, Tucker MA et al. The high risk of melanoma in melanomaprone families with dysplastic newi. Ann Int Med 1985, 102:458-65.

20. Rhodes AR, Sober A], Day Cl et al. The malignant potential of smal congenital newocellular nevi: An estimate of association based on a histologic study of 234 primary cutaneous melanomas. I Am Acad Dermatol 1982;6:230-41.

21. Ilig L Weidner Fundeiker $M$ et al. Congenital nevi $<10 \mathrm{~cm}$ as precursors to melanoma: 52 cases, a review, and a new conception. Arch Dermatol 1985;121:1274-81.

22. Marks R, Foley P, Goodman G. Hage BH, Selwood TS. Spontaneous remission of solar keratoses: The case of conservative management. Br J Dermatol 1986:115:649-55.

23. de Rooil MJM, Rampen FHI, Schouten L, Neumann HAM. Skin cancer sereening focusing on melanoma yiels more selective attendance. Arch Dermatol 1995; 131:422-5.

24. Koh HK, Lew RA, Prout MN. Screening for melanoma/skin cancer: Theoretic and practical considerations. J Am Acad Dermatol 1989:20:159-72. 
25. Chamberlain JM. Which prescriptive screening programmes are worthwhile? Epidemio Community Health 1984:38:270-7.

26. Kricker A, English DR, Randell PL et al. Skin cancer in Geraldton, Western Australia: A survey of incidence and prevalence. Med J Aust 1990;152;399-407.

27. Schneider IS, Moore DH, Sagebiel RW Early diagnosis of cutaneous malignant melanoma at Lawrence Livermore National Laboratory. Arch Dermatol 1990;126:767.9.

28. Elwood JM. Screening and early diagnosis for melanoma in Australia and New Zealand. In: Miller $A B$ et al. (eds). Cancer screening, pp. 243-55. Cambridge University Press, Cambridge 1991

29. Krol S, Keijser LMT, van der Rhee HI, Welvaart $\mathbb{K}$. Screening for skin cancer in the Netherlands. Acta Derm Venereol (Stockholm) 1991;71:317-21.

30. Rigel DS, Friedman $\mathbb{R}$ ], Kopf AW et al Importance of complete cutaneous examination for the detection of malignant melanoma. I Am Acad Dermatol 1986; 4:857-60.

31. de Rooij MJM, Rampen FHJ, Schouten LI, Neumann HAM Total skin examination during screening for melanoma does not increase detection rate. Br J Dermatol $1996 ; 135: 43-5$.

32. Rampen EHJ, van Huystee BEWI, Kiemeney LALM. Practical considerations of melanoma/skin cancer screening clinics. Dermatology 1992;184:190-3.

33. Elwood IM. Screening for melanoma and options for its evaluation. I Med Screening $1994 ; 1: 22-38$.

34. Rhodes AR. Public education and cancer of the skin; What do people need to know about melanoma and nonmelanoma skin cancer Cancer 1995;75:613-36.

35. Ellmann R. Screening for melanoma in the UK. In: Miller AB et al. (eds). Cancer screening, pp. 257-6. Cambridge University Press, Cambridge 1991.

36. Boyce JA, Bermhard JD. Total skin examination: Patient reactions. $\int$ Am Acad Dermatol $1986 ; 14: 280$.

37. Lookingbill DP. Yield from a complete skin examination: Findings in 1157 new dermatology patients. I Am Acad Dermatol 1988;18:31-7.

38. Chiarello SE. Complete skin examinations. Arch Dermatol 1989;125:706.

39. Bolognia IL, Berwick M, Fine JA. Complete follow-up and evaluation of a skin cancer screening in Connecticut. J Am Acad Dermatol 1990;23:1098-106.

40. Lee G, Massa MC, Welykyj S et al. Yield from total skin examination and effectiveness of skim cancer awareness program: Findings in 874 new dermatology patients. Carcer $1991 ; 67: 202-5$ 
Chapter 3

\title{
FACTORS INFLUENCING PARTICIPATION AMONG MELANOMA SCREENING ATTENDERS
}

\author{
M.J.M. de Rooij $]^{1}$ \\ F.H.J. Rampen ${ }^{2}$ \\ L.J. Schouten ${ }^{3}$ \\ H.A.M. Neumann ${ }^{4}$
}

Departments of Dermatology, University Hospital Nijmegen', St Anna Hospital $\mathrm{Oss}^{2}$, and University Hospital Maastricht ${ }^{4}$, Comprehensive Cancer Centres IKO (Nijmegen) and IKL (Maastricht) ${ }^{3}$, the Netherlands 


\section{SUMMARY}

We surveyed the demographic profile and motives prompting to participate among people attending voluntary melanoma screening clinics in Southern Limburg, the Netherlands, in June 1993. Precampaign public announcements addressed only melanoma and its precursor lesions. All attendees completed a detailed questionnaire addressing demographic particulars and specific fixed choice questions on their motivation to attend.

There were 4146 persons attending the screening clinics. Most attendees opted for examination of a specific lesion (71\%). More femalles than males participated. Fear of having skin cancer was an important reason to participate (27\%). Of all attenders, $16 \%$ had to be convinced by relatives or friends to attend the screens, and $33 \%$ would not have visited a physician on their own initiative when there had not been a free screening. Females were more concerned about skin cancer than males. The local and regional newspapers formed the most important precampaign publicity channel.

Free melanoma screenings attract large numbers of people. Males are underrepresented. They are less aware of the risk profile of melanoma. Future screenings should target the male population.

Theoretically, morbidity and mortality from melanoma can be reduced by early detection. Public education ${ }^{1,2}$ and selective screening, 3,4 are approaches to achieve earlier diagnosis and treatment. Screening activities on melanoma and its precursors are more effective when targeting defined high-risk groups. ${ }^{5}$

The aim of the present study is to evaluate the demographic characteristics and motives prompting to participate among persons attending a number of selective screening clinics held in Southern Limburg, the Netherlands. The approach differed from previous attempts in the United States and other countries. So far, screening exercises have addressed all types of skin cancer, melanoma and nonmelanoma skin cancers inclusive. The Southern Limburg campaign targeted melanoma and its precursor lesions only.

\section{METHODS}

In June 1993 ten voluntary melanoma screening clinics were organized in the southern part of Limburg, the Netherlands. The area counts approximately 650,000 inhabitants.

The general public was made aware of the screenings by articles in the regional newspapers, by announcements in the neighbourhood periodicals and on the local 
radio and television stations, and by posters in waiting rooms of general practitioners and pharmacists, and in public libraries. Attention was focused on the risk factors and warning signs of melanoma and its precursor lesions. We especially targeted subjects with a more then average mole count, "funny looking" moles, changing moles, a fair skin complexion, a propensity to sun burn rather than tan, and a personal or family history of melanoma. No reference was made to the symptoms and signs of nonmelanoma skin cancers and their precursors.

The campaign was carried out according to the design of previous clinics conducted in the Arnhem region, the Netherlands, in 1990,6.7 Only dermatologists and senior residents in dermatology carried out the screenings. The attenders were examined on two consecutive Saturdays at the out-patient dermatology departments of one university hospital and five district hospitals in the area. All participants received a numbered questionnaire at entry, addressing the following items: 1) sex and age, 2) place of residence, 3) level of education, 4) reason for participation: examination of a specific lesion ws complete skin check, 5) changes and symptoms of presenting skin lesions, 6) previous or intended visit to family physician for the same problem, 7) constitutional risk factors for melanoma, such as burning tendency and tanning ability, 8) publicity channels that led to participation in the project, 9) motivation For attending the screens, such as fear of skin cancer, cosmetic reasons, practical considerations, second opinion ('do not trust general physician'), interest in information on skin cancer, or other reasons (open question), 10) whether attending on own initiative or prompted by others, and 11) permission for follow-up.

In some instances more than one answer could be given. In these cases the total number of replies may outnumber the total group size. In other instances, because of missing, incomplete, or inapplicable data, the totals will not add to the total group size. Percentages were computed over the appropriate sets of information, excluding missing and inapplicable data.

Participants younger than 10 years of age did probably not fill-out the questionnaires themselves. Therefore we did also an analysis deleting this age group.

Persons with lesions regarded as suspicious of melanoma, nonmelanoma skin cancer, or distinct precursor states received a letter of referral with the presumptive diagnosis and the proposed line of management to hand over to their family physician. These persons were defined as positive screenees. No biopsies were taken during the screens. Positive screenees who had given informed consent to obtain outcome data were followed at 4 months and, in case of incomplete information, again at 10 months after the screens.

To test differences between samples the chi-squared statistic was used. 


\section{RESULTS}

In total, 4146 persons ( $60 \%$ females and $40 \%$ males) attended the screenings. Among these, 55 melanomas and 17 lentigo malignas were found clinically. ${ }^{5}$ The majority of participants were between 20 and 49 years of age $(52 \%)$. The female to male ratio was highest in the age category $20-39$ years.

Seventy-one percent of the screenees intended to show a specific skin lesion they were worried about. A general skin check was opted for by $23 \%$, whereas $6 \%$ gave both reasons for their visit (specific skin mark plus total skin check). Females opted more often for examination of a specific skin mark than males. In Table 1 the most important reasons for participation are summarized according to gender.

Table 1. Gender differences regarding factors influencing participation

\begin{tabular}{|c|c|c|}
\hline Reason or motivation to participate & Males & Fenales \\
\hline $\begin{array}{l}\text { Specific skin lesion } \\
\text { (vs general skin check) }\end{array}$ & $71 \%$ & $78 \% * *$ \\
\hline Signs or symptoms of cutaneous lesions & $45 \%$ & $58 \%$ *⿻ *t. \\
\hline $\begin{array}{l}\text { Prompted by relative or friend } \\
\text { (vs attending on own initiative) }\end{array}$ & $22 \%$ & $12 \% *$ \\
\hline Fear of skin cancer & $23 \%$ & $29 \% * *$ \\
\hline Cosmetic reasons & $19 \%$ & $23 \% *$ \\
\hline $\begin{array}{l}\text { Practical considerations } \\
\text { "Saturday is day off") }\end{array}$ & $27 \%$ & $19 \%$ \\
\hline $\begin{array}{l}\text { Second opinion } \\
\text { ("Do not trust general physician") }\end{array}$ & $5 \%$ & $7 \% *$ \\
\hline Interest in information on skin cancer & $24 \%$ & $29 \% *$ \\
\hline
\end{tabular}

Significant levels: ${ }^{* *} p<0.001 ;{ }^{* *} p<0.01 ;{ }^{*} p<0.05$

Among the persons attending with specific skin lesions, $58 \%$ had noticed changes in these lesions, whereas among those who attended for a general skin check, only $36 \%$ indicated changes in some skin lesions $(p<0.001)$. Women indicated signs or 
symptoms more frequently than men. In $60 \%$ of the screenees, these changes had been present for over 1 year. Delays of more than 1 year were as frequent in males as in females. Elderly persons exhibited substantially longer delays before attending the screening opportunity than persons of younger age $(p<0.001)$.

Thirty-six patients of the screenees had consulted their family physician or dermatologist previously for the same reason. Females scored higher in this respect than males ( $39 \%$ vs $32 \% ; p<0.001)$.

Of all screenees, $33 \%$ would not have visited a physician on their own initiative for the same problem when there had not been a screening campaign; $32 \%$ doubted whether they would have consulted a physician, and $36 \%$ stated that they would have scheduled a consultation in the near future anyhow. Females indicated more often than males that they would have consulted a physician for their lesion(s) anyhow, even when there had not been a screening campaign ( $38 \%$ vs $29 \% ; \mathrm{p}<0.001)$. Of the participants with symptoms, $22 \%$ stated that they probably would not have visited their physician when there had not been a free screening.

Of all participants, $16 \%$ had to be prompted by relatives or friends to attend the screens. Considerably more males than Females were persuaded by others to attend. Especially, persons without any signs or symptoms more often attended in response to urging from other people than those with signs or symptoms $(20 \%$ vs $13 \%$; $\mathrm{p}<0.001$ ).

Fear of having skin cancer was an important reason to attend the screenings in $27 \%$ of the participants. Females were more concerned of having skin cancer than males. Fear of skin cancer was more evident in those with a low education level as compared with screenees with higher education $(p<0.001)$. Also, fear of skin cancer was more frequently recordled by elderly persons than among the younger age groups $(p<0.001)$. The presence of signs and symptoms of skin lesions, as compared with their absence, was more frequently associated with fear of skin cancer ( $32 \%$ vs $21 \%$; $p<0.001$ ). An equally important reason for participation was the interest in information about skin cancer $(27 \%)$. The interest in information was highest in females (Table 1). Less important factors influencing participation were cosmetic or practical reasons (respectively $21 \%$ and $22 \%$ ), and obtaining a "second opinion" from the screening dermatologist $(6 \%)$. Twenty percent of the participants stated under "other reasons" that they visited the screenings "to have a skin check by a dermatologist".

The regional newspapers and neighbourhood magazines played the most important role in the precampaign awareness programme; $76 \%$ reported being informed about the campaign through these newspapers or periodicals. There was a striking difference in information through the newspapers and magazines with regard to 
level of education and age of the participants. Persons with a low education level got the information more frequently from newspapers and magazines than attendees with a higher education level $(p<0.001)$. Likewise, elderly persons were more often informed through the newspapers and magazines than younger persons $(p<0.001)$. Less important channels of information were relatives or friends $(20 \%)$, and posters $(15 \%)$. Gender differences in the responses to various types of advertisements were only conspicuous regarding the information through posters.

The announcements on the local radio and television station were reported by respectively $2 \%$ and $5 \%$ of the screenees only.

When the age group till 10 years was discarded, the overall results were not affected. Assessment of the reasons for attending among the confirmed melanoma cases $(n=13)$ was considered meaningless because of the small group sizes.

\section{DISCUSSION}

The demographic profile of the selective melanoma screening clinics in Southern Limburg shows a preponderance of female attendees over males (3:2). The melanoma population in the Netherlands is characterized by relatively more female than male patients, also at the ratio of about $3: 2 .^{8}$ This may suggest that the precampaign publicity attracted a screening population that is compatible with the reported gender distribution of melanoma patients. However, screening for skin cancer and melanoma in various parts of the world consistently demonstrates a preponderance of females, even in areas with a more equal melanoma distribution among the sexes, ${ }^{69}{ }^{96}$ ${ }^{12}$ Therefore, it is likely that the female preponderance noticed in this series a characteristic of screening in general.

Male patients seem to be less aware of malignant melanoma. ${ }^{13}, 14$ They attend their general physician or dermatologist with more advanced disease compared to females. ${ }^{15.17}$ Especially males should theoretically take advantage of early detection by public campaigns and screening exercises. It is therefore advisable to give special emphasis in such campaigns to reach the male population. ${ }^{18}$

In order to answer the question to what extent selective screening has an additional value above the existing health care system, it is important to investigate subjects who would not have visited their general practitioner for the same problem when there had not been organized a screening. In the present study particularly males would not have visited their general physician for the same problem. The same event has been reported by Girasek. ${ }^{19}$

There were 641 individuals who were prompted to attend by others (16\%). Again, 
males were more often persuaded by relatives or friends than females. In the study of Koh et al only $7 \%$ of all attendees were convinced by others to attend the screens. ${ }^{12}$ Also in his study more males than females had to be prompted by others ( $10 \%$ and $6 \%$ respectively). These observations have certainly to do with the fact that males are less interested in their naevi ${ }^{20}$ and are less aware of early signs and symptoms of melanoma. ${ }^{14}$ Koh et al showed that males in particular failed to recognize their own melanoma, ${ }^{13}$ Even lesions at "easy to see areas" were less often self-discovered.

The local and regional newspapers played an important role in the promotion of our screenings. In $76 \%$ of the screenees the written media were the most relevant publicity channel. We only used the local and regional press to launch our programme. These papers are mainly read by persons of the lower social strata. A national screening campaign, with announcements in the national newspapers, would undoubtedly attract more people of a higher education level. Fosters distributed in waiting rooms of general physicians and pharmacists ${ }_{f}$ and in public libraries appeared to be of minor importance. They were most often noticed by femalles. Posters might play a more important role if they are distributed at different places such as sporting facilities, banks, etcetera. The local radio and television were of negligible importance in this study. During screenings in the United States television has generated substantially more impact on the precampaign awareness programme. ${ }^{12,19}$ Expectedly, the role of television will increase when the national stations are used.

It has to be taken into account that information obtained by this questionnaire only reflects the motivation and reasons to participate of those who did visit the screenings. Koh et al. ${ }^{12}$ showed that (self-selected) participants of skin eancer and melanoma screenings differ from the general population in their risk profile and that they seem to be at appropriately high risk. Furthermore, the yields of confirmed skin cancers of these screenings are relatively high as compared with the expected harvest of prevalent cases from the general population. ${ }^{6,1,21,22}$ This selective attendance is of importance with regard to costs and effectiveness.

In the precampaign awareness programme of the present study special attention was paid to the signs and risk factors of melanoma. The question arises whether there are other groups among the general population who are at a more than average risk, not because of clinical characteristics or phenotypic risk profile but because of their minimal awareness of melanoma. Results from studies from Newman et $\mathrm{al}^{23}$ and Melia et $\mathrm{l}^{14}$ indicate that awareness is lowest among men, low socioeconomic groups, the under 25 s, the elderly, and those without a partner. Males visit screening opportunities more often after prompting by spouses, relatives, or friends. Such persons may play an important role in the early recognition of 
melanoma. It is known that melanoma is diagnosed at an earlier stage in marned persons. ${ }^{13,24}$

Melanoma screening as presented in this communication is feasible, seems to fulfil a need. The selection of screenees at more than average risk might be improved further. Motivation among the general public and disease perception are important issues that need special emphasis.

\section{ACKNOWLEDGEMENTS}

The project was supported by a grant from the Comprehensive Cancer Centres in Maastricht (IKL) and Nijmegen (IKO), the Netherlands. The help of many colleagues is gratefully acknowledged. ${ }^{5}$

Thanks to P.C.M. van de Kerkhof for his stimulating discussions. 


\section{REFERENCES}

1. Graham-Brown $\mathbb{R A C}$, Osborne JE, London SP, Fletcher A, Shaw $H_{\text {, Willams }}$, et al. The initial effects on workload and outcome of a public education campaign on early diagnosis and treatment of malignant melanoma in Leicestershire. Br J Dermatol $1990 ; 122: 53-9$

2. Mackie RM. Public and professional educational exercises on melanoma. Clin Dermatol $1992 ; 10: 91-6$.

3. Koh HK, Miller DR, Geller AC, Lew RA, Rampen FHI. Screening for melanoma and other skin cancers. Clin Dermatol 1992;10;97-103.

4. Elwood JM. Screening for melanoma and options for its evaluation. I Med Screening $1994 ; 1: 22-38$

5. de Rooil MJM, Rampen FHJ, Schouten LJ, Neumann HAM. Skin cancer screening focusing on melanoma yields more selective attendance. Arch Dermatol 1995;131:4225.

6. Rampen FHI, van Huystee BEWL, Kiemeney LALM. Melanoma/skin cancer screening clinies: Experiences in the Netherlands. I Am Acad Dermatol 1991;25:776-7.

7. Rampen FHJ, wan Huystee BEWL, Kiemeney LALM. Practical considerations of melanoma/skin cancer screening dinics. Dermatology 1992;184:190-3.

8. Nelemans PJ, Rampen FHJ. The epidemiology of cutaneous melanoma in the Netherlands: A descriptive study. Ned Tijdschr Geneeskd 1990; 134:2038-42.

9. Field SI. Melanoma/skin cancer screening in Michigan. J Am Acad Dermatol 1987;16.57883.

10. Olsen TG, Feeser TA, Conte ET, Schroeter AL. Skin cancer screening: A local experience. I Am Acad Dermatol 1987;16:637-41.

11. Bolognia JL, Berwick M, Fine JA. Complete follow-up and evaluation of a skin cancer screening in Connecticut. I Am Acad Dermatol 1990;23:1098-106.

12. Koh HK, Geller AC, Miller DR, Garuso A, Gage J, Lew RA. Who is being screened for melanoma/skin cancer? Characteristics of persons screened in Massachusetts. J Am Acad Dermacol 1991;24:271-7.

13. Koh HK, Miller DR, Geller AC, Clapp RW, Mercer MB, Lew RA. Who discovers melanoma? I Am Acad Dermatol 1992;26:914-9.

14. Melia J, Elman R, Chamberlain J. Inwestigating changes in awareness about cutaneous malignant melanoma in Brtain using the Omnibus Survey. Clin Exp Dermatol $1994 ; 19: 375-9$.

15. Shaw HM, McGovern VJ, Milton GW Farago GA, Mc Carthy WH. Malignant melanoma: Influence of site of lesion and age of patient in the female superiority in survival. Cancer $1980 ; 46: 2731-5$

16. Rampen FHI. Sex differences in survival from cutaneous melanoma. Int J Dermatol $1984 ; 23: 444-52$

17. Vossaert KA, Silverman MK, Kopf AW, Bart RS, Rigel DS, Friedman RJ, et al Influence of gender on survival in patients with stage I malignant melanoma. J Am Acad Dermatol $1992 ; 26: 429-40$.

18. Mackie RM, Hole DJ Audit of public education campaign to encourage earlier detection of malignant melanoma. BMJ 1992,304:1012.5.

19. Girasek DC. Motivating the public to take advantage of skin cancer screening. I Am Acad Dermatol 1986, 15:309-15.

20. Brandberg $X$, Bolund $C$, Michelson $H_{,}$Mansson-Brahme E, Ringborg U, Sjödén PO. Psychological reactions in public melanoma screening. Eur I Cancer 1993; 29A:860-3.

21. Rigel DS, Friedman RJ, Kopf AW et al. Importance of compjete cutaneous examination for detection of malignant melanoma. I Am Acad Dermatol 1986;14:857-60. 
22. Koh HK, Caruso A, Gage I, et al. Evaluation of melanoma/skin cancer screening in Massachusetts. Cancer 1990;65:375-9.

23. Newman 5 , Nichols $S$, Freer $C$, Izzard L. How much do the public know about noles, skin cancer and malignant melanoma? The results of a postal survey. Community Med $1988: 10: 351-7$.

24. Polednak AP. Malignant melanoma of the skin in upstate New York: Recent trends and characteristics. Cancer Detect Prevent 1985;8:485-95. 


\title{
Chapter 4
}

\section{SKIN CANCER SCREENING FOCUSING ON} MELANOMA YIELDS MORE SELECTIVE ATTENDANCE

\author{
M.J.M. de Rooij ${ }^{1}$ \\ E.H.J. Rampen ${ }^{2}$ \\ L.J. Schouten ${ }^{3}$ \\ H.A.M. Neumann ${ }^{4}$
}

Departments of Dermatology, University Hospital Nijmegen', St. Anna Hospital Oss $^{2}$, and University Hospital Maastricht ${ }^{4}$, Comprehensive Cancer Centres IKO (Nijmegen) and IKL (Maastricht) ${ }^{3}$, the Netherlands 


\section{SUMMARY}

Background: Screening theoretically reduces death and morbidity from malignant melanoma. The rationale of screening for monmelanoma skin cancer is more debatable, since mortality rates are very low.

Methods: We organized a screening campaign in Southern Limburg, the Netherlands in 1993. Press releases and public announcements referred only to melanoma. The results were compared with similar campaigns in Arnhem and Eindhoven, the Netherlands, in 1990; these, however, addressed skin cancer in general.

Results: There were 4146 people attending the 1993 screenings, compared with 2463 in 1990 . The proportion of screenees with lesions suggestive of melanoma increased from $1.1 \%$ in 1990 to $1.7 \%$ during the 1993 campaign $(p=0.04)$. The proportion of dysplastic naevi rose from $2.1 \%$ to $7.7 \%(p<0.001)$. Nonmelanoma skin cancers were less often encountered ( $3.7 \%$ in 1990 vs $2.6 \%$ in $1993 ; p=0.009$ ). Actinic keratoses were also less numerous $(6.3 \%$ vs $1.5 \% ; p<0.001)$.

Conclusion: Screening concentrating on melanoma increases the rates of lesions suggestive of melanoma and dysplastic naevi, whereas the proportions of basal and squamous cell carcinomas, and actinic keratoses decrease. These findings may have important implications with regard to the cost-effectiveness of skin cancer screening efforts.

Prognosis of malignant melanoma depends strongly on early recognition. Screening as a means of secondary prevention enhances early detection and, theoretically, reduces death and morbidity from melanoma., ${ }^{1,2}$ Visual exannination of the skin by dermatologists is an acceptable, reliable, and inexpensive screening tool. Since 1985 voluntary skin cancer and melanoma screening clinics have been held in the United States. ${ }^{37}$ Similar clinics were organized in the Netherlands in 1989 (Oss) and in 1990 (Arnhem and Eindhoven) ${ }^{8-10}$ The screening exercises in the Netherlands were pilot studies to investigate the practical implications of such screenings. All screenings in the United States and the Netherlands so far have concentrated on skin cancer in general, including both melanoma and nonmelanoma skin cancer.

Mortality from nonmelanoma skin cancer is low. In terms of health strategy priorities, these skin lesions are insignificant. One may argue that skin cancer screening should be confined to malignant melanoma. We studied the proportions of melanomas, dysplastic naevi, and other pigmented skin lesions and nonmelanoma skin cancers, after a screening programme with media attention focusing on melanoma only. 


\section{MATERIALS AND METHODS}

In June 1993, free melanoma detection clinics were conducted in Southern Limburg, the Netherlands, under the auspices of the Dutch Academy of Dermatology and Venereology and the Comprehensive Cancer Centres IKL (Maastricht, the Netherlands) and IKO (Nijmegen, the Netherlands). The area encompasses approximately 650,000 inhabitants. All dermatologists in the region participated in the study. The screenees were examined at six hospital locations on a first come, first served basis. The programme was announced in the regional newspapers, on the regional radio and television stations, and by posters in waiting rooms of general practitioners and in pharmacies and public libraries. Special emphasis was placed on the risk factors and symptoms of early malignant melanoma and its precursor lesions. No reference was made to the nonmelanoma skin cancers and their risk denominators.

Because of the large turnout, skin examinations were confined to specific lesions the attendants were worried about. Systematic examination of the entire skin was performed only on those who intentionally opted for a complete skin check and on those who showed a special skin mark that was suggestive of dysplastic naevus or melanoma. These factors were the same ones used in the 1990 programmes.

When more than one clinical diagnosis was considered, only the single worst diagnosis was recorded. No biopsies or therapeutic interventions were performed during the screenings.

The participant received a letter of referral with the proposed line of management to his or her family physician when a cancerous or precancerous lesion was suspected. Persons with borderline lesions or minimal extent of precursor states were not referred so as to avoid undue concern and medical treatment. Four months after the campaign, persons with a positive screen result were contacted for follow-up. Those who did not respond were approached again after 10 months.

The results of the Southern Limburg campaign were compared with those of two earlier campaigns in Arnhem in June 1990 and in Eindhoven in October 1990. The screenings in Arnhem and Eindhoven had been planned and executed in a similar way, but the precampaign public releases had emphasized skin cancer in general instead of melanoma in particular. To test for differences between the two populations, the chi-squared statistic was used. 


\section{RESULTS}

In Arnhem and Eindhoven in 1990, a total of 2463 participants had been registered. The campaign in Southern Limburg in 1993 attracted 4146 participants. There was no marked difference in the sex ratio between the 1990 and 1993 exercises. In Arnhem and Eindhoven, $47 \%$ of the screenees were younger than 50 years, compared with $66 \%$ in Southern Limburg. The shift toward younger participants was highly significant $(p<0.001)$. Table 1 summarizes the demographic profile of the attendees to both campaigns.

Table 1. Demographic profile of attendees at the screening clinics in 1990 and 1993

\begin{tabular}{|c|c|c|c|}
\hline & $\begin{array}{l}1990^{\circ} \\
(n=2463)\end{array}$ & $\begin{array}{l}1993 \# \\
(n=4146)\end{array}$ & $p$ \\
\hline \multicolumn{4}{|c|}{ Sex distribution } \\
\hline $\mathrm{M}$ & $966(39.4 \%)$ & $1678(40.5 \%)$ & \\
\hline$F$ & $1484(60.6 \%)$ & $2465(59.5 \%)$ & $>0.05$ \\
\hline Data missing & 13 & 3 & \\
\hline \multicolumn{4}{|c|}{ Age distribution } \\
\hline$\leq 19$ yrs & $195(7.9 \%)$ & $588(14.3 \%)$ & \\
\hline $20-29$ yrs & $223(9.1 \%)$ & $695(16.9 \%)$ & \\
\hline 30.39 yrs & $315(12.8 \%)$ & $698(16.9 \%)$ & \\
\hline $40-49$ yrs & $417(16.9 \%)$ & $747(18.1 \%)$ & \\
\hline $50-59$ yrs & $491 \quad(20.0 \%)$ & $593(14.4 \%)$ & \\
\hline $60-69$ yrs & $518(21.0 \%)$ & $539(13.1 \%)$ & \\
\hline$\geq 70 \mathrm{yrs}$ & $302(12.3 \%)$ & $262(6.4 \%)$ & $<0.001$ \\
\hline Data missing & 2 & 24 & \\
\hline
\end{tabular}

Armhem and Eindhoven, the Netherlands

\# Southern Limburg, the Netherlands.

Table 2 shows the most relevant findings related to skin malignant neoplasms. The proportion of screenees with lesions clinically suggestive of melanoma was higher in 1993 than during the campaigns in Arnhem and Eindhoven. Together, melanoma and lentigo maligna were suspected in $1.7 \%$ of the screenees in 1993, compared with only in $1.1 \%$ in $1990(p=0.04)$. Lesions suggestive of nonmelanoma skin cancer were less numerous in 1993. The proportion of persons with presumptive nonmelanoma skin cancer (basal and squamous cell carcinoma and Bowen's disease) decreased from $3.7 \%$ in 1990 to $2.6 \%$ in $1993(p=0.009)$. 
Table 2. Presumptrve diagnoses of melanoma and nonmelanoma skin cancer

\begin{tabular}{|c|c|c|c|}
\hline 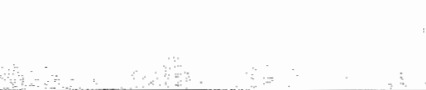 & $\begin{array}{l}1990^{\circ} \\
(n=2463)\end{array}$ & $\begin{array}{l}1993 \# \\
(n=4146)\end{array}$ & $p$ \\
\hline Melanomas & & & \\
\hline Malignant melanona & 21 & 55 & \\
\hline Lentigo maligna & 5 & 17 & \\
\hline Totals & $26 / 26(1.1 \%)$ & $72 / 69(1.7 \%)$ & 0.04 \\
\hline \multicolumn{4}{|l|}{ Nonmelanoma skin cancers } \\
\hline Basal cell carcinoma & 84 & 95 & \\
\hline Squamous cell carcinoma & 5 & 6 & \\
\hline Bowen's disease & 3 & 13 & \\
\hline Totals & $92 / 91(37 \%)$ & $114 / 106(2.6 \%)$ & 0.009 \\
\hline
\end{tabular}

"Anhem and Eindhoven, the Netherlands

\# Southern Limburg, the Netherlands

- Numbers of malignant neoplasms/numbers of attendees; percentages and p values relate to numbers of attendees.

Table 3. Presumptive diagnoses of precursor lesions and benign conditions

\begin{tabular}{|c|c|c|c|}
\hline & $\begin{array}{l}1990^{\circ} \\
(n=1817)\end{array}$ & $\begin{array}{l}1993 * \\
(n=4146)\end{array}$ & $\mathrm{p}$ \\
\hline \multicolumn{4}{|l|}{ Naevil } \\
\hline Naevocellular & $724 \quad(39.9 \%)$ & $2333(56.3 \%)$ & $<0.001$ \\
\hline Dysplastic & $38 \quad(2.1 \%)$ & $319(7.7 \%)$ & $<0.001$ \\
\hline Congenital & $52(2.9 \%)$ & $370(8.9 \%)$ & $<0.001$ \\
\hline Halo & $10(0.6 \%)$ & $43(1.0 \%)$ & $>0.05$ \\
\hline Blue & $9(0.5 \%)$ & $24(0.6 \%)$ & $>0.05$ \\
\hline Lentigines, freckles & $120(6.6 \%)$ & $229(5.5 \%)$ & $>0.05$ \\
\hline \multicolumn{4}{|l|}{ Keratoses } \\
\hline Actinic & $114(6.3 \%)$ & $63(1.5 \%)$ & $<0.001$ \\
\hline Seborthoeic & $600(33.0 \%)$ & $1118(27.0 \%)$ & $<0.001$ \\
\hline Dermatofibromas & $134(7.4 \%)$ & $194(4.7 \%)$ & $<0.001$ \\
\hline Vascular Iesions & $114(6.3 \%)$ & $124(3.0 \%)$ & $<0.001$ \\
\hline Fibromas, skin tags & $89(4.9 \%)$ & $168(4.1 \%)$ & $>0.05$ \\
\hline Cysts & $62(3.4 \%)$ & $27(0.7 \%)$ & $<0.001$ \\
\hline Viral warts & $43(2.4 \%)$ & $39(0.9 \%)$ & $<0.001$ \\
\hline $\begin{array}{l}\text { Eczema, psoriasis, } \\
\text { fungal infections }\end{array}$ & $182(10.0 \%)$ & $115(2.8 \%)$ & $<0.001$ \\
\hline
\end{tabular}

*Arnhem and Eindhoven, the Netherlands

\# Southern Limburg; the Netherlands. 
Data pertaining to precursor lesions and benign skin conditions are presented in Table 3. At two of six clinics in the Arnhem region, no presumed diagnoses had been recorded, apart from skin malignant neoplasms. The total number of attendees with evaluable data for precursor lesions and benign skin marks in 1990 was 1817. The proportion of dysplastic naevi had increased substantially in 1993 as compared with 1990. Also, common and congenital naevocytic naevi were more frequently encountered in 1993. However, the proportion of freckles and solar lentigines had slightly decreased. Actinic keratoses were distinctly more numerous in 1990 than in 1993 . Finally, clinically benign lesions and generalized skin conditions, such as seborthoeic keratoses, dermatofibromas, angiomas, viral warts, eczema, psoriasis, and fungal infections, were less often seen during the last screening, all at a statistically significant level.

Follow wup of the persons with presumed skin malignant neoplasms seen in 1990 was only achieved in the region of Arnhem, with 1961 participants; no follow-up data were available for the clinic held in Eindhoven with 502 screenees. In 1993, follow-up was accomplished at all clinics in Southern Limburg. The proportion of melanomas confirmed by pathologic examination was similar in both groups $(0.3 \%)$. Six melanomas were diagnosed in Arnhem and 13 in Southern Limburg.

Table 4. Numbers of malignant neoplasms confirmed by pathologic examination

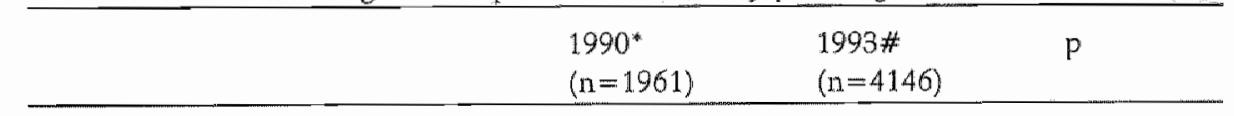

\section{Melanomas}

Lentigo maligna

Melanoma in situ

Invasive melanomas

$<1$ mm thick

$\geq 1 \mathrm{~mm}$ thick

Totals thickness unknown

$$
(n=1961)
$$

$\begin{array}{ll}1 & 4 \\ 0 & 3\end{array}$

$\begin{array}{ll}1 & 5 \\ 3 & 1 \\ 1 & 0 \\ 6 / 6(0.3 \%) & 13 / 1\end{array}$

$6 / 6(0.3 \%) \quad 13 / 13(0.3 \%) \quad 0.04 *$

Nonmelanoma skin cancers

Basal cell carcinoma

Squamous cell carcinoma

Bowen's disease

40

43

1

4

Totals
4

$13 / 13(0.3 \%)-0.044$


Most melanomas diagnosed in Southern Limburg were early lesions: only one patient had a melanoma 1 mm thick or more. In Arnhem, tumour microstage was documented in five of six cases; three of these were $1 \mathrm{~mm}$ thick or more. This shift to thinner lesions was statistically significant ( $p=0.04$, Mann-Whitney test). The proportion of screenees with nonmelanoma skin cancer confirmed by pathologic examination was larger in Arnhem than in Southern Limburg $2.1 \%$ and $1.0 \%$, respectively; $p=0.001)$. Table 4 gives an overview of the malignant neoplasms confirmed by pathologic examination at follow-up.

The difference in age distribution of both study populations prompted us to perform a logistic regression analysis, including sex and age in the model. For all naevocellular lesions: (common naevi, congenital naevi, dysplastic naevi, and melanoma), the odds ratios were statistically significantly increased in the Southern Limburg screening as compared with the Arnhem screening. The odds ratio for melanoma, including lentigo maligna, was 1.84 (95\% confidence interval, 1.16 to 2.92$)$.

\section{COMMENT}

Screening offers much potential for reducing mortality from malignant melanoma. However, many questions about proper methods of screening for skin cancer and melanoma and its ultimate value remain unanswered. ${ }^{1,2,11,13}$ Detection campaigns have definite unwarranted effects in terms of creating anxiety and incurring extra health expenditures. Since 1985, the American Academy of Dermatology has been sponsoring open-access screening clinics ${ }^{3.7}$ Similar clinics have been organized in the Netherlands. ${ }^{0.10}$ So Far attention has been paid to both melanoma and nonmelanoma skin cancer. Nonmelanoma skin cancer is seldom lethal and does not warrant screening. Screening confined to melanoma instead of screening for skin cancer in general may considerably increase the yield of positive screens.

This study shows that when special emphasis is placed on the risk factors and symptoms of malignant melanoma and its precursor lesions in the public announcements and press releases, the percentages of screenees attending with skin lesions clinically suggestive of common moles, congenital naevi, dysplastic naevi, and melanoma are higher. However, skin lesions clinically suggestive of squamous cell carcinoma, basal cell carcinoma, and actinic keratoses are less frequent. This also applies to benign skin conditions, eg, eczema, psoriasis, dermatofibromas, and seborrhoeic keratoses.

We also compared the biopsy-proved skin malignant neoplasms between both campaigns. Six melanomas were recorded in 1990; one lentigo maligna and five 
invasive melanomas. In the 1993 campaign, 13 melanomas were diagnosed: four lentigo maligna lesions, three in situ superficial spreading melanomas, five invasive melanomas less than $1 \mathrm{~mm}$ thick, and only one thick melanoma (2.1 mm). Although the propartion of confirmed melanomas in both programmes was similar $(0.3 \%)$, the relative yield of early lesions was distinctly higher in the 1993 programme $(p=0.04)$. The total number of confirmed melanomas might have been higher in Southern Limburg if all suspected melanoma cases had been followed up. Follow-up was incomplete for two possible melanomas and two cases of lentigo maligna. In Arnhem all presumptive melanoma diagnoses were followad up. The total of 13 confirmed melanomas seems rather low. There were 72 potential melanomas diagnosed, including 17 lentigo malignas, in 69 persons. Sixty-eight tumours were adequately followed up. This gives a positive predictive value of only $19 \%$. This low test performance probably results from the inclusion of many pigmented lesions with low clinical suspicion among the presumptive melanoma diagnoses.

The yield of histologically confirmed dysplastic naevi was 48. In Arnhem only 10 dysplastic naevi were histopathologically confirmed. Despite the incomplete followup of persons with presumed dysplastic naevi in both screening exercises, and the rather subjective interpretation of diagnostic minutiae of dysplastic naevi by individual dermatologists and histopathologists, we are confident that the true rate of dysplastic naevi was substantially higher in the recent campaign.

The peak occurrence of cutaneous melanoma is at 40 to 50 years of age. Nonmelanoma skin cancer generally afflicts the elderly. Our 1990 campaigns exhibited a relative excess of elderly persons with peak attendance rates between 40 and 70 years. The 1993 series showed a preponderance of adult screenees, with peak attendance rates between 20 and 50 years. The shift toward a younger cohort is encouraging. In this respect, age is probably not a confounder. Nevertheless, we executed a multivariate analysis, which disclosed screening location to be an independent risk variable. In Southern Limburg, significantly more melanomas were clinically diagnosed than in Arnhem.

Attendees of skin cancer and melanoma screening programmes differ from the general population in their risk profile. ${ }^{14}$ People attending in response to the multimedia publicity efforts seern to be at appropriately high risk. Screening exercises show a relatively high yield of confirmed skin cancers, as compared with the expected harvest of prevalent cases from the general population. ${ }^{367,9}$ On the other hand, the proper value of self-examination and self-selection as a screening tool has been questioned." To maximize the yield of screening, it is imperative to tailor programmes to attract 
those persons at highest risk. Our survey demonstrates that precampaign publicity messages must focus on melanoma.

A most promising finding of our project is the decreased proportion of nonmelanoma skin cancers and certain precancerous states of low or negligible clinical and epidemiologic concern: basal and squamous cell carcinomas, and actinic keratoses. It is questionable whether screening procedures can alter the natural course of nonmellanoma skin cancer in a significant proportion of those screened. One of the major drawbacks of the rather unfocused screening efforts on skin cancer conducted so Far in the United States and in the Netherlands is the initiation of insignificant and borderline cases into the medicall circuit. Screening only for melanoma may provide a means of increasing the detection rate of an important and potentially lethal disease. Selective screening for melanoma may improve cost-effectiveness. It also may decrease the risk of overtreatment of a great number of persons with minor or questionable disease.

\section{ACKNOWLEDGEMENTS}

The following dermatologists participated in the Limburg screening programme: PIMJ Bessems, LEG Bossuyt, H Deleu, MJT Go, RFHJ Hulsmans, LCG Kerkhofs, AMJ van der Kley, MJ Korstanje, JCCA Lambers, HCJ Liberton, PAFA van Neer, RLMA Prevoo, CJG Sanders, PJ Velthuis, KJM Vissers-Croughs, and J Wuite. Thanks are due to P'M Berretty, BEWL van Huystee, LALM Kiemeney, and CHHM Nijs for help in the organization of the screening exercises in Arnhem and Eindhoven. We would like to thank Brigitte Gijsen en Raph de Rooij for their assistance with the organization of the clinics. Sandra van Heertum was very helpful with the data processing. This study was supported in part by a grant from the Comprehensive Cancer Centres IKL (Maastricht) and IKO (Nijmegen). These are nonprofit government supported bodies that deal with the management, education, interinstitutional treatment strategies, and screening of cancer on a regional level.

Presented as a poster exhibit at the American Academy of Dermatology Meeting; New Orleans, La, February 4-9, 1995. 


\section{REFERENCES}

1. Koh HK, Lew RA, Prout MN. Screening for melanoma/skin cancer: theoretic and practical considerations. J Am Acad Dermatol 1989; 20: $159-72$.

2. Koh $H K$, Miller $D R$, Geller $A G$, et al. Screening for melanoma and other skin cancers. Clin Dermatol 1992; 10: 97-103.

3. Rigel DS, Friedman RJ, Kopf AW, et al. Importance of complete cutaneous examination for the detection of malignant melanoma. I Am Acad Dermatol 1986, 14: 857-60.

4. Field SI. Melanoma/skin cancer screening in Michigan. I Am Acad Dermatol 1987; 16: $578 \times 83$.

5. Olsen TG, Feeser TA, Conte ET, et al. Skin cancer screening: a local experience. I Am Acad Dermatol 1987; 16:687.41.

6. Bolognia JL, Berwick M, Fine IA. Complete follow-up and evalwation of a skin cancer screening in Connecticut. J Am Acad Dermatol 1990; 23: 1098-106.

7. Koh HK, Caruso A, Gage I, et al. Evaluation of melanoma/skin cancer screening in Massachusetts. Cancer 1990; 65: 375-9.

8. Groenendal H, Rampen FHI, Broekman JM. Bewolkingsonderzoek naar huidkanker; etw varingen in Oss. Ned Tijdschr Geneeskd 1990; 134: 2057-8.

9. Rampen FHJ, wan Huystee BEWL Kiemeney LALM. Melanoma/skin cancer screening cinics: experiences in the Netherlands. I Am Acad Dermatol 1991; 25: 776-7.

10. Rampen FHJ, van Huystee BEWL, Kiameney LALM. Practical considerations of melanoma/skin cancer screening clinics. Dermatology 1992; 184: 190-3.

11. Rampen FHJ, Neumann HAM, Kiemeney LALM. Fundamentals of skin cancer/ melanoma screening campaigns. Clin Exp Dermatol 1992; 17: 307-12.

12. McDonald C). Status of screening for skin cancer. Cancer 1993; 72: 1066-70.

13. Elwood JM. Screening for mellanoma and options for its evaluation. J Med Screening 1994; 1: 22-38.

14. Koh HK, Geller AC, Miller DR, et al. Who is being screened for melanoma/skin cancer? I Am Acad Dermatol 1991; 24:271-7.

15. Rampen FHJ, Berretty PJM, van Huystee BEWL, et al. Lack of selective attendance of participants at skin cancer/melanoma screening clinics. J An Acad Dermatol 1993; 29 . $423-7$. 
Chapter 5

\title{
TOTAL SKIN EXAMINATION DURING SCREENING FOR MALIGNANT MELANOMA DOES NOT INCREASE THE DETECTION RATE
}

\author{
M.J.M. de Rooij \\ E.H.J. Rampen ${ }^{2}$ \\ L.J. Schouten ${ }^{3}$ \\ H.A.M. Neumann ${ }^{4}$
}

Departments of Dermatology, University Hospital Nijmegen ${ }^{1}$, St. Anna Hospital $\mathrm{Oss}^{2}$, and University Hospital Maastricht ${ }^{4}$, Comprehensive Cancer Centres IKO (Nijmegen) and IKL (Maastricht) ${ }^{3}$, the Netherlands 


\section{SUMMARY}

Totâl skin examination during public screening for malignant melanoma is often advocated, but the benefit of this approach has not been established properly. We assessed the yield of examination of the entire skin, in addition to examination of intentionally shown skin lesions, in people attending melanoma screening clinics in Southern Limburg, the Netherlands, in 1993. Of the 4146 attenders, 2910 (70\%) showed a specific skin spot. Additional examination of the entire skin was offered to 1385 people. There were 1221 evaluable cases. Fourteen presumptive diagnoses of malignancies were encountered: seven malignant melanomas, all with low clinical suspicion, and seven basal cell carcinomas. Histology revealed three basal cell carcinomas. No malignant melanomas were confirmed by histology. It is concluded that additional total skin examination during screening for malignant melanoma is not worthwhile, except perhaps for persons presenting lesions that are suspicious of melanoma or dysplastic naevi.

Screening for malignant melanoma aims at timely recognition and, thus, theoretically reduces death from this tumour. Several questions about proper screening methods remain unanswered. ${ }^{1.3}$ One problem is the value of inspection of the entire skin in screenees who intend to show only one specific skin spot. Most authors advocate additional, total, skin examination. ${ }^{1,4}$ Complete skin examination seems to have certain advantages, as most malignant melanomas are found on covered parts of the body. On the other hand, an entire skin examination is time consuming, and may be embarrassing. The aim of this study was to investigate the yield of additional total skin examination in participants of a melanoma screening campaign.

\section{MATERIALS AND METHODS}

In June 1993, a number of voluntary melanoma screenings were conducted in Southern Limburg, the Netherlands. ${ }^{5}$ Participants were asked to indicate whether they opted for examination of one, or a few, specific skin mark (s), or for a complete skin check. Those who intended to show a specific lesion were offered additional, total skin examination, when time and staffing allowed.

All those showing a skin lesion suggestive of malignant melanoma or dysplastic naevus were formally offered a total skin check, according to the study protocol. These screenees were excluded from the final analysis of additional total skin examinations. If a malignancy or premalignancy was suspected, the participant received a letter of referral with the proposed line of management to his/her general practitioner. All 
positive screenees were followed. Four months after the campaign, treatment particulars and histopathology data were compiled. With regard to the nonresponders, follow-up was repeated after 10 months.

When appropriate, the chi-squared statistic was used to test for differences between two samples. When the sample sizes were too small for a chi-squared test, Fisher's exact probability test was used.

\section{RESULTS}

A total of 4146 participants were screened. Of these, $2910(70 \%)$ opted for examination of a specific skin mark, and 1197 (29\%) for a complete skin check (39 unknown). Of the 2910 persons who intended to show a specific skin lesion, 1385 $(48 \%)$ were offered additional total skin examination. Of these, $1356(98 \%)$ agreed to examination of the entire skin. Of the 1356 screenees who accepted an additional skin check, 1.35 showed, at first examination, a skin mark clinically suspicious of dysplastic naevus or malignant melanoma. These persons systematically underwent a total skin check, according to the study protocol. Thus, 1221 screenees remained for evaluation.

Table 1. Yield of additional complete skin examination $(n=1221)$

\begin{tabular}{lll}
\hline Clinical diagnosis & $\begin{array}{l}\text { Number } \\
\text { of cases }\end{array}$ & $\begin{array}{l}\text { Histopathological } \\
\text { diagnosis }\end{array}$ \\
\hline Malignant melanoma & 1 Dysplastic naevus \\
& 3 Common mole \\
& 2 Trauma \\
Basal cell carcinoma & 1 Lentigo simplex \\
& 3 Basal cell carcinoma \\
& 1 Sebormoeic wart \\
& 1 Naevocellular naevus \\
& 1 Treatment without histology \\
& 1 Incomplete rollow up
\end{tabular}


There were 14 presumptive diagnoses of malignancies, seven of malignant melanomas, with a low clinical suspicion, and seven of basal cell carcinomas (Table 1). Follow-up was complete in 12 instances ( $86 \%$ ). One person, with a presumed basal cell carcinoma did not visit her physician, although she was encouraged to do so twice. One screenee, with a presumed basal cell carcinoma, was treated without histology. Histology in the compliant cases revealed three basal cell carcinomas. Nó biopsy-proved melanomas were encountered.

Of the 49 screenees with presumptive diagnoses of premalignancies seen on additional total skin examination, follow-up was achieved in 45 cases $(92 \%)$. No malignancies were detected on histology in this group.

The initial examination of lesions about which the attendants were concerned, including cutaneous examination in those who opted initially for a total skin check, yielded substantially more presumptive malignancies and premalignancies than the additional total skin examination (Table 2). Histology revealed 13 malignant melanomas (in 13 persons) and 44 nonmelanoma skin cancers (in 42 persons) following initial screening. These findings contrast with no melanomas at all $(p=0.05)$, and only three basal cell carcinomas $(p=0.007)$, respectively, detected in the additional, total skin examination group.

Table 2. Numbers of presumptive malignancies and premalignancies detected at primary examination and during additional total skin examination

\begin{tabular}{|c|c|c|c|}
\hline Clinical diagnosis & $\begin{array}{l}\text { Initial } \\
\text { examination } \\
n=4146\end{array}$ & $\begin{array}{l}\text { Adelitional total } \\
\text { skin examination } \\
n=1221\end{array}$ & $\begin{array}{l}\text { Significance } \\
\text { (p) }\end{array}$ \\
\hline Malignant melanoma* & $69(1.7 \%)$ & $7(0.6 \%)$ & 0.005 \\
\hline Basal cell carcinoma & $95(2.3 \%)$ & $7(0.6 \%)$ & $<0.001$ \\
\hline Squamous cell carcinoma & $6(0.1 \%)$ & $0(-)$ & NS \\
\hline Bowen's disease & $13(0.3 \%)$ & $0(-)$ & 0.05 \\
\hline Acrinic keratosis & $63(1.5 \%)$ & $3(0.2 \%)$ & $<0.001$ \\
\hline Dysplastic naevus & $319(7.7 \%$ & $40(3.3 \%)$ & $<0.001$ \\
\hline Congenital naevus & $370(8.9 \%)$ & $5(0.4 \%)$ & $<0.001$ \\
\hline $\begin{array}{l}\text { Other cancerous and } \\
\text { precancerous lesions }\end{array}$ & $3(0.1 \%)$ & $1 \quad(0.1 \%)$ & $\mathbb{N S}$ \\
\hline
\end{tabular}

Including lentigo maligna

NS, not significant. 


\section{DISCUSSION}

Examination of the entire skin is advocated during the annual skin cancer/melanoma screening programmes supported by the American Academy of Dermatology (AAD) ${ }^{8}{ }^{4}$ The argument is that most malignant melanomas are found on covered skin. During screening clinics in the Netherlands, so far, only lesions specifically presented by the screenees have been evaluated. ${ }^{6,7}$ Screening activities in the Netherlands attract large numbers of people. Considering the lack of space and manpower, it is impossible to perform a total skin check routinely on screening participants being concerned about only a single skin mark.

Little is known about the importance and feasibility of complete cutaneous examination during skin cancer screening clinics. Rigel et al conducted a free skin cancer screening particularly to survey this issue." Attendees were asked to fully disrobe, and gown for a complete skin examination. A total skin check was accepted by 1385 of 2239 participants (62\%). The yields of the complete and partial examinations were 13 and one malignant melanomas, respectively. It is questionable, however, whether this increase in malignant melanoma diagnoses in the total skin examination group is related to chance detection. The different findings reported


differences in methodology. Rigel et al distinguished between exposed (easy-to-see) and covered (hard-to-see) areas. People who consented to undress completely were categorized as having a total skin exam, as opposed to those having a partial examination of sun-exposed skin only. In our campaign, screenees were asked to show specific lesions that bothered them, irrespective of body area. In addition, they were encouraged to have the rest of their body surface examined. The melanoma patients described by Rigel et al probably opted for examination of covered skin, because they were worried about a skin mark on covered skin.

Lookingbill ${ }^{8}$ and Lee et al ${ }^{9}$ reported relatively high yields of incidental malignancies found on complete cutaneous examination of dermatology patients. Nearly all tumours were basal cell carcinomas. It is not clear how many of these patients would have shown their hidden tumours anyway as a secondary complaint, irrespective of the opportunity of a total skin check. It has been established that malignant melanomas are regularly shown in passing during office visits for other ailments. ${ }^{10}$

The chance of diagnosing a cutaneous malignant melanoma during additional, total skin examination appears to be extremely low. Only seven cases of low clinical suspicion were recorded, among 1221 persons examined. None of these cases proved to be a malignant melanoma at follow-up. The initial skin check in our campaign 
yielded more biopsy-proved malignancies and premalignancies than additional examination of the entire skin. Thirteen malignant melanomas were found, among 4146 screenees. Of these, 12 persons intended to show this specific lesion. Only one malignant melanoma was found in a person who voluntarily opted for total skin examination. In addition, 43 histology-proved basal cell carcinomas, and one case of Bowen's disease, were encountered on initial screening. Of the 1221 persons undergoing additional total skin examination, only three had a biopsy-proved basal cell carcinoma.

In a strict sense, the open access early detection clinics held in Southern Limburg were not screening processes. As public education, self-selection and physician examination may be inextricably intertwined, especially in the case of skin cancer and melanoma, " we consider such campaigns as a type of focused and selective screening, focused on the population at the highest risk, and based on self-selection of persons with a high level of awareness and concern. If, however, non-dermatologist physicians are inadequate at identifying pigmented lesions suspicious of being malignant melanomas, ${ }^{12,13}$ one may assume that persons at a screening are even worse at this. The AAD experience suggests that people at high risk for skin cancer generally are selecting themselves appropriately to be screened. ${ }^{14}$ Non-selective screening of adult women in a high-incidence region (Australia) yielded only one malignant melanoma among 7450 participants. ${ }^{15}$ Screening exercises for skin cancer and melanoma produce yields that are considerably higher. ${ }^{46,16,17}$ It is concluded that focussed and selective screening for skin cancer and malignant melanoma is an easy means of attracting relatively high numbers of positive screenees.

Although the available screening test, the dermatologist's eye, is very accurate in distinguishing malignant from benign pigmented lesions, ${ }^{12,13,18,19}$ the small numbers of dermatologists in most Western countries preclude regular, large-scale screening programmes. In order to offer a reliable screening opportunity following a public education campaign, it is imperative to narrow the scope of such screening exercises. Many more screenees can be seen if only index lesions are examined, without routine additional complete skin checks. Adhering to this approach, we have been able to examine 150-200 persons per investigator per day.

Our results indicate that additional total skin examination in people showing specific skin spots during screening for malignant melanoma, is not necessary. A possible exception is the group of attendees exhibiting lesions that are suggestive of malignant melanoma or dysplastic naevi. Disrobing, gowning, and chaperoning, are time consuming. The investment of physician time can be considerable. More screenees 
can be seen with limited provider time if only partial skin examinations are performed. This may increase the cost-effectiveness of melanoma screening.

\section{ACKNOWLEDGEMENTS}

This study was supported in part by a grant from the Comprehensive Cancer Centres IKL (Mastricht) and IKO (Nijmegen), the Netherlands. The following dermatologists participated in the screening programme: P.J.M.J. Bessems, L.E.G. Bossuyt, H. Deleu, M.J.T. Go, R.F.H.J. Hulsmans, L.C.G. Kerkhofs, A.M.J. van der Kley, M.J. Korstanje, J.C.C.A. Lambers, H.C.J. Liberton, P.A.F.A van Neer, R.L.M.A. Prevoo, C.J.G. Sanders, P.J. Velthuis, K.J.M. Vissers-Croughs, and J. Wuite. We would like to thank Brigitte Gijsen and Raph de Rooij for their assistance with the organization of the clinics. Sandra van Heertum was very helpful with the data processing.

Part of this material was presented as a poster exhibit at the American Academy of Dermatology Annual Meeting, New Orleans, USA, February 4-9, 1995, and at the Melanoma '95 Meeting, Brighton, UK, May 10-12, 1995. 


\section{REFERENCES}

1. Koh HK, Lew RA, Prout MN. Screening for melanoma/skin cancer: Theoretic and practical considerations. I Am Acad Dermatol 1989; 20: 159-72.

2. Koh HK, Miller DR, Geller $\mathrm{AC}$, et al. Screening for melanoma and other skin cancers. Clin Dermatol 1992; 10: 97-103.

3. Elwood JM. Screening for melanoma and options for its evaluation. I Med Screening 1994; 1: 22-38.

4. Rigel DS, Friedman RI, Kopf AW et al. Importance of complete cutaneous examination for the detection of malignant melanoma. I Am Acad Dermatol 1986, 14:857-60.

5. de Rooij MIM, Rampen FHJ, Schouten LJ, Neumann HAM. Skin cancer screening focusing on melanoma yields more selective atrendance. Arch Dermatol 1995, 131: 422 5.

6. Rampen FH], van Huystee BEWL, Kiemeney LALM. Melanoma/skin cancer screening clinics: Experiences in the Netherlands. I Am Acad Dermatol 1991; 25: 776-7.

7. Rampen FHJ, van Huystee BEWL, Kiemeney LALM. Practical considerations of melanoma/skin cancer screening clinics. Dermatology 1992; 184: 190-3.

8. Lookingbill DP. Yield from a complete skin examination. Findings in 1157 new dermatology patients. I Am Acad Dermatol 1988; 18:31-7.

9. Lee G, Massa MC, Welykyj S, et al. Yield from total skin examination and effectiveness of skin cancer awareness program. Findings in 874 new dermatology patients. Cancer $1991 ; 67: 202-5$.

10. Rampen FHI, Rümke $\mathbb{P}$, Hart AAM. Patients' and doctors' delay in the diagnosis and treatment of cutaneous melanoma. Eur J Surg Oncol 1989; 15: 143-8.

11. Koh HK, Geller AC, Miller DR, Lew RA. The early detection of and screening for melanoma. Cancer 1995; 75: 674-83.

12. Cassileth BR, Clark WH, Lusk $\mathbb{E}$, et al. How well do physicians recognize melanoma and other problem lesions? I Am Acad Dermatal 1986; 14:555-60.

13. Rampen FHJ, Rümke P. Referral pattern and accuracy of clinical diagnosis of cutaneous melanoma. Acta Derm Venereol (Stockh) 1988; 68:61-4.

14. Koh HK, Geller AC, Miller DR, Lew RA. Who is being screened for melanoma/skin cancer Characteristics of persons screened in Massachusetts. I Am Acad Dermatol $1991 ; 24: 271-7$.

15. Raphael M. Cancer detection in working women: a repot on 7450 subjects. Med I Aust $1977 ; 2: 557-60$

16. Bolognia $\mathrm{IL}$, Berwick $M$, Fine $\mathrm{IA}$. Conplete follow-up and evaluation of a skin cancer screening in Connecticut. J Am Acad Dermatol 1990,23: $1098,106$.

17. Koh HK Caruso A, Gage I, et al. Evaluation of melanoma/skin cancer screening in Massachusetts. Cancer 1990; $65: 3759$.

18. Grin CM, Kopf AW, Welkovich $B$, et al. Accuracy in the clinical diagnosis of malignant melanoma. Arch Dermatol 1990; 126:763-6.

19. Rampen FHJ, Casparie-van Velsen IAMG, wan Huystee BEWL, et al. False-negative findings in skin cancer and melanoma screening. I Am Acad Dematol 1995; 33;59-63. 
Chapter 6

\title{
VOLUNTEER MELANOMA SCREENINGS: FOLLOW-UP, COMPLIANCE, AND OUTCOME
}

\author{
M.J.M. de Rooij ${ }^{1}$ \\ E.H.J. Rampen ${ }^{2}$ \\ L.J. Schouten ${ }^{3}$ \\ H.A.M. Neumann ${ }^{4}$
}

Departments of Dermatology, University Hospital Nijmegen', St. Anna Hospital $\mathrm{Oss}^{2}{ }^{2}$ and University Hospital Maastricht ${ }^{4}$, Comprehensive Cancer Centres IKO (Nijmegen) and IKL (Maastricht) ${ }^{3}$, the Netherlands 


\section{SUMMARY}

Background: Follow-up information on free melanoma screening clinics is not readily available.

Objective and methods: We studied the follow-up, compliance, and outcome of positive screenees after a screening campaign for melanoma in the Netherlands.

Results: Of the 4146 participants, $486(11.7 \%$ ) had a suspicious premalignant or malignant lesion warranting referral to his or her general plyysician indicating the proposed line of management. Participants with borderline lesions were not referred. Referral of borderline cases should have resulted in a considerable increase of the number of positive screenees (18.1\%). All positive screenees but two gave permission for follow-up. Only 18 screenees (3.7\%) were lost during follow-up. Moreover, one screenee with a presumed basal cell carcinoma and six screenees suspicious of having a premalignant lesion decided not to seek medical attention despite several reminders. The positive predictive value for melanoma was $17.2 \%$, and for nonmelanoma skin cancers was $42.9 \%$.

Conclusion: A selective referral policy may reduce the generated costs of melanoma. screenings substantially. Adequate follow-up of positive screenees is mandatory in order to determine the ultimate yield and usefulness of such campaigns.

Cutaneous melanoma fulfils most basic principles of screening for disease set out by Wilson and Jungner. ${ }^{12}$ Screening itself gives no health benefit. Diagnostic and treatment services for positive screenees have to be available and positive screenees have to be followed for definitive mamagement. The usefulness and justifiability of screening depends on the extent to which positive screenees can be followed and treated. We studied the referral rate, compliance with referral, the final histopathological diagnosis, and the positive predictive value of a dermatologist's exam in a volunteer screening campaign for melanoma in the Netherlands in 1993.

\section{MATERIALS AND METHODS}

In June 1993 a number of voluntary melanoma screenings were conducted in Southern Limburg, the Netherlands. The area has approximately 650,000 inhabitants. All dermatologists in the region participated in this project. The screenees were examined on two consecutive Saturdays at one university hospital and five district hospitals. In the precampaign awareness programme special emphasis was placed only on the risk factors and symptoms of melanoma. Nonmelanoma 
one basal cell carcinoma, five dysplastic maevi, and one congenital naevus. These participants decicled not to seek medical attention (incomplete follow-up, patient's delay).

Histopathologic examination was acheved in almost all cases with suspected malignancy $(162 / 183,88.5 \%)$. Those with presumed premalignancies were evaluated by histology in 243 of 752 instances (32.3\%). Of the 69 persons with presumed melanoma, including lentigo maligna, 64 underwent excisional. biopsy. Eleven melanomas were confirmed histologically (positive predictive value, $11 / 64=17.2 \%$ ). If all suspected cases are included, then the positive predictive value is $15.9 \%(11 /$ 69). Two persons with clinical suspicion of dysplastic naevus proved to have a lentigo maligna and malignant melanoma in situ, respectively. In summary, there were 13 persons with a pathologically confirmed melanoma (all but one with thickness $<1$ mm)

Of the 95 persons with suspicious basal cell carcinoma, 81 were biopsied, 36 of which were confirmed by pathologic examination. All six persons with presumptive squamous cell carcinoma were evaluated by biopsy. No squamous cell carcinomas could be proved by histology. Of the 13 persons with presumed Bowen's disease, 11 were subjected to biopsy. None of these was confirmed histologically. Furthermore, eight malignancies were found by histologic assessment, which diagnoses were not considered clinically: seven basal cell carcinomas (clinical diagnoses: squamous cell carcinoma, 1; Bowen's disease, 4; actinic keratosis, 1 ; and naevocellular naevus, 1) and one Bowren's disease (clinical diagnosis: basal cell carcinoma). The positive predictive value of the dermatologist's visual exam for nonmelanoma skin cancers was $38.6 \%(39 / 101)$ for those referred and $42.9 \%$ (39/91) for those biopsied.

Of the 239 persons with dysplastic naevi who received a letter of referral, 200 underwent histologic assessment. In 35 cases dysplastic naevi were confirmed histologically (positive predictive value, $17.5 \%$ ). Out of the 23 attendees referred because of suspicion of actinic keratoses, 12 were subjected to biopsy and six could be confirmed (positive predictive value, 50.0\%).

\section{DISCUSSION}

The precise effectiveness, health benefits, and costs of volunteer melanoma screenings are unknown. In this respect, the proportion of those referred among the participants is important. A high referral rate may signify many borderline cases being referred, which increases heal th care expenditures and decreases the cost-effectiveness of the screening. 
Referrals in the present study ( $11.7 \%$ ) are in contrast with those in other published studies from the United States ${ }^{5-8}$ and Germany. Bolognia et al" reported 128 persons out of 251 attendants $(50.9 \%)$ having a positive screen clinically. In the study of Koh et a ${ }^{6} 787$ out of 2560 screenees ( $30.7 \%$ ) had an abnormal exam and were advised to visit their general physician or dermatologist for follow-up. Field et $\mathrm{al}^{7}$ and Olsen et al ${ }^{8}$ described, respectively, $29.8 \%$ and $36.2 \%$ referrals. Schadendorf et al ${ }^{1}$ examined 423 persons during a free skin cancer screening campaign. Out of these, $26.2 \%$ were suspicious of having a malignant or premalignant skin lesion warranting referral. Rampen et a $1{ }^{10}$ reported $10.2 \%$ referrals during a number of Dutch screenings carried out in 1990 . This percentage corresponds with the referral rate reported in the present study. In both Dutch studies screenees with minimal extent of precursor states or with precursors with low degree of suspicion were not referred in order to avoid unnecessary concern and medical treatment. If all persons with suspicious precancerous lesions had been referred, the proportion of relerred screenees in the present study would have been $18.1 \%$.

A more selective referral policy has important implications for the workload of general physicians, dermatologists, surgeons, and pathologists after the screenings. The costs of medical care induced by screening exercises can be reduced considerably in this manner. When lesions with slight suspicion of dysplastic naevus or actinic keratosis are not referred, it is very unlikely that important malignancies will be missed. ${ }^{11}$ The effectiveness of melanoma screening programmes can only be determined when the participants are followed systematically. In the present study follow-up information was obtained from all screenees with suspected malignancy. From those with suspected premalignancy, in all but 18 persons was follow-up information available. Thus, 18 persons (3.7\%) were lost to follow-up despite several efforts to contact them by mail or telephone. Moreover, there were seven participants $(1.4 \%)$ who did not schedule a consultation. Thus, totally 459 of those referred $(94.8 \%)$ did seek medical care. Our results show the feasibility of adequate follow-up. They compare favourably with the follow-up data reported by Bolognia et al ${ }^{5}(87.5 \%)$ and Rampen et al ${ }^{10}(90.3 \%)$. In the study of Koh et al ${ }^{6}$ follow-up information was available in only $63 \%$ of all cases; $15 \%$ of the referred screenees did not respond and $22 \%$ did not schedule a visit with their general practitioner or dermatologist. This discrepancy may partly be due to the differences in the health care system and medical insurance in the Netherlands and the United States. Koh et al speculate that 'persons who failed to comply either had no regular health care provider or dermatologist or did not know how to obtain proper treatment ${ }^{3}$. Bolognia et al ${ }^{5}$ describe in their paper various reasons given for not seeking recommended care: 
concern about a benign lesion but not the suspect lesion, only wanting reassurance that they did not have melanoma, and lack of insurance. Recently, Koh et alt2 presented follow-up particulars of the American Academy of Dermatology-sponsored. skin cancer screenings. Only information about screenees suspicious of having melanoma was given. Out of 4458 positive screenees, $174(3.9 \%)$ persons could not be traced for follow-up and $903(20.2 \%)$ screenees did not visit their physician for further advice. The authors suggest that more adequate follow-up can be achieved by using a centralized follow-up system. In the Netherlands we also have the experience that follow-up results are more complete when they are collected centrally.

In most published studies, the yield of skin cancer and melanoma screening has been reported in terms of presumptive clinical diagnoses. Few studies have included details of pathologically confirmed mallignancies. ${ }^{5,6}, 6_{2}, 15$ In the present study, especially those attendants with presumed malignancies were evaluated by histology (162/ $183 ; 88.5 \%$ ). Those with presumed precursors were evaluated by histology in only 243 of 752 instances $(32.3 \%)$. The scope of any screening exercise ends with histopathological assessment of subjects positive on screening, followed by appropriate treatment. Skin biopsies are important outcome measures of total yield, positive predictive value, and cost-benefit ratio of the screening. Final assessment and treatment in a structured manner are crucial ingredients of skin cancer and melanoma screening campaigns.

The value of volunteer screening for skin cancer largely depends on the numbers of melanomas detected. Rigel et al ${ }^{13}$ found 14 suspicious malignant melanomas among 2239 screenees $(0.6 \%)$. All these lesions were histopathologically confirmed. Interestingly there appeared to be no false-positive screenees. Koh et al discovered 9 malignant melanomas among 2560 screenees $(0.4 \%$ ). Bolognia et al failed to detect any melanomas among 251 screenees $^{5}$, and Rampen et $\mathrm{al}^{10}$ found six histology-prom wen melanomas, including one lentigo maligna, among 2564 screenees $(0.2 \%)$. In the present study 13 melanomas were histologically confirmed among 4146 participants $(0.3 \%)$.

In the present study only 11 melanomas out of 64 biopsied suspicious lesions could be histologically confirmed. This is due to the fact that many lesions with low suspicion were included in the presumptive diagnosis group. Therefore, the positive predictive value for melanoma is low $(17.2 \%)$. When only the first diagnosis is considered the positive predictive value for malignant melanoma (including lentigo maligna) increases to $34.4 \%(11 / 32)$. Koh et $a^{12}$ found 364 confirmed melanomas out of 3237 lesions biopsied (11.2\%). Clinical diagnoses included melanoma and 
"rule out melanoma". When only melanomas were considered the predictive value increased to $17.0 \%$.

Squamous cell carcinoma seems to be difficult to diagnose clinically. None of the presumed cases of squamous cell carcinoma and Bowen's disease in our series were histologically confirmed. The final diagnoses of the suspected squamous cell carcinomas were: one basal cell carcinoma, two actinic keratoses, one seborrhoeic keratasis, one keratoacanthoma, and one pseudoepithiomatous hyperplasia. On the other hand, basal cell carcinoma has distinct clinical characteristics, which results in a relatively high positive predictive value (in this study $44.4 \%$ ).

It should be realized that different definitions have been used for calculating the positive predictive value. Koh et $\mathrm{al}^{6}$ give two different positive predictive values: one low value for true positives/total screened and a higher value for true positives/ total followed. The positive predictive value reported by Bolognia et $\mathrm{al}^{5}$ was based on histologic confirmation of lesions that were biopsied. Rampen et al ${ }^{10}$ reported two values for all suspected skin cancers: one low value for those histologically confirmed out of those referred and one higher value for those histologically confirmed out of those followed ('including and excluding defaulters').

Elwood ${ }^{14}$ emphasizes that nonmelanoma skin cancers require only simple treatment and have excellent prognosis. Thus, the argument for skin cancer/melanoma screening needs to be made primarily for melanoma. If the whole programme is justified only as melanoma screening exercise, the predictive value is calculated as melanomas confirmed/total screenees followed. In that case, the positive predictive value in our series is only $2.8 \%(13 / 459)$.

Differentiating early melanomas from dysplastic naevi can be very difficult. This has been shown in two of our screenees: one suspicious dysplastic naevus proved to be a lentigo maligna and another one proved to be an in situ melanoma. This illustrates one of the potential hazards of screening in general and melanoma screening in particular: false-negative screens may delay future consultation because of a false feeling of safety. Screenees must be made aware of the fact that a negative screen does not guarantee that the person will not develop melanoma in the (near) future.

More appropriate selection of referrals for further management theoretically decreases work load and costs of medical care induced by screenings. In this way the number of false-positive results can be minimized and unnecessary biopsy and surgery can be avoided. This can partly be achieved by excluding from referral those with questionable disease or minor precursor states. Selective referral can also be achieved by adding of a second discriminatory test to the primary screening test. ${ }^{3}$ The 
screening test used so far in skin cancer and melanoma screenings is the trained eye of the clermatologist. The use of the dermatoscope can be advocated as an additional measure for screening pigmented skin lesions. ${ }^{15,26}$ Thus, the number of participants who are referred for skin lesions of questionable importance could possibly be diminished. However, several questions about the proper value of the dermatoscope in general have to be solved before this technique can be recommended in screening settings.

Further refining of referral procedures might increase cost-effectiveness of volunteer melanoma screenings. Almost complete follow-up is feasible with the use of a centralized follow-up system. The work load of follow-up is time consuming. Yet, follow-up is an inherent part of the screening procedure. A more uniform approach to evaluate screenings is also necessary to compare results in different studies. Although, it has to be taken into account that the outcome of volunteer screenings is also dependent on the specific circumstances such as the health care system of the country where the screenings are held.

\section{ACKNOWLEGDEMENTS}

This study was supported in part by a grant from the Comprehensive Cancer Centres IKL (Maastricht) and IKO (Nijmegen), the Netherlands. The following dermatologists participated in the screening programme: P.J.M.J. Bessems, L.E.G. Bossuyt, H. Deleu, M.J.T. Go, R.F.H.J. Hulsmans, L.C.G. Kerkhofs, A.M.J. van der Kley, M.J. Korstanje, J.C.C.A. Lambers, H.C.J. Liberton, P.A.F.A. van Neer, R.L.M.A. Prevoo, C.J.G. Sanders, PJ. Velthuis, K.J.M. Vissers-Croughs, and J. Wuite. We would like to thank Brigitte Gijsen and Raph de Rooij for their assistance with the organization of the clinics. Sandra van Heertum was very helpful with the data processing. Thanks are due to Els Salemink and Diny de Heus for the preparation of the manuscript. 


\section{REFERENCES}

1. Wilson JMG, Jungner $G$. The principles and practice of screening for disease. Public Health Papers, No. 34. Geneva: WHO, 1968.

2. Rampen FHJ, Kiemeney LALM, Neumann HAM. Fundamentals of skin cancer melanoma screening campaigns. Clin Exp Dermatol 1992;17:307-12.

3. Cole P, Morrison AS. Basic issues in population screening for cancer. J Natl Cancer Inst $1980 ; 64: 1263-72$.

4. de Rooij MJM, Rampen FHJ, Schouten LI, Neumann HAM. Skin cancer screening focusing on melanoma yields more selective attendance. Arch Dermatol 1995;131:4225.

5. Bolognia JL, Berwick M, Fine JA. Complete follow-up and evaluation of a skin cancer screening in Connecticut. I Am Acad Dermatol 1990;23:1098-106.

6. Koh HK, Caruso A, Gage I, et al. Evaluation of melanoma/skin cancer screening in Massachusetts: preliminary results. Cancer 1990;65:375-9.

7. Field SI. Melanoma/skin cancer screening in Michigan. J Am Acad Dermatol 1987;16:57883.

8. Olsen TG, Feeser TA, Conte ET, et al. Skin cancer screening: a local experience. J Am Acad Dermatol 1987;16:637-41.

9. Schadendorf $\mathrm{D}, \mathrm{Haas} \mathrm{N}, \mathrm{Ostmeier} \mathrm{H}$, et al. A campaign to fight malignant melanoma: a local experience in Berlin. Eur J Dermatol 1992;2:532-3.

10. Rampen FHJ, van Huystee BEWL. Kiemeney LALM. Melanoma/skin cancer screening clinics: experiences in the Netherlands. I Am Acad Dermatol 1991;25:776-7.

11. Rampen FHJ, Casparie-van Velsen IJAMG, Huystee van BEWL, Kiemeney LALM, Schou* ten LJ. False-negative findings in skin cancer and melanoma screenings. J Am Acad Dermatol 1995;33:59-63.

12. Koh HK, LA Norton, Geller AC, et al. Evaluation of the American Academy of Dermatology's national skin cancer early detection and screening program. J Am Acad Dermatol 1996,34:971-8.

13. Rigel D5, Friedman RJ, Kopf AW, et al. Importance of complete cutaneous examination for the detection of malignant melanoma. I Am Acad Dermatol 1986;14:857 60 .

14. Elwood JM. Screening for melanoma and options for evaluation. J Med Screening $1994,1: 22-38$.

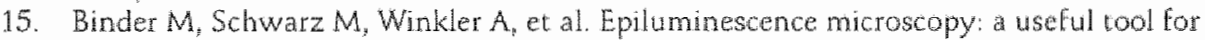
the diagnosis of pigmented skin lesions for formally trained dermatologists. Arch Dermatol 1995:131:286-91.

16. Epstein $\mathrm{E}$. Instrumentation for epiluminescence microscopy: the gap between research and practice. Arch Dermatol 1996,132,91.2. 


\title{
Chapter 7
}

\section{SCREENING FOR MELANOMA:} WATCH THE EARLY BIRD!

\author{
M.J.M. de Rooij ${ }^{3}$ \\ F.H.J. Rampen ${ }^{2}$ \\ L.J. Schouten ${ }^{3}$ \\ H.A.M. Neumann ${ }^{4}$
}

Departments of Dermatology, University Hospital Nijmegen", St. Anna Hospital $\mathrm{Oss}^{2}$, and University Hospital Maastricht ${ }^{4}$, Comprehensive Cancer Centres IKO (Nijmegen) and IKL (Maastricht) ${ }^{3}$, the Netherlands 


\section{SUMMARY}

It may be questioned whether people attending skin cancer and melanoma screening clinics are sufficiently aware of their own risk profile. In June 1993, 4146 people were examined in Southern Limburg, the Netherlands, during a voluntary melanona screening project. Positive screenees, i.e. those with presumed malignancies or with distinct precursor lesions, attended early during the day rather than late. This indicates that people with cancerous or precancerous skin lesions are, on the whole, sufficiently concerned as to take maximum advantage of the screening opportunity. Our findings also imply that abundant provider time and staffing are necessary during the early hours of such screenings.

Screening for melanoma and other skin cancers is recommended and practised in many countries. Screening is especially worthwhile for high risk groups. So Ear, skin cancer and melanoma screening programmes have been based on public education campaigns followed by free consultation. It may be questioned whether the general public is sufficiently capable of purposeful self-assessment. ${ }^{-4}$ Despite adequate precampaign educational messages, screening programmes produce large numbers of negative screenees. There is a risk of overtreatment, anxiety, and increased health system costs. Therefore, we need data to demonstrate that persons who voluntarily attend melanoma/skin cancer screenings are, on the whole, at risk for the disease. In 1993 we conducted a number of free melanoma screening clinics in Southern Limburg, the Netherlands. The main aims of the project were to investigate: (1) the value of screening for melanoma only, instead of screening for skin cancer in general; and (2) the extra yeld of total skin examination additional to examination of specific lesions the attendees are worried about More or less fortuitously, we noticed that people with cancerous or precancerous lesions attended relativelly early in the morning, and that the rate of trivial lesions increased during the day. The workload was highest during the morning sessions and decreased in the afternoon. These observations may indicate that participants who appraise their lesions with accuracy, are maximally motivated to attend the screenings. In addition, our findings may have practical implications regarding staffing of the screening exercises. The present study was initiated to address these points.

\section{MATERIALS AND METHODS}

In June 1993 ten, free melanoma screening clinics were held in Southern Limburg, the Netherlands. The screenings took place over two consecutive Saturdays. All 
dermatologists in the region participated in this project. The area has a population of approximately 650,000 .

At each dinic, attendants were divided into three equal groups, the early and latecomers at both ends, and an intermediate group. Because of the retrospective nature of the study we were unable to ascertain the precise time of first and last attendances in each group.

All clinically suspicious malignancies were recorded. Diagnoses included were: melanoma, lentigo maligna, basal and squamous cell carcinoma, and Bowen's disease. All patients with presumptive malignant lesions received a referral letter. Precursor states were divided into two groups: those with borderline lesions and those with more obvious disease. The attendants in the first group were advised to see a doctor in due course on their own initiative. The persons in the latter category were given a letter of referral for their general physician to secure proper treatment at their earliest convenience. Diagnoses included were actinic keratosis, dysplastic and congenital naevus, and sebaceous naevus. Persons with clinically suspicious skin cancer and those with clear evidence of a precursor state warranting referral, comprised the positive screenee group. Negative screenees were those with borderline precursor lesions and those with benign skin marks.

After 4 months and again after 10 months the screen-positive participants were followed. To this end the positive screenees were contacted by letter or telephone, dermatologists were asked for treatment and pathology particulars, and the Dutch national pathology data bank (PALGA) was scrutinized for cancerous and precancerous diagnoses among the positive screenees. Completeness of follow-up of positive screenees was $95 \%$.

Statistical significance of differences between the groups was assessed using the non-parametric test of Kruskal-Wallis. When appropriate, statistical significance of trends was tested by using logistic regression.

\section{RESULTS}

There were 4146 attendants with evaluable records. Of these, 1381 were categorized as early-comers, 1380 were in the intermediate group, and 1385 were late-comers. Relatively more positive screenees came early, whereas innocuous lesions were more often seen late. In Table 1 the screenees are grou ped by clinical diagnosis and according to time of presentation. More presumptive cancerous and distinct precursor lesions were seen early during the screenings $(p=0.03)$. This trend was observed during both screening days and was very consistent at almost all screening locations. The 
total number of referrals (positive screenees, i.e. presumptive malignant lesions and distinct precursor lesions combined) decreased from 190 in the early group to 139 in the intermediate group, and to 117 in the late group $(p<0,001)$.

Table 1 also presents the follow-up data of positive screenees. Histologically confirmed melanomas and nonmelanoma skin cancers are shown separately. More melanomas and nonmelanoma skin cancers were found among the early-comers as compared with the later groups $(p=0.006)$. Numbers include melanoma in situ and carcinoma in situ. As for melanoma only, the trend of decreasing incident cases during the day did not reach statistical significance $(p=0.10)$. Small numbers, however, preclude meaningful statistical analysis. All but one melanomas were of favourable microstage (Breslow thickness $<1 \mathrm{~mm}$ ).

Table 1. Farticulars of screenees according to time of attendance

Time of attendance

Significance $(p)$

$\begin{array}{lll}\text { Early } & \text { Intermediate } & \text { Late } \\ n=1381 & n=1380 & n=1385\end{array}$

Clinical diagnosis

Malignant lesion

$68(4.9 \%) \quad 61(4.4 \%) \quad 42(3.0 \%)$

Precursor lesion, distinct

$122(8.8 \%) \quad 78(5.7 \%) \quad 75(5.4 \%)$

Frecursor lesion, borderline $106(7.7 \%) \quad 138(10.0 \%) \quad 34(9.7 \%)$

Benign lesion $\quad 1085(78.6 \%) \quad 1103(79.9 \%) \quad 1134(81.9 \%) \quad 0.03^{*}$

Histologic diagnosis

Melanoma

$7(0.5 \%)$

4. $(0.3 \%)$

$2(0.1 \%)$

$0.10^{* *}$

Nonmelanoma

skin cancer

$20(1.4 \%)$

$14(1.0 \%)$

$8(0.6 \%)$

$0.03^{\text {in }}$

Total

$27(2.0 \%)$

$18(1.3 \%)$

$10(0.7 \%)$

$0.006^{* *}$

Fear of skin cancer

$408(29.5 \%) \quad 354(25.7 \%)$

$349(25.2 \%)$

$0.01^{\text {* * }}$

* Kruskal-Wallis test

* Logistic regression. 
Fear of having skin cancer was an important reason to attend the screens in 1111 persons $(26.8 \%)$. Early-coners admitted fear of skin cancer more often than screenees in the intermediate and late groups (Table $1 ; p=0.01$ ).

\section{DISCUSSION}

Screening on the basis of self selection appears to be a suitable method for the early detection of melanoma and nonmelanoma skin cancer. How accurate self-screening is, depends largely on the appropriateness of precampaign public educational programmes. Promotional strategies should attract the proper target population.

There is some doubt about the ability of the general public to appraise skin lesions as risky. ${ }^{12,4}$ This is not surprising since reliable interpretation of warning signs of melanoma may be extremely difficult for even non-dermatologist physicians, ${ }^{5 \cdot 7}$ and even for dermatologists. Girasek noticed that attendees of skin cancer screening clinics were unable to attribute their high risk status to their symptoms. ${ }^{\text {She allso }}$ found that positive screenees were no more likely than negative screenees to seek medical attention of their own volition, had a screening opportunity not been offered. Likewise, Weinstock emphasized that the screenee's perception that a melanoma warning sign or risk factor is present, may be inaccurate. ${ }^{2}$ On the other hand, there are literature data suggesting that high risk persons are, in general, sufficiently aware of their own risk profile 38

Rather by chance we noticed that during a screening project in 1993 relatively mare malignancies were diagnosed during the early hours of the screenings. The workload was highest during the morning sessions. These observations prompted us to conduct the present investigation. Our findings indicate that positive screenees are, on the whole, more seriously worried about their skin lesions than screen-negative persons. They apparently visit the screening location as soon as it suits them in order to take maximal advantage of the screening. Another interpretation might be that those individuals who get up early are at higher risk of developing skin cancer. This possibility seems most unlikely.

We also noticed that screening concentrating on melanoma, instead of skin cancer in general, increases the numbers of lesions suggestive of melanoma and dysplastic naevi. This implies that people attending in response to multimedia publicity efforts seem to be at appropriately high risk.

One may argue that at the beginning of the screening exercise dermatologists display greater alertness or have a lower referral threshold, which causes a higher referral rate. If that was the case then the number of false-positive screenees would be highest 
among the early-comers and the number of true-positive screenees (proved by histology) would be more or less equal in the three groups according to time of attendance. In fact, the rate of true positives decreased steadily during the day. Moreover, fear of cancer was more often recorded by the early-comers than by the late-comers. In previous skin cancer screening campaigns in the Netherlands we encountered very low false-negative results (three out of 1551 persons followed). " These findings indicate that the trends reported herein are screenee-dependent and not screener-dependent.

We noticed that during the morning sessions more persons per hour were attending than in the afternoon. Added to this, the rate of positive screenees was highest in the early hours. Screen-positive persons need more thorough examination, they have to be advised and reassured, referral notes have to be written, et cetera. This has definite practical implications. One of the most fundamental prerequisites of skin cancer and melanoma screening campaigns is the optimal organization of the screens. ${ }^{12,13}$ High attendance rates and increased positive findings during the first hours of the screening necessitates abundant provider time, extra auxiliary personnel, and ample examination rooms.

\section{ACKNOWLEDGMENTS}

The following dermatologists participated in this effort:

P.J.M.J. Bessems, L.E.G. Bossuyt, H. Deleu, M.J.T. Go, R.F.H.J. Hulsmans, L.C.G. Kerkhofs, A.M.J. van der Kley, M.J. Korstanje, J.C.C.A. Lambers, H.C.J. Liberton, P.A.F.A. van Neer, R.L.M.A. Prevoo, C.J.G. Sanders, P.J. Velthuis, K.J.M. Vissers Croughs, and J. Wuite. We would like to thank Brigitte Gijsen and Raph de Rooij for their assistance with the organization of the clinics. Sandra van Heertum was very helpful with the data processing. Thanks are due to Els Salemink and Diny de Heus for the preparation of the manuscript. 


\section{REFERENCES}

1. Girasek DC. Motiwating the public to take advantage of skin cancer screening. I Am Acad Dermatol 1986; 15: 309-15.

2. Weinstock MA. Prevalence of the early warning signs of melanoma among participants in the 1989 Rhode Island skin cancer screening. J Am Acad Dematol 1990; 23:516-8.

3. Koh HK, Geller AC, Miller DR, Caruso A, Gage I, Lew RA. Who is being screened for melanoma/skin cancere J Am Acad Dermatol 1991; 24:271-7.

4. Rampen FHJ, Berretty PM, wan Huystee BEWL; Kiemeney LALM, Nijs CHHM. Lack of selective attendance of participants at skin cancer/melanoma screening clinics. J Am Acad Dermatol 1993; 29: 423.7.

5. Caissileth BR, Clark WH, Lusk $\mathbb{E}$ J, Frederick BE, Thompson CJ, Walsh WP. How well do physicians recognize melanoma and other problem lesions? I Am Acad Dermatol 1986; 14. $555-60$.

6. Rampen FHJ, Rümke P. Referral pattern and accuracy of clinical diagnosis of cutaneous melanoma. Acta Derm Venereol (Stockh) 1988; 68: 61-4.

7. Williams $H C$, Smith $D$, du Vivier A. Melanoma. Differences observed by general surgeons and dermatologists. Int I Dermatol 1991; 30:257-61.

8. Curley RK, Cook MG, Fallow Field ME, Marsden RA. Accuracy in clinically evaluating pigmented llesions. Br Med I 1989; 299: 16-8.

9. Grin CM, Kopf AW, Welkovich B, Bart RS, Jevenstein MJ. Accuracy in the clinical diagnosis of malignant melanoma. Arch Dermatol 1990; 126: 763-6.

10. de Roolj MJM, Rampen FHJ, Schouten $\mathbb{L}$, Neumann HAM. Skin cancer screening focusing on melanoma yields more selective attendance. Arch Dermatol 1995; 131: 4225.

11. Rampen FHJ, Casparie-van Velsen IJAMG, van Huystee BEWL, Kiemeney LALM, Schouten LJ. False-negative findings in skin cancer and melanoma screening. I Am Acad Dermatol 1995; 33: 59-63.

12. Koh HK, Lew RA, Proud MN. Screening for melanoma/skin cancer: Theoretical and practical considerations. I Am Acad Dermatol 1989; 20: 159-72.

13. Rampen FHI, van Huystee BEWL, Kiemeney LALM. Practical considerations of melanoma/skin cancer scteening clinics. Dermatology 1992; 184: 190-3. 
Changers

Chapter 8

GENERAL DISCUSSION AND CONCLUSIONS 
Cutaneous melanoma causes a considerable morbidity and mortality worldwide: The peak occurrence of superficial spreading melanoma and nodular melanoma lies between 40 and 50 years of age. Consequently, it mainly affects younger people. Many decades the early signs and symptoms of cutaneous melanoma are well documented. Theoretically, every melanoma can be detected in an early stage while it is thin and curable. It has been shown that surveillance of groups of people at high risk of melanoma results in detection of melanoma at an earlier stage than otherwise would occur. Public education programmes targetting on those at highest risk (skin phenotype, family or personal history of melanoma, multiple and/or dysplastic naevi) may have the same effect. Melanoma screening as a measure of secondary prevention can be organized at low costs. The screening tool, the trained eye of the dermatologist is an inexpensive, safe, reliable and generally accepted means of early detection. The melanoma screenings in Southern Limburg were visited by many self-selected participants. Dermatologists did the skin checks and determined which screenees should be referred for further advice. This is necessary to avoid too much strain on the services of general physicians. The screenings could be organized easily in the existing Dutch health care system. Future campaigns can be refined and improved further.

What does volunteer screening mean? The present study is based on the results of a public education campaign focusing on melanoma, followed by open access clinics or 'skin check' sessions in June 1993. In the literature public education campaigns combined with such open access clinics have been described as 'screenings', 'screening clinics', 'volunteer screenings', 'targeted screenings', and 'free screenings'. Actually, the use of these terms is not correct because in a strict sense these open access clinics are not genuine screening interventions. ${ }^{2}$ Participants are not selected from population listings as is the case in mammary or cervical cancer screenings. Participants of open access clinics are self-selected. They attend the clinics because of their skin phenotype or risk factors (screening) or because of suspicious skin spots (case finding). Thus, the use of the term 'screening' is rather misleading. We consider these campaigns as a type of volunteer targeted and selective screening, focused on the population at the highest risk and based on self-selection. The target group is recruited by selective announcements during the publicity campaign.

What is the most ideal period? Early summertime is the most ideal period to organize such campaigns. In this period people wear lighter clothing and are probably more 
aware of any skin problems. ${ }^{3}$ Furthermore, during the summer period dermatologists, who form the most reliable screening test (visual examination of the skin), are generally less busy.

Who should perform the screenings: Only dermatologists or senior residents in dermatology performed the examinations during the Southern Limburg campaign. Several studies show that dermatologists are best trained in recognizing (early) melanomas and differentiating melanomas from other pigmented skin lesions. Missing a melanoma has important implications. Ideally, false-negative findings should be reduced to virtually zero, which cannot be guaranteed by non-dermatologists. Overdiagnosing suspected skin lesions, (false-positive screens), on the other hand, leads to undue concern and overtreatment and induces substantial costs.

At what Location should be screened? Most screenings so far in the Netherlands have been carried out in outpatient dermatology departments of university or district hospitals. Although we feel that these locations have distinct advantages, some authors believe that free skin cancer detection clinics should be carried out in public buildings like libraries or schools, or at health fairs. ${ }^{4}$ Screening clinics should never be undertaken for the benefit of any specific physician or hospital. Therefore these authors believe that such clinics should not be carried out in private offices or hospitals. On the other hand, hospitals are familiar to the general public, there is abundant space to park and they can be reached by public transport rather easily. Outpatient dermatology departments have waiting-room facilities and sufficient examination rooms. Most importantly, outpatient dermatology departments are well equipped and adequately lighted for skin examination purposes.

Beach locations are less suitable. Although beaches seem very appropriate for primary prevention interventions, we feel that such locations have clear disadvantages with regard to early detection exercises. When screening at the beach is considered, special facilities have to be provided, which induces extra costs. Furthermore, screening at the beach never has a local or even regional character which might interfere with adequate follow-up and evaluation of positive screenees.

What is the role of the general practitioner? In our project, the general practitioners were notified about the campaign by personal mailings. Furthermore, a special informative meeting had been organized. Only 20 out of 350 general practitioners in the Southern Limburg area attended this meeting. In the programme emphasis was placed on pigmented skin lesions, especially (early) melanoma and its precursor 
lesions. Attention was also paid to populations at risk to develop melanoma. Such a meeting focusing on secondary prevention serves important educational goals. General practitioners do not see many melanomas. Theoretically, educational messages may improve their skills. However, a British study showed that education of general practitioners did not influence the early detection of melanomas; anly after education of the general public on the early signs and symptoms of melanoma more and thinner melanomas were detected. ${ }^{5.6}$ Nevertheless, general practitioners see many pigmented skin lesions in their daily practice. They can give information about early signs and symptoms and risk factors of melanoma. Conceivably, the information given can be optimalized by illustrated leaflets and brochures.

Which publicity chammels are most relevant? The aim of the present publicity campaign and the open access clinics was announced through pamphlets and through articles in the regional newspapers and periodicals. The voluntary screenings were held in a more or less secluded area of the netherlands: Southern Limburg. General practitioners and pharmacists were asked to expose pamphlets in their waiting rooms. The pamphlets were also exposed in public libraries and hospitals. In the future other locations should be considered like banks, sport facilities, schools, post offices, and railway and bus stations. In the Southern Limburg study only the regional newspapers and neighbourhood periodicals were approached for the precampaign announcements and proved to be most important. It can be expected that, in the context of a national screening intervention, the precampaign awareness programme will have more impact when also the national newspapers and the national radio and television stations are used.

Which target groups should be focused upont The message should be a positive one. When melanoma is found and treated early, total cure can be obtained. An aggressive approach will induce unnecessary concern. In the publicity campaigns one of the unique properties of melanoma must be emphasized: It is an easily visible tumour. Many melanoma patients are aware of the existence of specific skin spots. Special vigour should be given to the early changes and symptoms of melanoma. Delay is usually not caused by fear or ignorance but more by lack of knowledge ${ }^{5,7}$ Several studies show that late symptoms such as pain and bleeding are more concerning than early warning signs such as changes in colour and size. ${ }^{a+1}$ interestingly, in the formal leaflets of the Dutch Cancer Foundation ("Acht goede redenen om naar de dokter te gaan", 1994) pain and bleeding of pigmented skin lesions are listed first. Temoshok showed that persons with little or no knowledge 
about melanomas tended to develop thicker lesions. "Also people with tumours on difficult to see areas often present later: Self-examination of the skin has great significance." So far during the campaigns in the Netherlands these items have not been especially focused upon. They may be of particular importance when developing new programmes.

Various groups in the general population are at more than average risk to develop melanoma because of their skin phenotype (blond hairs, blue eyes, freckling, burning tendency), because of more than average mole counts, or because of a personal or family history of melanoma. Theoretically, there are other groups at special risk because of their known 'less awareness' of melanoma (e.g. men, elderly persons, and single persons). ${ }^{13}$ Also in the present study less men attended the screenings and they were prompted more often by relatives or friends to attend. ${ }^{14}$ Further studies are necessary to demonstrate whether it is worthwhile to focus education campaigns especially on these risk categories.

Is screening for nonmelanoma skin cancer worthwhile? The major objective of (volunteer) screening is reducing mortality and morbidity by finding disease and starting effective trearment at an earlier stage. Although nonmelanoma skin cancer is an important health problem, the benefit of screening is very doubtful. Nonmelanoma skin cancer has a low mortality rate. The problems which may result from these skin tumours are totally different from those of melanomas and need their own approach. We feel that the nonmelanoma skin cancers should not be a subject for screening. In the present study it was shown that relatively more melanomas and atypical naevi could be detected against less nonmelanoma skin cancers and benign skin lesions after a precampaign awareness programme focusing on melanoma onlly. ${ }^{15}$

What is the role of ultraviolet (UV) light? Since the precise cause of melanoma is not known, it is not easy to develop primary prevention programmes on melanoma. Avoidance of and protection against UV radiation is an important measure to curtail the development of nonmelanoma skin cancer. In several public education campaigns also emphasis is placed on the role of sun protection to prevent melanoma. Yet, there are many unsolved issues in the possible role of UV in the aetiology of melanoma. There are potential dangers when the possible causal role of UV in the development of melanoma is emphasized too much. Especially those people who avoid sun exposure or those who discover lesions on sun protected areas are at risk of delayed diagnosis. ${ }^{16, \%}$ 
What about total skiw examination? In the present study the general public was offered a free skin check by a dermatologist. The clinics were organized in such a way that a maximum of attendees could be examined with a minimum of provider time (estimated 150-200 persons per dermatologist per day). ${ }^{16}$ Only specific skin lesions the attendees were worried about were examined. In 1385 attendees an additional total skin check was offered. This proved to have only a minimal yield. No melanomas were detected at additional total skin examination ${ }^{19}$ it can be expected that future campaigns can be more efficient when complete skin exams are performed selectively.

Are there other practical considerations? Many positive attendees visited the open access clinics early during the day. ${ }^{20}$ They seemed to be able to select themselves appropriately and were maximally motivated to attend the screenings. Abundant staff should be available during the morning hours to limit waiting time. Watch the early bird!

Which screens should be regarded as positive? During the open access clinics no diagnostic or therapeutic procedures were performed. When subsequent examination or treatment was necessary the attendees received a letter of referral to their general practitioner with the proposed line of management. Thus, only approximately $10 \%$ of all screenees used the regular health care facilities. The referrals were selected carefully and unnecessary referral or treatment of those with minimal extent of disease (borderline cases) was avoided. An unmanageable strain on the general practitioners' services is unlikely. The same applies to the pathologists' workload generated by melanoma screening campaigns. ${ }^{22}$ In the United Kingdom in 1986 several publicity campaigns for melanoma without screening clinics were organized. Because of the strain put on the health services it was decided that these campaigns should not be continued. ${ }^{24}$

Should screening be organized periodically: Ideally: yes. Screening should be a continuing process and not a single occasion activity. ${ }^{23}$ There is no useful information on the optimal frequency of melanoma screenings (once every 2 years?). A potential danger of periodic screening is delay of people who possibly postpone their appointment knowing a free screening is coming.

Is follow-up necessary? In the Southern Limburg project we adhered to a strict followup protocol. When the screen-positive participant had given permission, follow-up 
about melanomas tended to develop thicker lesions. ${ }^{12}$ Also people with tumours on difficult to see areas often present later. Self-examination of the skin has great significance. ${ }^{12}$ So far during the campaigns in the Netherlands these items have not been especially focused upon. They may be of particular importance when developing new programmes.

Various groups in the general population are at more than average risk to develop melanoma because of their skin phenotype (blond hairs, blue eyes, freckling, burning tendency), because of more than average mole counts; or because of a personal or family history of melanoma. Theoretically, there are other groups at special risk because of their known 'less awareness' of melanoma (e.g. men, elderly persons, and single persons). ${ }^{13}$ Also in the present study less men attended the screenings and they were prompted more often by relatives or friends to attend. ${ }^{14}$ Further studies are necessary to demonstrate whether it is worthwhile to focus education campaigns especially on these risk categories.

Is screening for nonmelanoma skin cancer worthwhile? The major objective of (volunteer) screening is reducing mortality and morbidity by finding disease and starting effective treatment at an earlier stage. Although nonmelanoma skin cancer is an important health problem, the benefit of screening is very doubtful. Nonmelanoma skin cancer has a low mortality rate. The problems which may result from these skin tumours are totally different from those of melanomas and need their own approach. We feel that the nonmelanoma skin cancers should not be a subject for screening. In the present study it was shown that relatively more melanomas and atypical naevi could be detected against less nonmelanoma skin cancers and benign skin lesions after a precampaign awareness programme focusing on melanoma only. ${ }^{1: 5}$

What is the role of ultraviolet (UV) light? Since the precise cause of melanoma is not known, it is not easy to develop primary prevention programmes on melanoma. Avoidance of and protection against UV radiation is an important measure to curtail the development of nonmelanoma skin cancer. In several public education campaigns also emphasis is placed on the role of sun protection to prevent melanoma. Yet, there are many unsolved issues in the possible role of UV in the aetiology of melanoma. There are potential dangers when the possible causal role of UV in the development of melanoma is emphasized too much. Especially those people who avoid sun exposure or those who discover lesions on sun protected areas are at risk 
What about total skin examination? In the present study the general public was offered a free skin check by a dermatologist. The clinics were organized in such a way that a maximum of attendees could be examined with a minimum of provider time (estimated 150-200 persons per dermatologist per day). ${ }^{15}$ Only specific skin lesions the attendees were worried about were examined. In 1385 attendees an additional total skin check was offered. This proved to have only a minimal yield: No melanomas were detected at additional total skin examination. ${ }^{19}$ It can be expected that future campaigns can be more efficient when complete skin exams are performed selectively.

Are there other practical considerations? Many positive attendees visited the open access clinics early during the day. ${ }^{20}$ They seemed to be able to select themselves appropriately and were maximally motivated to attend the screenings. Abundant staff should be available during the morning hours to limit waiting time. Watch the early bird!

Which screens should be regarded as positive? During the open access clinics no diagnostic or therapeutic procedures were performed. When subsequent examination or treatment was necessary the attendees received a letter of referral to their general practitioner with the proposed line of management. Thus, only approximately $10 \%$ of all screenees used the regular health care facilities. The referrals were selected carefully and unnecessary referral or treatment of those with minimal extent of disease (borderline cases) was avoided. An unmanageable strain on the general practitioners' services is unlikely. ${ }^{31}$ The same applies to the pathologists' workload generated by melanoma screening campaigns. ${ }^{22}$ In the United Kingdom in 1986 several publicity campaigns for melanoma without screening clinics were organized. Because of the strain put on the health services it was decided that these campaigns should not be continued. ${ }^{24}$

Should screening be organized periodically? Ideally: yes. Screening should be a continuing process and not a single occasion activity. ${ }^{23}$ There is no useful information on the optimal frequency of melanoma screenings (once every 2 years?). A potential danger of periodic screening is delay of people who possibly postpone their appointment knowing a free screening is coming.

Is follow-up necessary? In the Southern Limburg project we adhered to a strict followup protocol. When the screen-positive participant had given permission, follow-up 
was accomplished. Follow-up particulars about the recommended visit to the general practitioner and, when appropriate, the outcome of histological examination were collected. This follow-up has been performed by the author by visiting the regional dermatologists and by phone calls and mallings. Only 18 referred screenees $(3.7 \%)$ were lost during follow-up. Overall, compliance with referral was adequate. Although this elaborate type of follow-up has been proved to be extremely efficient, it is most time consuming In future screenings, this part of the screening intervention has to be developed further. Dermatologists who examine or treat positive attendees should also contribute to the complation of follow-up data. Only with adequate follow-up of positive screenees the ultimate yield and usefulness of such campaigns can be determined. Follow-up must be considered as an inherent part of screening.

What are the ethical and legal aspects of screening? Combined public education campaigns and screening sessions have potential hazards. Not all participants will benefit from the screening. First, there is the problem of the false-positive screens. These attendants undergo unnecessary diagnostic and treatment procedures. On the other hand, there may be false-negative participants who are given a false feeling of safery. In this respect it is encouraging that no melanomas were missed during a previous campaign. ${ }^{26}$ Furthermore, participants have to be made aware of the fact that a negative skin check is no guarantee that skin cancer will not develop in the future. These possible complications, risks, and limitations have to be explained to the attendants of skin check clinics.

How much will volunteer melanoma screening cost: The present study was supported in part by a grant from the Comprehensive Cancer Centres IKO (Nijmegen) and IKJ (Maastricht). Our programme has been inexpensive because volunteer dermatologists, residents, and heal th care professionals participated in the project. There are many hidden costs: the organization of the screenings, the guidance of screeners and auxiliary personnel, the follow-up of positive screenees, the costs of hospital facilities and services, and the induced expenses for positive screenees. Further evaluation of public education programmes with selected referral is necessary to determine cost-effectiveness. Costs must be weighed against benefits. Theoretically, the benefits are clecreased mortality and morbidity, savings in the use of health care resources, improvement of quality of life, and increase of economic productivity. The main question remains: Who should pay for this? The consumers, the health insurance companies, the government?

108 How can we educate the general public about early signs and symptoms of cutaneous 
melanoma, at minimal costs and a maximal yield in terms of thin melanomas? Public education programmes on melanoma without subsequent skin check sessions seem to have important effects on the number of self-referrals to general physicians and dermatologists. This may induce extra costs and unnecessary treatment and concern. Theoretically, the Southern Limburg study provides a new approach in which an education campaign is complemented by a free volunteer screening of those at highest risk by dermatologists at minimal costs. As a result of this selection of referrals much unnecessary treatment can be avoided.

Conclusions: Studies according to the American Academy of Dermatology model carried out so far in the Netherlands show that they are feasible and seem to fulfil a need. Screening should concentrate on melanoma only. The rationale of screening for nonmelanoma skin cancer is debatable. Total skin exams, additional to the assessment of specific index lesions people present with, are time consuming and not yielding. The organization of volunteer screening interventions on melanoma encompasses adequate follow-up and treatment of positive screenees. Evaluation in terms of treatment outcome is essential. Screenings are carried out within existing health care facilities. In the Netherlands there are regional Comprehensive Cancer Centres, and there is a national registry for pathology reports (PALGA) which makes it possible to organize and implement new programmes. It is relatively easy and very attractive to develop these secondary prevention programmes further. Future studies should be set up in cooperation with dermatologists, epidemiologists, health education specialists, general physicians, pathologists, and the Comprehensive Cancer Centres. Health economists, the Dutch Cancer Foundation, and governmental bodies should also be involved in future programmes.

A word of caution on provider time is necessary. It is our experience that regionat screening exercises can be appropriately staffed by dermatologists if two days (consecutive Saturdays) are scheduled. Large scale, national screenings with an appeal to the national publicity channels may result in a much larger attendance than in the previous campaigns and provider time may turn out to be insufficient. Up to now self-selected melanoma screenings in the Netherlands have been pilot studies. Only after more insight has been achieved into the cost-effectiveness of volunteer melanoma screenings, such prevention interventions can be introduced on a larger (national) scale and/or on a regular basis (once every 2 years?). In any case, close cooperation between national governmental departments and anti-cancer councils on the one hand, and practising dermatologists on the other hand is regarded as a sine qua non. 


\section{REFERENCES}

1. Incidence of cancer in the Netherlands, 1992. Fourth report of the Netherlands Cancer Registry Eds. Visser OP, Coebergh WW, Schouten U. Utrecht, 1995.

2. Rampen FHI, de Rooil MM. Screening for melanoma: methods, advantages, and limits. In: Epidemiology, causes and prevention of skin diseases. Grob JI, Mackie RM, Stern RS, Weinstock MA (eds) pp. 166-73. Blackwell Science, Oxford, 1997.

3. Blum $A$. Elwanger $U$, Carbe $C$. Seasonal patterns in cutaneous malignant melanoma diagnosis in central Europe; an analysis of more than 24,000 patients. I Eur Acad Dermatol Venereol 1996,7, Suppi2:S85.

4. Field SI. Melanoma/skin cancer screening in Michigan. I Am Acad Dermacol. $1987: 16578-83$.

5. Doherty VR, Mackie RM. Reasons for poor prognosis in British patients with cutaneous malignant melanoma. Br Med ) 1986:292:987-9.

6. Mackie RM, Hole D. Audit of public education campaign to encourage earlier detection of malignant melanoma. Br Med I 1992;304:1012-5.

7. Cassileth BR, Temoshok L, Frederick BE, et al. Patient delay and physician delay in melanoma diagnosis. I Am Acad Dermatol 1988;18591-8.

8. Newman $S$, Nichols $S$, Freer $C$, Izzard L. How much do the public know about moles, skin cancer, and malignant melanoma? The results of a postal survey. Community Med $1988 ; 10: 351-7$.

9. Hennrikus D, Girgis A, Redman S, Sanson-Fisher RW. A community study of delay in presenting with signs of melanoma to medical practitioners. Arch Dermatol $1991 ; 127,356-61$.

10. Rampen EHJ, Rümke P, Hart AAM. Patients' and doctors'delay in the diagnosis and treatment of cutaneous melanoma. Eur J Surg Oncol 1989;15:143-8.

11. Temoshok $\mathbb{L}$, Diclemente KI, Sweete DM, Blois MS, Sagebiel RW. Factors related to patient delay in seeking medical attention for cutaneous melanoma. Cancer $1984 ; 54: 3048-53$

12. Girgis A, Campbell EM, Redman S, Sanson-Fisher RW. Screening for melanoma: a community survey of prevalence and predictors. Med J Aust 1991;154:338-43.

13. Melia I, Ellman R, Chamberlain J. Investigating changes in awareness about cutaneous malignant melanoma in Britain using the Omnibus Survey. Clin Exp Dermatol $1994: 19.375 \% 9$

14. de Rooij MJM, Rampen FHI, Schouten LJ, Neumann HAM. Factors influencing participation among melanoma screening attenders. Acta Derm Venereol (Stockholm) in press.

15. de Rooil MIM, Rampen FHI, Schouten L], Neumann HAM. Skin cancer screening focusing on melanoma yields more selective attendance. Arch Dermatol 1995;131:422-5.

16. Rhodes AR. Public education and cancer of the skin. What do people need to know about melanoma and nonmelanoma skin cancere Cancer $1995 ; 75: 613-36$.

17. Williams HC. Melanoma with no sun exposure. Lancet 1995;346:581.

18. Rampen FHI, wan Huystee BEWL, Kiemeney LALM. Practical cosiderations of melanoma/ skin cancer screening clinics. Dermatology 1992;184:190-193.

19. de Rooij MIM, Rampen FHI, Schouten I..], Neumann HAM. Total skin examination during screening for malignant melanoma does not increase detection rate. Br I Dermatol $1996 ; 135: 42-5$.

20. de Rooij MIM, Rampen FHI, Schouten LI, Neumann HAM. Screening for melanoma: Watch the early bird! Eur I Dermatol 1996,6:170-1.

21. Rampen FHJ, Beretty PJM, van Huystee BEWL, Kiemeney LALM, Nijs CHHM. General practitioner's workload after skin cancer/melanoma screening clinics in the Netherlands. Dermatology 1993; 186:258-60. 
22. Rampen FHI, de Rooij MJM, Schouten LJ, Casparie-van Velsen IJAGM, Neumann HAM. Pathologists' workload generated by a melanoma screening campaign. I Eur Acad Dermatol Venereol 1996;7, Suppl2:S84.

23. Wilson, J.M.G. and Jungner, G. (eds). The principles and practice of screening for disease. Public Health Papers, No.34. WHO, Geneva 1968.

24. Ellman R. Screening for melanoma in the U.K. In: Miller AB, ed. Cancer screening. Geneva: UICC, 1991:257-66.

25. de Rooij MJM, Rampen FH], Schouten LJ, Neumann HAM. Volunteer melanoma screenings: follow-up, compliance, and outcome. Dermatol Surg, in press

26. Rampen FHJ, Casparie- van Velsen IJAMG, Van Huystee BEWL et al. False-negative findings in skin cancer and melanoma screening. J Am Acad Dermatol 1995;33:59-63. 


\section{APPENDIX}




\section{ORGANIZATION OF A VOLUNTARY MELANOMA SCREENING CAMPAIGN}

The present study describes voluntary melanoma screenings in a more or less secluded area of the Netherlands, Southern Limburg. The screenings were carried out under de auspices of the Dutch Society of Dermatology and Venereology and the Comprehensive Cancer Centres IKO (Nijmegen) and IKL (Maastricht). All activities were initiated and coordinated by a relatively small group of highly motivated people. When national programmes are planned, national cancer societies and governmental departments might be important sources of cooperation and publicity.

Any secondary prevention intervention on melanoma must be based on selfexamination and self-referral of persons at risk. Approaches to public education and consecutive screening may vary considerably according to the health care system in the relevant country: family physician-based versus specialist-based.

Family-doctors may act as initial screeners in countries with a specialist-referral service rather than a specialist-based service, such as Britain. In countries with major specialist health care facilities, such as the United States, voluntary melanoma clinics may offer open access to dermatologists.

Theoretically, the general practitioner network may filter much of the workload which is generated by the screening. On the other hand, clinical diagnosis is less accurate and the rate of false-positive and false-negative screens will increase.

The following schedule of a public education campaign and screening exercise is largely based on the establishment of open access screening Eacilities run by dermatologists.

\section{TIME TABLE}

12-15 mo - Decide on how and when to launch the campaign:

- regional? national?

- one month? one week? one or two weekends?

- spring or early summer is probably the best period of the year. 
10-12 mo - Inform local dermatologists and/or the national dermatology society of the plans.

- Approach regional and/or national cancer societies or other cancer organizations for their help.

- Approach health care ministry or other governmental bodies and invite their assistance.

- Appoint a campaign manager.

- Start fund raising and co-sponsoring.

6-10 mo - Fix campaign date(s):

- be sure that dates do not clash with national holidays.

- Prepare dermatologists' conference and encourage appropriate participation.

- Formulate issues for research.

4-6 mo - Prepare leaflets and posters.

- Compile lists of participating dermatologists/centres, community organizations that might assist, and newspapers and broadcast media.

- Supply local dermatologists with an overview of all the planning activities, including a complete time table:

- secure tight organization,

- focus attention on melanoma and dysplastic naevi,

- total body examination or not?

- guidelines for referral,

- emphasize adequate follow-up,

- encourage research activities.

2-4 mo - Prepare screening forms, questionnaires, and referral letters.

- Organize instructive meeting for dermatologists.

\section{Local activities:}

- Prepare general physicians" conference and encourage appropriate participation.

- Appoint programme director for each screening location.

- Establish contact with the hospital service, or other representatives to plan screening site, auxiliary personnel, and routing.

- Recruit volunteers. 
1-2 mo - Secure final arrangements regarding preparation of leaflets, handout materials, posters, and screening forms.

\section{Local activities:}

- Prepare any press releases.

2-4 wk - Send posters to screening clinics to be distributed in the respective areas.

- Coordinate publicity efforts.

\section{Local activities:}

- Secure abundant facilities:

- examination rooms,

- auxiliary personnel,

- traffic flow and sign-posting.

- Send free posters to general physicians, pharmacies, community organizations, and public places.

- Organize information meeting for general physicians:

- lecture tormat on signs and symptoms of melanoma and precursor lesions,

- instruction and discussion format on prerequisites, goals, and organization of the screens.

1-2 wk - Confirm all arrangements with screening sites.

- Send support and hand-out materials to screening sites.

- Conduct interviews in regional and/or national newspapers, and on regional and/or national radio and television.

\section{Local activities:}

- Organize instruction meeting for auxiliary personnel.

- Conlirm all local arrangements.

- Secure that all information materials and screening forms have arrived.

- Arrange local interviews and other press releases.

- If only local/regional screenings are planned:

- inform dermatologists from adjacent areas about the programme 


\section{DATE(S) OF SCREENING}

1-2 wk - Confirm that screening forms and questionnaires from all clinics after have returned.

- Send thark-you notes to participants.

- Contact all participating dermatologists to stimulate follow-up activities.

\section{Local activities:}

- Send thank-you notes to all volunteers and other participants.

- Assess results of the screening itself:

- numbers of attendants,

- numbers of positive screens (melanoma, nonmelanoma skin cancers, precursor lesions),

- any problems encountered.

- Prepare press announces on preliminary results.

- Be sure that all forms are send to the campaign manager or central organization.

- Start follow-up of positive screenees with presumed melanoma or other important/metastasizing tumours.

2 wk-2mo - Evaluate results of the screening.

after Local activities:

- Complete follow-up of positive screenees and send follow-up data to campaign manager/central organization.

$>2$ mo Collect follow-up data.

after - Assess final results, including follow-up.

- Contact media for press releases on final results.

- Report on final results and recommendations, and, if applicable, on research findings.

\section{Local activities:}

- Further follow-up: optional. 


\section{FURTHER READING}

1. Koh HK, Lew RA, Prout MN. Screening for melanoma/skin cancer: Theoretic and practical considerations. I Am Acad Dermatol 1989;20:159-72.

2. Koh $\mathrm{HK}_{n}$ Miller DR, Geller AC, Lew RA, Rampen FHI. Screening for melanoma and other skin cancers. Clin Dermatol 1992:10:97-103.

3. Rampen FHJ, van Huystee BEWL, Kiemeney LALM. Practical considerations of melanoma/skin cancer screening dinics. Dermatology 1992;184:190-3.

4. Elwood J. Screening for melanoma and options for its evalwation. J Med Screening $1994 ; 1: 22-38$.

5. Rhodes AR. Public education and cancer of the skin. What do people need to know about melanoma and nonmelanoma skin cancerc Cancer 1995;75:613-36.

6. de Rooij MJM, Rampen FHI, Schouten LJ, Neumann. HAMl Skin cancer screening focusing on melanoma yields more selective attendance. Arch Dermatol 1995:131:4225.

7. American Academy of Dermatology: Melanoma/skin cancer detection and prevention. month. Director's kit 1996.

8. Koh HK, Geller AC, Miller DR, Grossbart TA, Lew RA. Prevention and early detection strategies for melanoma and skin cancer. Current status. Arch Dermatol 1996;132:43643.

9. Mackie RM (ed). Primary and secondary prevention of malignant melanoma. Pigment Cell, Vol.11. Basel: Karger 1996.

10. de Rooij MIM, Rampen FHJ, Schouten LJ, Neumann HAM. Total skin examination during screening for malignant mela noma does not increase detection rate. Br I Dermatol $1996 ; 135: 42-5$ 
SUMMARY 
In this thesis the results are described of a volunteer melanoma screening campaign in Southern Limburg, the Netherlands, in June 1993.

Chapter 1. The introduction deals with some general aspects on cutaneous melanoma. Successively, the epidemiology, classification, clinical signs and symptoms, differential diagnosis, staging and prognostic factors, treatment, followup, and precursor lesions of melanoma have been briefly reviewed. Cutaneous melanoma is an easily visible tumour that can be recognized and treated early, in a stage with excellent prognosis.

Chapter 2. The fundamentals, methods, advantages, and limits of secondary prevention programmes for skin cancer in general and melanoma in particular are discussed. Public education campaigns followed by free screening sessions for those at highest risk, offer particular challenges with regard to skin cancer and, especially, melanoma.

Chapter 3. The characteristics and motives of attendees of volunteer melanoma screenings are analyzed in this chapter. Females predominate over males, especially in the 20-49 age group. Most participants intended to show only one or a few specific lesion(s). The newspapers represented the most important publicity channel to participate. Important reasons to visit the clinics were: getting more information on skin cancer, and fear of having skin cancer. Future screening interventions should predominantly target the male population.

Chapter 4. The outcome of the volunteer skin cancer/melanoma screenings in 1990 are compared with the results of the focused melanoma screenings in 1993 in Southern Limburg. The latter campaign yielded a more selective attendance in terms of more suspicious melanomas and dysplastic naevi, and less nonmelanoma skin cancers, actinic keratoses, and benign skin lesions.

Chapter 5. Additional total skin examination during screening for melanoma does not increase the detection rate. Among 1221 persons having complete skin exams 
additional to examimation of intentionally shown skin lesions, no melanomas were encountered. Only 3 basal cell carcinomas were detected. It is concluded that total skin examination during melanoma screening is not worthwhile.

Chapter 6. The feasibility of adequate follow-up, and the outcome of positive screenees after the volunteer melanoma screenings are described. In this study, complance with follow-up was appropriate. Refining the referral and follow-up procedures seems to be necessary.

Chapter 7. During the melanoma screenings it was noticed rather by chance that relatively more malignancies were diagnosed durimg the early hours of the screenings. Analysing the histological data the clinical results could be confirmed. This suggests that persons with skin cancer or melanoma are, on the whole, sufficiently concerned as to take maximum advantage of the screening opportunity. Our findings have also practical implications with regard to staffing of the screenings.

Chapter 8. In this summarizing chapter several unique properties of the volumteer melanoma screening concept in the Netherlands are discussed. One striking point is the fact that the campaign has been organized within the existing facilities of the Dutch health care system. It is tempting to speculate about future extensions of this concept. Before any decisions as to large-scale, national campaigns can be made, one must be fully Eamiliar with the principles and practice of these volunteer melanoma screenings. Screening for melanoma has to be evaluated on its own merits. Additional multidisciplinary studies may finally determime whether the present concept is costweffective and a reliable and justifiable approach to control cutaneous melanoma. 


\section{SAMENVATTING}


Hoofdstuk 1. Het melanoom van de huid is een vorm van huidkanker. Het wordt ook wel kwaadaardige moedervlek genoemd. Hoewel het basaalcel- en plaveiselcelcarcinoom van de huid veel vaker voorkomen, is de mortaliteit van het melanoom het hoogst van alle huidmaligniteiten. In Nederland overlijden er bijna 400 mensen per jaar aan de gevolgen van deze vorm van huidkanker. Dit heeft onder andere te maken met het feit dat het melanoom reeds in een vroege fase kan metastaseren. Ondanks enkele decennia van intensief onderzoek, zijn er (nog) geen succesvolle behandelingen on twikkeld voor het hematogeen gemetastaseerde melanoom. Vooralsnog zijn op dit moment alleen vroege ontdekking en chirurgische behandeling van de primaire tumor de belangrijkste wapens.

Het melanoom van de huid heeft de unieke eigenschap dat het een maligniteit is die aan de 'buitenkant' zit en voor iedereen zichtbaar is. Reeds jaren zijn de vroege kenmerken van een (zich ontwikkelend) melanoom bekend en kunnen worden samengevat in de $\mathrm{ABCD}$-regel (Asymmetry, Border, Colour, Diameter): asymmetrie van de afwijking, onregelmatige randen, wisselende kleurschakeringen: bruin, blauwzwart, roze-rood, wit, en diameter $>6 \mathrm{~mm}$. Theoretisch zou het mogelijk moeten zijn dat een melanoom door zowel medici als niet-medici in een vroege fase wordt opgemerkt en herkend. In deze fase is behandeling eenvoudig (poliklinische ingreep onder plaatselijke verdoving) en de kans op genezing heel groot.

In dit inleidende hoofdstuk worden enkele algemene aspecten van het melanoom beschreven, waaronder de epidemiologie, classificatie, klinische kenmerken, differentiële diagnose, prognostische factoren, behandeling en follow-up. Verder wordt aandacht besteed aan de belangrijkste precursors van het melanoom: de congenitale naevus en de dysplastische naevus.

Hoofdstuk 2. In de loop van de jaren zijn er wereldwijd verschillende strategieën ontwikkeld om melanomen in een vroegere fase te ontdekken. Deze zogenaamde secundaire preventie-programma's bestaan uit publieksvoorlichting alléén (Engeland) of uit publiekscampagnes en open dagen met onderzoek en advies door een dermatoloog (Verenigde Staten). Deze laatste zogenaamde volunteer melanoma/ skin cancer screenings worden sinds 1985 jaarlijks georganiseerd en worden door de American Academy of Dermatology gesponsord.

Het effect van (volunteer) screening is het grootst wanneer aan bepaalde voorwaarden voor screening wordt voldaan. Het melanoom voldoet aan de meeste van deze principes, het basaalcelcarcinoom en in mindere mate het plaveiselcelcarcinoom doen dit niet. Daarom is de huidige studie alleen gericht op het melanoom van de huid. 
In dit hoofdstuk worden bedoelde principes van screening als een vorm van secundaire preventie met betrekking tot huidkanker uiteengezet. Daarnaast wordt het speciale katakter van de beschreven screeningsactie, welke bestaat uit een voorlichtingsprogramma voor het publiek, gevolgd door open dagen, beschreven. Er is hierbij sprake van screening op basis van zelfonderzoek en zelfselectie. In dit kader hebben wij ons zo veel mogelijk beperkt tot het melanoom van de huid. Dit model is zeer aantreklkelijk maar onvoldoende uitgewerkt.

Hoofdstuk 3. De beschreven studie is gebaseerd op gegevens die tijdens de 'Open dagen kwaadaardige moedervlek' op 12 en 19 juni 1993 in Zuid-Limburg zijn verzameld. In dit hoofdstuk worden demografische kenmerken, gegevens over de publiciteitskanalen en bewreegredenen van de bezoekers van de open dagen beschrewen. In totaal werden de dagen door 4146 personen bezocht. Er waren meer vrouwen dan mannen (respectievelijk $59.5 \%$ en $40.5 \%$, p $<0.001$ ). De meeste bezoekers willden één of enkele specifieke laesie(s) laten zien (71\%). Een minderheid opteerde voor inspectie van de totale huid. Mannen kozen vaker voor een totale huidinspectie dan vrouwen (respectievelijk $29.0 \%$ en $21.6 \%$, p<0.001). De kranten speelden voor alle groepen de belangrijkste rol in de publiciteitscampagne. Mond-tot-mondreclame en huis-aan-huisbladen kwamen op de tweede en derde plaats. Omdat alleen de lokale radio-en televisiestations op kleine schaal bij de publieksactie waren betrokken, was de impact hiervan te verwaarlozen. "Meer informatie over huidkanker" en "Ik ben bang dat ik huidkanker heb" waren de belangrijkste redenen de open dagen te bezoeken (respectievelijk $27.1 \%$ en $26.8 \%$ ). Opvallend was dat "Zaterdag is een vrije dag" een belangrijke reden was de dagen te bezoeken voor $22.2 \%$ van de deelnemers. Van alle participanten bezochten $84.2 \%$ de screenings op eigen initiatief. Aanzienlijk meer mannen dan vrouwen waren door een familielid of vriend op de open dagen geattendeerd (respectievelijk $21.6 \%$ en $11.9 \%, p<0.001$ ). Mannen zijn op de open dagen ondervertegenwoordigd en zij zijn minder op de hoogte van de risicofactoren van het melanoom. Dit zijn redenen om toekomstige acties meer op de mannelijke populatie te richten.

Hoofdstuk 4. De uitkomsten van de open dagen in 1990 in Arnhem e.o. (gericht op huidkanker in het algemeen) en in 1993 in Zuid-Limburg (alleen gericht op het melanoom) worden met elkaar vergeleken. Het blijkt dat er een betere selectie plaatsvindt wanneer alleen aandacht aan het melanoom en dysplastische naevi wordt 
besteed. Het aantal screenees met kinische verdenking op nelanoom nam toe van $1.1 \%$ in 1990 naar $1.7 \%$ in $1993(\mathrm{p}=0.04)$. Het aantal dysplastische naevi nam toe van $2.1 \%$ naar $7.7 \%$ ( $p<0.001$ ). Epitheliomen werden minder vaak ontekt $3.7 \%$ in 1990 versus $2.6 \%$ in $1993 ; p=0.009$ ). Ook actinische keratosen waren minder talnijk $(6.3 \%$ versus $1.5 \% ; p<0.001)$. Deze bevindingen zijn uitermate belangrijk met betrekking tot de kosten en effectiviteit van dergelijke campagnes.

Hoofdstuk 5. In de literatuur wordt totale huidinspectie tijdens publieksacties op basis van zelfselectie geadwiseerd. Standaard doorgevoerde totale huidinspectie kost relatief veel tijd. Tijdens de Zuidlimburgse actie werd aan 1385 mensen die alleen een bepaald plekje wilden laten zien, gevraagd zich aanvullend van top tot teen te laten nakijken. Het is van belang te vermelden dat bezoekers met atypische naevi of verdenking op melanoom standaard aan een totale huidinspectie werden onderworpen. Er waren 1221 evalueerbare personen. Op deze wijze werden geen extra melanomen ontdekt. Bij histologisch onderzoek konden slechts drie basaalcelcarcinomen worden bevestigd. Omdat totale huidinspectie tijdrovend is en niet meer melanomen blijkt op te leveren, wordt geconcludeerd dat het tijdens screening voor melanoom op basis van zelfselectie niet zinvol is standaard totale huidinspectie uit te voeren. Dit werkt zeker ook kostenbesparend.

Hoofdstuk 6. OE melanoomscreening op basis van zelfselectie zinvol is kan pas worden beoordeeld wanneer de uiteindelijke opbrengst bekend is. Hiervoor is follow. up van de naar de huisarts verwezen bezokkers noodzakelijk. Op deze wijze kan. worden nagegaan of er aanullend pathologisch onderzoek is verticht. In de Zuidlimburgse studie werden 486 bezoekers (11.7\%) verwezen wegens voor maligniteit of premaligniteit verdachte afwijkingen (positieve screenees). Personen met "borderline" atwijkingen werden niet verwezen. Verwijzing van "borderline" laesies zou hebben geresulteerd in een aanzienlijke toename van het aantall positieve screenees (18.1\%). Ondanks intersieve follow-up kon van 18 personen $(3.7 \%)$ geen informatie worden verkregen (Klinische diagnoses: dysplastische naevi 8 , congenitale naevi 9 , actinische keratose 1). Bovendien bleken er zeven personen te zijn die afzagen van aanvullend onderzoek en advies (klinische diagnoses: basaalcelcarcinoom 1, dysplastische naevi 5 , congenitale naevus 1). De positief voorspellende waarde voor het melanoom was $17.2 \%$ en voor de epitheliomen $42.9 \%$. Een adequate follow-up is noodzakelijk en blijkt in Nederland goed haalbaar. Alleen op deze 
wilze kan de uiteindelike opbrengst en het nut van dergelijke campagnes worden bepaald.

Hoofdstak 7. Per toeval werd tijdens de uitwerking van de resultaten van de screenings ontdekt dat vooral de vroege bezoekers op deze dagen een gemiddeld 'zwaardere' diagnose hadden (meer kwaadaardige huidafwijkingen). Bij nadere analyse werd dit bevestigd. Behalve dat er dus anwijzingen zijn dat het publiek zich alleszins redelijk kan selecteren, heeft dit ook praktische consequenties en moeten de screening clinics onmiddellijk na de start goed bemand zijn omdat juist dan de meeste verwijzingen plaatsvinden, hetgeen meer tijd kost.

Hoofdstuk 8. In dit afsluitende hoofdstuk worden een aantal eigenschappen van volunteer melanoma screenings nog eens onder de loep genomen. Van belang is dat we hier met een unieke, voor iedereen zichtbare vorm van kanker te maken hebben. Het gegeven dat het hele project binnen de bestaande structuren van onze gezondheidszorg kon worden uitgevoend, is veelbelovend woor de toekomst. Er kan met de ervaringen van huidige studie onvoldoende worden bepaald of deze opzet kosteneffectief is. Inzicht in de kosten-effectiviteit is wenselijk om besluiten te kunnen nemen over invoering op grotere schaal. Voor het nemen van beslissingen over de ontwikkeling van vervolgstudies is het noadzakelijk dat volunteer melanoma screening op zijn eigen merites wordt beoordeeld. Verwarring met reguliere, bestaande bevolkingsonderzoken zoals voor het mamma- en cervixscarcinoom is een gevaar. Alleen aanvulend, multidisciplinair onderzoek zal uiteindelijk kunnen bepalen of deze benactering kosten-effectief is en een zinvolle bijdrage levert om de aanzienlijke morbiditeit en mortaliteit van het melanoom van de huid te bestrijden. Tot slot wordt een draaboek gepresenteend voor een regionale of landelijke screeningsactie (appendix). 


\section{DANKWOORD}

Prof.dr. H.A.M. Neumann, beste Martino, je vroeg me, juist voor ik naar Cambridge op cursus ging in december 1992, of ik een bijdrage wilde leveren aan de organisatie van een melanoomscreening in Zuid-Limburg. Dit zou dan leiden tot een artikel. Hoewel ik niet wist wat dit precies betekende was ik hiervoor well te vinden. Het bleek echter naast mijn opleiding, een enorme klus die ik met de hulp van velen heb weten te klaren. De belangstelling voor deze twee open dagen overtrof onze stoutste verwachtingen en al. snel liet je me weten te verwachten dat er meer dan één artikel uit deze studie moest voortkomen. Jij had het al snel over mijn promoticonderzoek en ik hield in eerste instantie vol dat het slechts mijn melanoomstudie betrof. Je hebt me ervan weten te overtuigen dat er inderdaad meer uit te halen was en zie hier het resultaat. Daarnaast ben ik onder jouw bezielende begeleiding opgeleid tot allround dermatoloog 'nieuwe stijl'. Hiervoor dank.

Dr. F.H.J. Rampen, beste Frans, jij bent de initiator van en man achter dit onderzoek. Ik kende je aanvankelijk alleen van een foto achter op je melanoomboek. Snel. kwam ik er achter dat je behalve een ervaren onderzoeker ook zeer gedreven bent en hoge eisen stelt. Je had echter ook heel veel geduld en gaf mij alle gelegenheid in het onderwerp melanoom en screening thuis te raken. We hebben de afgelopen jaren heel wat afgereisd. Want hoewel er per Fax-apparatuur heel wat te 'bespreken' viel ging er niets boven een middag life discussiëren. Dit gebeurde (na je spreekuur) in Oss, (in het weekend) in Wijchen, in Maastricht, in Nijmegen, in Asten of in Venray. Jij hebt me een spoedcursus 'academic writing' gegeven; hierin word je immers als basisarts niet opgeleid. Jouw intensieve en stimulerende bijdrage is van essentieel belang geweest bij de succeswolle afronding van dit onderzoek. Ik waardeer het zeer dat je altijd weer met veel enthousiasme tijd voor me makkte. De begeleiding van deze studie deed je immers naast je drukke werkzaam heden als dermatoloog te Oss. Hiervoor dank.

Dr. L.J. Schouten, beste Leo, jouw bijdrage vanuit de epiclemiologie is van grote betekenis geweest. Ook jij had het geduld mij bij te scholen. Bovendien zouden zonder jouw hulp en inzet de vele data niet bewerkt zijn tot de 'results' zoals nu beschreven. Jij vertaalde immers onze vragen naar leesbare kruistabellen. Dit deed je naast je werkzaamheden als hoofd kankerregistratie bij het IRL te Maastricht. tevens gedetacheerd bij het IKO te Nijmegen. Bovendien werkte jij aan de voltooiing van je eigen proefschrift. Ik realiseer me hoe bevoorrecht ik ben geweest dat ik altijd onaangekondigd een beroep op je heb kunnen doen. En dit was nooit tevergeefs! Dank je wel. 
Prof.dr.dr PC.M van de Kerkhof, beste Peter, als juist geregistreerd (ongepromoweerd) dermatoloog haalde je me naar Nijmegen om de staf te komen versterken. Hoewel alle data van mijn onderzoek reeds waren verzameld betekende dit niet dat het manuscript reeds ter beoordeling klaar lag. Jij gaf me echter de ruimte ook mijn nieuwe taken in te vullen. I kon de stages flebologie, dermatochirurgie / oncologie en proctologie naar eigen inzicht organiseren. Dankzij de structurur van de afdeling en de welwillendheid van eenieder kon dit in zeer korte tijd gebeuren. Daarnaast heb je me steeds aangemoedigd het onderzoek snel af te ronden om ook nieuwe ontwikkelingen verder te kunnen exploreren.

Beste collegae uit de regio Zuid-Limburg (maar ook van daarbuiten). Op verschillende plaatsen in mijn boekje heb ik jullie reeds bedankt voor jullie inspanningen. Zonder deze hulp was dit project nooit geslaagd. Voor zo ver ik heb kunmen nagaan in de literatuur is er nooit eerder een vergelij kbare studie gepubliceerd met dit grote aantal (bijna 4200!!) screenees. Ook op deze plaats wil ik jullie en jullie hulppersoneel (verpleegkundigen, administratief personeel en familieleden) nog eens nadrukkelijk bedanken.

Brigitte Gijssen en Raph de Rooij, jullie hulp tijdens de voorbereidingen van de screenings is van grote betekenis geweest. Jullie hebben mede de basis gelegd voor het succes van deze actie. Bovendien Raph, jouw posters hangen nu nog steeds in verschillende wachtkamers van de poliklinieken dermatologie in Zuid-Limburg. Bedankt.

Sandra van Heertum, zonder jouw accurate bijdrage waren al die gegevens uit de enquêtteformulieren nooit bewerkbare data geworden. Ook heb je de laatste hand gelegd aan menig manuscript. Dank hiervoor.

Dank aan de pathologen uit de regio Zuid-Limburg, in het bijzonder Ton Vermeulen. Dankzij de bereidwilligheid van zijn secretariat kon ik menig ontbrekend histologisch verslag traceren.

Kees-Peter de Roos, Marion van Gasselt, Ivo Koedam, Joep Veraart, Marc Verhaegh, Birgitte Maessen, Judith Ostertag en Monique Thissen, jullie hebben je tijdens de open dagen als hulppersoneel verdienstelijk gemaakt. Ik wil jullie hiervoor bedanken. Bovendien hoop ik dat het nu helemaal duidelijk is waarom en waarvoor ik op mijn studiemiddag steeds op pad moest.

Pieter yan cler Valk, Peter Steijlen, Elke de Jong en Peter Arnold, bedankt voor de ruimte die jullie me steeds gaven aan mijn studie te werken. Teamwork is dat! Diny de Heus en Els Salemink, bedankt voor de secretariële ondersteuning. Nooit deed ik tevergeefs een beroep op jullie. Ans Meij, dank voor je hulp bij het verzame132 len van alle literatuur. 
Hilde de Heus, dank aan jou en je team voor het verzetten van al die spreekuren en het creëren van ruimte voor mijn onderzoek op vrijdagmiddag.

Joep de Jong, Ron Grooten, Michel Dierckx, dank voor al jullie geduld en goede adviezen voor de uitvoering van dit boekje. Jullie hebben een prachtvak! Alexander, dank woor je support. Je weet hoe zeer ik dit waardeer. 


\section{LIST OF PUBLICATIONS}

\section{Full papers}

1. Rooij MIM de. Laser treatment of leg telangiectases. Scripta Phlebologica $1993 ; 2: 56-8$

2. Blaauw AAM, Schuwirth LWT, Rooij MJM de, Vleuten CPM van der, Linden S van der. How well do general practitioners in the Netherlands recognize Lyme borreliosis? Journal of Thickborn diseases 1994;1:68-73

3. Rooij MJM de, Neumann H.AM. Granuloma telangiectaticum after argon laser treatment of a spider nevus. Dermatological Surgery 1995;20:354-59

4. Rooij MJM de, Rampen FHJ, Schouten LJ, Neumann HAM. Skin cancer screening focusing on melanoma yields more selective attendance. Archives of Dermatoly 1995;131:422-25

5. Rooij MJM de, Rampen FHJ, Schouten L], Neumann HAM. Screening for melanoma: watch the early bird! European Journal of Dermatoly 1996;6:170-1

6. Rooij MJM de, Rampen FHJ, Schouten LJ, Neumann HAM. Total skin examination during screening for malignant melanoma does not increase the detection rate. British Journal of Dermatology 1996;135:42-5

7. Janssen MCH, Wollersheim HCH, Asten WNJC van, Rooij MJM de, Novakova IRO, Thien Th. The posttrombotic syndrome: a review. Phlebology 1996;11:86-94

8. Janssen MCH, Claassen JAHR, Asten WNJC van, Wollersheim HCH, Rooij $M J M$ de, Thien Th. Validation of the supine pumpfunction test: a new noninvasive tool in the assessment of deep venous insufficiency. Clinical Science 1996;91:483-8

9. Kerkhof PCM van de, Rooij MJM de. Multiple squamous cell earcinoma in a psoriatic patient following high-dose treatment: response to long-term acitretin maintenance. British Journal of Dermatology 1997;136:275-8

10. Janssen MCH, Haenen JH, Asten WNJC van, Wollersheim HCH, Heystraten FMJ, Rooij MJM de, Thien Th. Clinical and haemodynamic sequelae of deep venous thrombosis: retropective evaluation alter 7 to 13 years. Clinical Science 1997;93:7-12

11. Rooij MJM de, Rampen FHJ, Schouten LJ, Neumann HAM. Factors influencing participation among melanoma screening attenders. Acta DermatoVenereologica (Stockholm) in press

12. Rooij MJM de, Rampen FHJ, Schouten LJ, Neumann HAM. Volunteer melanoma screening: Follow-up, compliance, and outcome. Dermatological Surgery, in press 
13. Rooij MIM de. Huidafwigkingen bij diabetes mellitus. Nederlands Tijdschrift voor Dermatologie en Venereologie, in press

14. Brokelman WJ, Wobbes Th, Tiggeler RG, Rooij MJM de, Raemakers JM, Whet DA van der. Malignant neoplasms after renal transplantation presentation and course. submitted

\section{Book contribution:}

1. Rampen $\mathrm{H} H$ J, Rooij MJM de. Screening for melanoma: methods, advantages, and limits. In: Epidemiology, causes and prevention of skin diseases. Grob J), Mackie RM, Stern RS, Weinstock MA (eds). pp. 166-73. Blackwell Science, Oxford, 1997

\section{Abstracts:}

1. Blaauw MAM, Schuwirth LWT, Rooij MJM de, Vletten CPM van der, Linden S van de. How well do general practitioners, rheumatologists, dermatologists recognize lyme borreliosis? Arthritis and Rheumatism 1992,35; S 177. Abstract

2. Rooij MIM de, Verhaegh MEJM, Neumann HAM. Mohs" microscopisch gecontroleerde chirurgie. Ned Tijdsch Dermatol Venereol 1993;6:227

3. Verhaegh MEIM, Neumann HAM, Rooij MJM de. Histological differentiation differences in the center and peripheral zone of recurrent basal cell carcinomas treated with Mohs' surgery. In: Abstract Book. XIVth Congress of the International Society for Dermatologic Surgery, October 1-4: 15, 1993, Sevilla, Spanje

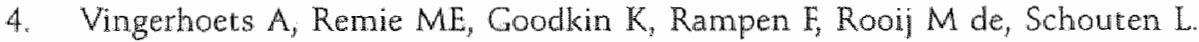
Psychological factors and cutaneous malignant melanoma. Psychobiologie der Stressbewatigung. The 7th International Coping-Workshop, January 1994, Bielefeld

5. Hulsmans RFHJ, Rooij MJM de, Vermeulen AHM, Neumann HAM. Microvenular hemangioma. In: Abstract Book, Joint Annual Meeting The British Saciety for Dermatopathology and the International Society of Dermatopathology, July 131994 , London

6. Rooij MJM de, Rampen FHJ, Schotiten LJ, Neumann HAM. Melanoma screening clinics in the Netherlands. In: Abstract Book, Annual Meeting American Academy Dermatology, February 1995, New Orleans

7. Rooij MJM de, Rampen FH], Schouten LT, Neumann HAM. Profile of people attending melanoma screening clinics in the Netherlands. Abstract ] Eur Acad Dermatol Venereol 1995;5 (suppl 1):599, 10-15 October, Brussels

136 8. Rooij MIM de, Rampen FHJ, Schouten LI, Neumann HAM. Dépistage clinique 
du mélanome en Hollande. Nouv Dermatol 1995; 14(supp】 1):32

9. Rooij MJM de, Rampen FHJ, Schouten LJ, Neumann HAM. Skin cancer screening focusing on melanoma. Melanoma Research 1995;5(suppl 1):32

10. Neumann HAM, Rooij MJM de, Rampen FHJ, Schouten LJ. Yield of melanoma screening clinics. In: Abstract Book, XVIth Congress of the International Society for Dermatologic Surgery, October 1995, Budapest

11. Vingerhoets $A$, Remie ME, Goodkin $K$, Rampen $F$, Rooij $M$ de, Shouten $L$. Psychological factors and cutaneous dysplastic processes. In: Abstract Book, Third International Congress on Behavioral Medicine, July 6-9, 1995, Amsterdam

12. Rooij MIM de. Psychodematology in daily practice. In: Abstract Book, 6th International Congress on Dermatology and Psychiatry. April 20-22, 1995, Amsterdarn

13. Remie ME, Visser A, Vingerhoets A, Goodkin K, Rampen F, Rooij M de, Schouten LJ. Expression of emotions and cutaneous processes. In: Abstract Book, 6th International Congress on Dermatology and Psychiatry. April 20.22, 1995, Amsterdam

14. Arnold WP, Rieu P, Steijlen PM, Rooij MJM de. Van Lohuizen syndrome; report of a case with severe congenital anomalies of the heart. Abstract Book: Vth Congress European Society of Pediatric Dermatology, September 4-8, 1996, Rotterdam

15. Rooij MJM de, Rampen FHJ, Schouten LJ, Neumann HAM. Screening for melanoma. New aspects. In: Abstract Book 26 th Annual Meeting European Society for Dermatological Research, September 28 - October 1, 1996, Amsterdam

16. Rampen FHJ, Rooij MJM de, Schouten LJ, Casparie-Van Velsen IJAGM, Neumann HAM. Pathologist's workload generated by a melanoma screening campaign. J Eur Acad Dermatol Venereol 1996;7(suppl 2):S84, October 1996 Lissabon.

17. Rooij MIM de. Venous malformations and compression therapy. Why should compression therapy be considered? In: Syllabus Hemangiomas and Vascular Malformations, November 25-26, 1996, Nijmegen.

18. Janssen MCH, Asten WNIC van, Wollersheim H, Rooij MJM de, Thien Th. A new technique in the assessment of damage after deep venous thrombosis. The supine venous pump function test. The Netherlands Journal of Medicine 1996; 48:A81.

19. Claassen JAHR, Janssen MCH, Asten WNIC, Wollersheim H, Rooij MJM de, Thien Th. The supine wenous pump function test: normal values and results in 
patients with the post-trombotic syndrome. The Netherlands Journal of Medicine 1996;48:A79

20. Janssen $M C H$, Asten WNJC van, Wollersheim $H$, Rooij MJM de, Thien Th. Validation of the supine venous pump function test; a new non-invasive tool in the diagnosis of chronic venous insufficiency. Scripta Phlebologica 1997;5:19

21. Rooil MIM de. Diagnostiek van huidmalligniteiten. In: Abstract Book: Huisartsendag Subtopklinische zorg in relatie tot de huisartspraktijk, 8 april 1997, Nijmegen

22. Rooij MJM de. Veneuze pathologie. In: Abstract Book: Non-invasieve vaatdiagnostiek bij veneuze pathologie. Onderwijsdag Nederlands Belgische Vereniging voor non-invasieve vaatdiagnostiek, 18 april 1997, Nijmegen 


\section{CURRICULUM VITAE}

Michette de Rooij werd geboren op 19 september 1963 te Zeddam (gem. Bergh GId). In 1981 behaalde zij het diploma Gymnasium B aan het dr. Mollercollege te Waalwijk. Van 1981 tot 1987 studeerde zii geneeskunde aan de Rijksuniversiteit Limburg te Maastricht (thans Universiteit Maastricht). Tijdens haar studie was zij als student assistent werkzaam in het Skils-lab van de faculteit geneeskunde (hoofd: dr. P.M.T.A. Bartholomeus). Tevens was zij tijdens haar studie bestuurslid van studentenvereniging $\mathrm{KOKO}$. Direct na het behalen van het basisartsdiploma in november 1987 startte zij als assistent-geneeskundige Interne Geneeskunde in het azM te Maastricht (hoofd: prof.dr. J.A. Flendrigt). In november 1988 werd begonnen als assistent-geneeskundige op de afdeling Longziekten van het azM te Maastricht (hoofd: prof.dr. L.H. Grevet). Vanaf juni 1989 was zij werkzaam als assistent-geneeskundige in het De Weverziekenhuis te Heerlen (dr. J. Wuite, dr. M.J.T. Go en drs. J.C.C.A. Lambers). Op 1 november 1990 werd gestart met de opleiding Dermatologie in het azM te Maastricht (opleiders: prof.dr. W.J.B.M. van der Staak, prof.dr. H.A.M. Neumann). Tijdens haar opleiding startte zij met wetenschappelijk onderzoek. Op 1 augustus 1994 werd zij geregistreerd als dermato-venereoloog. Sinds 1 september 1994 is zij als universitair docent verbonden aan de afdeling Dermatologie van het Academisch Ziekenhuis St Radboud te Nijmegen met als aandachtsgebieden flebologie, dermatochirurgie/oncologie (hoofd: prof.dr.dr. P.C.M. wan de Kerkhof). Het onderzoek werd hier voortgezet en afgerond. 


\section{LIST OF ABBREVIATIONS}

$\begin{array}{ll}\text { AAD } & : \text { American Academy of Dermatology } \\ \text { ABCD(E) rule : } & \text { mnemonic for: Asymmetry, Border irregularity, Colour variegation, } \\ & \text { Diameter }>6 \mathrm{~mm} \text {, and Elevation } \\ \text { AJCC } & : \text { Americal Joint Committee on Cancer } \\ \text { ALM } & : \text { acral-lentiginous melanoma } \\ \text { DNS } & : \text { dysplastic naevus syndrome } \\ \text { DTIC } & : \text { dacarbazine } \\ \text { LM } & : \text { lentigo maligna } \\ \text { LMM } & : \text { lentigo maligna melanoma } \\ \text { NM } & : \text { nodular melanoma } \\ \text { PUVA } & : \text { photochemotherapy } \\ \text { SSM } & : \text { superficial spreading melanoma } \\ \text { UICC } & : \text { Union Internationale contre le Cancer } \\ \text { UV } & : \text { ultra violet } \\ \text { WHO } & : \text { World Health Organization }\end{array}$

